Portland State University

PDXScholar

$1-1-1980$

\title{
The production of culture on the Oregon Federal Arts Project of the Works Progress Administration
}

Carolyn Howe

Portland State University

Follow this and additional works at: https://pdxscholar.library.pdx.edu/open_access_etds Let us know how access to this document benefits you.

\section{Recommended Citation}

Howe, Carolyn, "The production of culture on the Oregon Federal Arts Project of the Works Progress Administration" (1980). Dissertations and Theses. Paper 824.

https://doi.org/10.15760/etd.824

This Thesis is brought to you for free and open access. It has been accepted for inclusion in Dissertations and Theses by an authorized administrator of PDXScholar. Please contact us if we can make this document more accessible: pdxscholar@pdx.edu. 


\title{
THE PRODUCTION OF CULTURE ON THE OREGON FEDERAL ARTS PROJECT OF THE WORKS PROGRESS ADMINISTRATION
}

\author{
by \\ CAROLYN HOWE
}
A thesis submitted in partial fulfillment of the requirements for the degree of
MASTER OF ARTS
in
SOCIOLOGY

Portland State University

1980 
TO THE OFFICE OF GRADUATE STUDIES AND RESEARCH:

The members of the Committee approve the thesis of Carolyn Howe presented July $18,1980$.
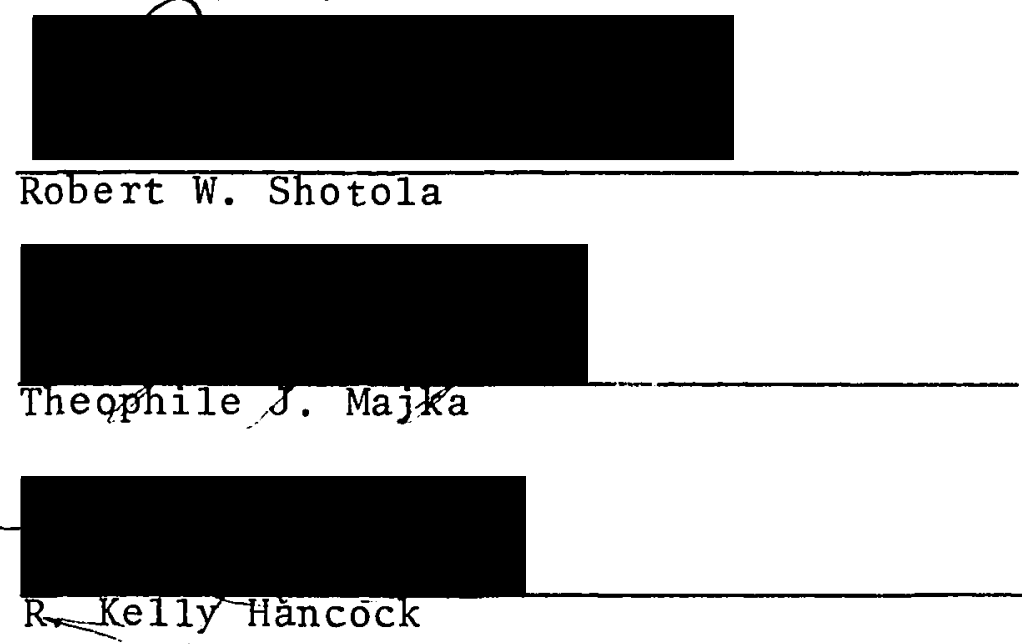

APPROVED :

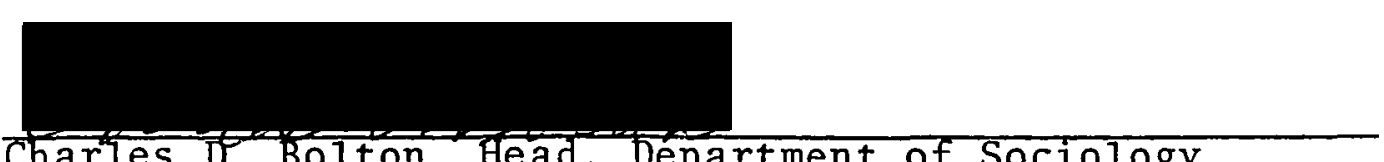

Charies 1. Bolton, Head, Department of Sociology

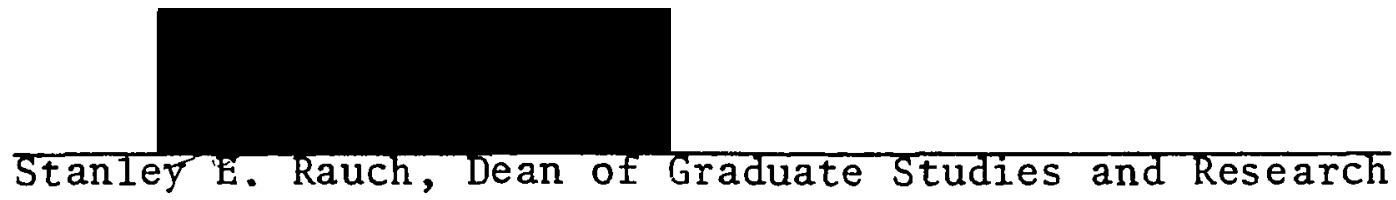


AN ABSTRACT OF THE THESIS OF Carolyn Howe for the Master of Arts in Sociology presented July 18, 1980.

Title: The Production of Culture on the Oregon Federal Art Projects of the Works Progress Administration

APPROVED BY MEMBERS OF THE THESIS COMMITTEE:
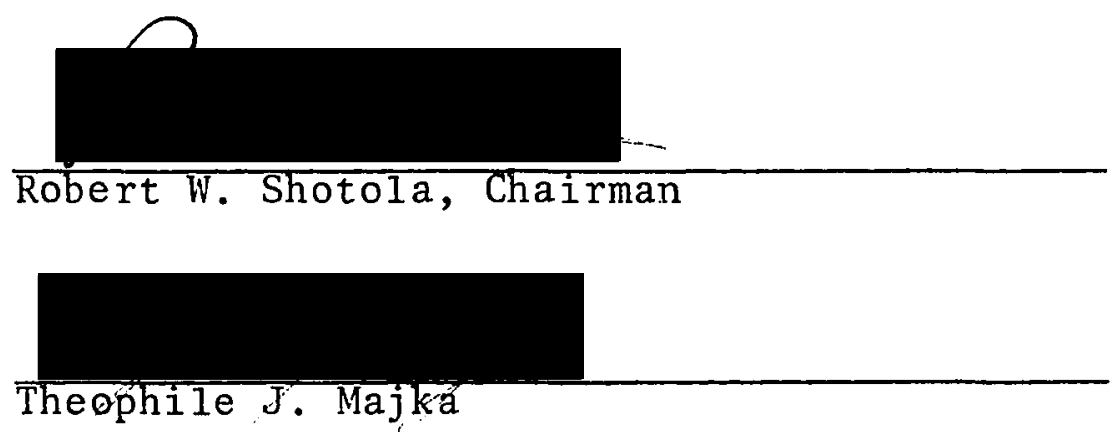

This thesis adaresses the relationship between art and society by examining the production of culture on the Oregon Federal Art Project (FAP) of the Works Progress Administration (WPA). The author examines the social conditions and decision-making processes which shaped the art that was produced and determined who produced and who consumed the art of the FAP. Also examined are the changing social relations of art prior to, during, and after the WPA's Federal Art Project. The research for the thesis utilized inductive methods of research aimed at theory con- 
struction rather than theory testing, although theoretical questions guided the gathering and analysis of data.

Most of the data were obtained from primary sources, including interviews with fifteen people who had varying degrees of familiarity with the Oregon FAP; letters of correspondence, memos, and other primary documents on the Oregon FAP were used extensively. Secondary sources supplemented these primary sources by providing an overview of the national FAP and providing comparative data on the New York City FAP.

An important factor in the establishment of the national FAP was the political activism of artists, particularly in New York. In Oregon, where only a handful of artists were politically active, the upper class administrators of the FAP seemed to have had more autonomy in shaping the direction of the program. It is argued that in many cases the goals of the FAP, to provide employment for artists on relief and to use the skills of these people to create socially useful projects, were undermined due to the orientations and inclinations of administrators and business sponsors of the projects who emphasized the professional art aspect of the FAP rather than the relief, socially useful aspect of the project. Nevertheless, the Oregon FAP brought about a change in the social relations among the ariist and the art audience; not only was art made more available to the Oregon public through the public display of art works, 
and through the free instruction of art at community art centers, but artists, themselves, were for the first time employed to exchange their labor, as artists, for a wage. In this sense, the FAP was seen as a kind of "cultural revolution," although an examination of the social relations of art following the 1930 s reveals that the cultural revolution took the form of an entrepreneurial, petit bourgeois revolution, rather than the socialistic revolution many artists had hoped for. It is suggested that the nature of this revolution stems, in part, from the characteristics of the FAP, where artists were government empioyees, yet were administered by a bureaucracy staffed by an elite which traditionally had been the patrons of art. The conclusions of this thesis are stated in the form of tentative propositions that await further testing in subsequent comparative studies of the FAP. 


\section{PREFACE}

This thesis addresses the relationship between art and society by examining the production of culture on the Oregon Federal Art Project (FAP) of the Works Progress Administration (WPA). Based on the assumption that artists and the arts develop and grow under prevailing social conditions, the thesis discusses the social conditions in the United States in the $1930 \mathrm{~s}$ that led to the creation of the WPA/FAP and that affected the implementation and the productive outcome of the Oregon FAP.

The Oregon FAP is not examined primarily for the style and content of the art, but for the social conditions and decision-making processes that determined the production of culture--that is, how art was produced, who produced the art, who consumed the art, and how decisions were made regarding each of these. These issues are addressed by exploring four spheres of analysis relating to external and internal social conditions on the national and Oregon levels. The first sphere examined is the external social conditions affecting the entire nation which led to the creation of the WPA and the FAP. The internal social conditions of the WPA/FAP make up the second and third spheres of analysis; these refer to the structure, goals, and regulations of the FAP on the national and Oregon levels, respectively. The 
fourth sphere refers to the external social conditions operating on the local level which directly and indirectly influenced the implementation and operation of the Oregon FAP. While each sphere is examined at least marginally, some aspects are emphasized because of their centrality to an understanding of the production of culture on the Oregon FAP. Thus, a central question addressed by the thesis is how effectively were the goals of the FAP carried out in Oregon and to what extent did various social conditions enhance or impair the implementation of these goa1s? A second major question addressed is what social conditions were most instrumental in shaping the overall production of culture on the Oregon FAP? Finally, to what extent and in what ways did the FAP in general and the Oregon FAP in particular change the social conditions and social relations of art in the United States and in Oregon?

Throughout the thesis, a class struggle perspective, as outlined by Esping-Anderson, Friedland, and Wright (1976), is employed. This perspective identifies labor, capital, and the state as primary units of analysis, with the relations between these making up the central focus of the analysis.* The class struggle perspective can be usefully

*Except where the context clearly dictates otherwise, the term "state" is used throughout to refer to the institutions of "the government, the administration, the military and the police, the judicial branch, sub-central government and parliamentary assemblies --which make up 'the state,' and whose interrelationship shapes the form 
applied to an understanding of the FAP because, as pointed out in the thesis, the FAP was formed in response to the social movements of the $1930 \mathrm{~s}$ which expressed the conflicts between labor, capital, and the state.

In addition to a class struggle perspective, the thesis utilizes four models suggested by Michael Useem (1976) which propose four conditions under which the federal government supports the arts. These models serve as guides to the analysis of the Oregon FAP; each one suggests a category for exploration of the 1ocal, external social conditions affecting the art produced and the conditions of its production.

CHAPTER OUTLINE

Chapter One discusses the theoretical and methodological background of the thesis. The theoretical perspective of the sociology of the arts underlying the analysis employ-

of the state system" (Miliband, 1969:54). The focus here will be on the federal government--particularly the executive and legislative branches. The terms "upper class" and "capitalist class" are used interchangeably throughout the thesis. Szymanski (1978:33) defines the capita1ist class as "that class of people which owns and controls the major factories, mines, farms, transportation and communications enterprises, merchandizing companies, and financial institutions in the United States." Domhoff (1971:75) writes of the upper class as a ruling class which har "cohesion," "consciousness," and "consensus." A broad estimate nould place the upper class as comprising about 0.5 percent o the population. This 0.5 percent holds twenty percent if all privately held wealth in the country (Szymanski, 1978:34). 
ed throughout the thesis is presented along with an explanation of the class struggle perspective and Useem's four mode1s. A methodological discussion concludes the chapter. After providing a brief overview of the national and Oregon FAP, Chapter Two examines the social conditions that led to their creation; it focuses on the social relations between labor, capital, and the state, and points out the social movements of unemployed artists which petitioned the federal government for a permanent federal art project. The chapter also $100 \mathrm{ks}$ at the internal structure, goals, and the key regulations that affected both levels of the FAP. Finally, the social and class backgrounds of the project administrators and the Oregon artists are discussed as background to an examination of the social relations affecting the visual arts before, during, and after the WPA/FAP.

Chapter Three focuses on the external and internal social conditions affecting the production of culture on the Oregoi FAP. Regarding internal conditions, it addresses how the program's structure, goals, and regulations complemented or interfered with each other. Applying Useem's (1976) models, it examines the external influences of business community, government, and local labor conditions on the process and outcomes of the Oregon FAP.

Chapter Four concludes the thesis with a summary and suggests conclusions regarding the relationships between various social conditions and the importance of these in 
vi i

determining the process and outcome of cultural production on the Oregon FAP. The changes that took place during the WPA/FAP are compared with the social conditions affecting the arts before and after the 1930 s and suggestions are made as to the impact the FAP had on the subsequent development and direction of art production in the United States. 


\section{ACKNOWLEDGMENTS}

This work stems in part from interviews conducted as a research assistant on a project funded by the Institute on Aging, Department of Urban Affairs, Portland State University. From January through September of 1979 I worked on that project, entitled "Life Satisfaction Among Senior Portland Artists," with Dr. Robert Shotola, Department of Sociology at Portland State University, and Harry Widman, Dean of the Portland Museum Art School. I am indebted to Dr. Shotola, Dean Widman, and the Institute on Aging for their support.

The people who made this research come alive, and to whom I extend my deepest gratitude, are the artists, administrators, and community people whom I interviewed for this research. Their names, listed according to the order in which they were interviewed, are: Martina Gangle Curl, Jack McLarty, Leta Kennedy, Charles Heaney, Bill Givler, Rachael Griffin, Douglas Lynch, Gladys Everett, Margery Hoffman Smith, Louise Gilbert, Mike Russo, Pietro Belluschi, Louis Bunce, Ray Neufer, and Barbara Sprouse. These people will probably never know how special it was to make their acquaintance. I would like to give special thanks and acknowledgment to Martina Gangle Curl, who became my friend during the course of my research and whose three lengthy 
interviews provided me with a wealth of valuable information and insight. It was through Martina Curl that I became acquainted with a rare collection of Runquist brothers' paintings, and her stories about Albert and Arthur Runquist helped me get to know these men whom I would like to have met.

I am especially indebted to Sarah Munro, archivist for Friends of Timberline, for allowing me to enter her home many times to use the files of documents from Timberline Lodge, the Burt Brown Barker Papers, and the 0. B. Daws on Papers. Those documents were primary sources for my thesis and, more than any other source, formulated the questions and issues addressed herein.

Special thanks also go to my thesis committee, Robert Shotola, Theo Majka, and R. Kelly Hancock, for their support and interest in my work. Dr. Shotola and Dr. Majka were particularly helpful in their criticisms of earlier drafts of this work; their comments, aimed at improving my theoretical formulations, were much appreciated. Dr. Shotola's editing of earlier drafts of the thesis have made the present text more readable. In an effort to complete this work, I left unheeded some of the committee's suggestions which might have strengthened my arguments and improved the organization and style of the thesis. My knowledge that more data could be added to strengthen this study has led me to view this thesis not as the end, but as a step 
in the beginning of a process.

The research process that culminated in this thesis might not have been had it not been for three special friends who encouraged me along the way. Roger Walke deserves special credit for being one of the first persons to take an interest in the data I was collecting; in particular I recall a long discussion at a party where he enthusiastically probed into my data and helped me formulate categories, issues, and hypotheses. That discussion and subsequent ones reenergised my interest at just the right times. The second friend who deserves credit is my father, Jack Howe, who, for as long as I can remember, encouraged my interest in the arts. When my interest is sociology turned towards the sociology of the arts, his interest and enthusiasm led me to see the connection between my current research and my childhood interests. Finally, my greatest intellectual and personal gratitude goes to my friend, partner, and husband, Jerry Lembcke, whose own intellectual work and commitment inspired me; our discussions together, his criticisms of an earlier paper on this topic, his personal support and friendship, and his constant belief in my ability to do better, encouraged, challenged, and sustained me throughout the year and a half that I worked on this project.

Three additional pecple deserve special mention for their help with this project. I am grateful to G. William Domhoff for taking the time to comment extensively on a 
paper entitled "Women in the Administration of the Oregon Federal Art Project" which was accepted for delivery at the March, 1980 University of Pittsburgh Conference on Women in the Arts. Many of the ideas from that paper and some of Domhoff's suggestions have been incorporated into this thesis. Thanks are also due to Jeremy Egolf, whose criticisms on Chapter One of the manuscript challenged me to confront several of its inadequacies before it was too late to fix them. I am especially thankful to him for his crucial help in the last hours of panic before the dead1ine. Last but not least, I want to thank Ruth Beam, who typed the thesis with little forewarning and without much time.

Ultimately, this work was inspired by the many people who have attempted and are trying to build a democratic, "people's culture" that expresses the conditions and aspirations of people struggling to build a better world. My recent interest in such arts has been inspired by Quilapayun and Inti Illimani, two Chilean musical groups, 1iving in exile, which have attempted to create a new musical form expressing both the native culture and the contemporary music and struggles of the Chilean people. Their music, which sings of the realities of oppression and the potentialities for liberation, has inspired me to $100 \mathrm{k}$ for art forms that express the aspirations and struggles of working people in this country. I have begun that search with this 
study of the WPA Federal Art Project. Those who helped build that project and who participated on it are those to whom this work is dedicated. 
I THEORY AND METHODOLOGY . . . . . . . . . . . 1

Theoretical Discussion. . . . . . . . 1

Sociology of the Arts

Why Government Patronage?:

Four Models

Class Struggle Theory

Methodological Discussion . . . . . 18

II SOCIAL RELATIONS AND CONDITIONS AFFECTING

THE NATIONAL AND OREGON FEDERAL ART PROJECT 28

Historical Overview . . . . . . . 29

Oregon Project

Social Conditions Leading to the

Establishment of the Federal

Art Project. . . . . . . . .

The National Scene

The Oregon Scene

Artists Organize

Influences at the Administrative Leve 1

Summary of Social Conditions

Social Relations and the FAP. . . . . 57

New Relations of Art Patronage 
Class Backgrounds of FAP Administrators

Class Backgrounds of Artists

Summary of Social Relations

Summary and Conclusions . . . . .

II I GOVERNMENT SUPPORT AND CONFLICTING GOALS ON THE OREGON FEDERAL ART PROJECT. . . .

National Goals and the Oregon FAP . .

Implementing the Oregon Federal

Art Project. . . . . . . . .

"Art for Art's Sake?"

Art for Whom?

Art for Everyone

Summary: Art for Art's Sake

Art and the Business Community

Art and Govermnent Programs

Art and Ideology

Ideological Orientations of Oregon Supervisors

Ideological Struggles and the End of the FAP

Ideology and Support for the Arts: Conclusions

Summary and Conclusions . . . . . .

IV CONCLUSION: A MODEL OF THE OREGON FEDERAL

ART PROJECT. . . . . . . . . . . . .

A Mode1 of Social Conditions Affecting the Oregon Federal Art Project.

External Social Conditions: The National Level

Internal Social Conditions: The National Leve1

Social Conditions in Oregon

The Cultural Revolution . . . . . 
PAGE

APPENDIX B: RELIEF AND NON-RELIEF ARTISTS AND CRAFTSWORKERS ON THE OREGON FEDERAL ART PROJECT. . . . . . . . . . . . . . 184 APPENDIX C: PERSONS INTERVIEWED NOT ON THE OREGON FEDERAL ART PROJECT. •........ 190 


\section{LIST OF TABLES}

TABLE

PAGE

I Number of Workers and Salary Expenditures for Three Types of Sponsors . . . . . . 108

II Number of Workers and Salary Expenditures at Timberline Lodge . . . . . . . . 110

III Percent of Workers and Salary Expenditures

for Relief and Non-relief Artists and

Craft Workers at Timberline Lodge . . . . 111

IV Distribution of Monthly Salary Expendi-

tures for Timberline Lodge, Elite

Institutions, and Public Institutions, by Percentages and Actual Do11ar Figures. . 114 


\section{LIST OF FIGURES}

FIGURE

PAGE

I A Model of the Social Conditions Affecting the Production of Culture on the Oregon Federal Art Project. . . . . . 152 


\section{CHAPTER I}

\section{THEORY AND METHODOLOGY}

This thesis explores the relationship between art and society by presenting a case study of the Oregon Federal Art Project (FAP). This chapter addresses the theoretical background pertinent to this study by focusing on the orientations of the sociology of the arts and of social movements theories which have been employed throughout the thesis. Following these theoretical discussions, the methodological approach to the conduct of this research is presented.

\section{THEORET ICAL DISCUSSION}

\section{Sociology of the Arts}

...changes in the external conditions of life bring about changes in the internal life of human beings ....A society does not stamp personalities from a die, but no one can go beyond its possibilities for freedom and growth. It has been the special province of the arts to reveal these changes in human internal life, to show what it has meant to live in a particular society (Finkelstein, 1976).

Art operates within the boundaries and social conditions set by its society--specifically the particular class relations, mode of production, institutions, and ideology of that society (Finkelstein, 1976; Hadjinicolaou, 1978; 01son, 1978; Williams, 1973). These boundaries provide the 
tools and conditions for creative activity and they influence its direction and form. At the same time, individuals and collectives of individuals remain actors within society, and within its boundaries they act to construct new realities and make possible new directions for human activity. Much of this creative process occurs in the symbolic world (Berger and Luckmann, 1967); that is, human beings, through conscious human activity, act and interact in such a way as to create society, which, in turn, imposes itself as an autonomous entity to subsequent generations. Artists, as an integral part of this process, develop and grow within socially defined boundaries; their work ultimately becomes a part of that boundary we call society. Thus, art is both a reflection of and a creation of social reality (Finkelstein, 1976; Sanchez Vazquez, 1973).

To understand the arts at any point in history, it is thus necessary to view the social conditions which form the external reality or boundaries of the society. The word "boundary" is used metaphorically, for human existence is always in the process of social development, and social conditions are dynamic, not static. To comprehend artists and the arts in a social context, the refore, we must consider them historically, and examine the changes that occur within the larger social context as well as within the internal lives of people.

The 1930 s was clearly a time of tremendous change 
within the United States. Although the basic mode of production remained a capitalist one, the legal, ideological, and industrial structures of the society underwent important reforms as new relationships between capital, labor, and the state were developed to adjust to the changing conditions of the substructure, brought about by and characterized by the economic crisis. A sociological analysis of the New Deal art projects must perforce examine the relationships between the macro-level social conditions of the $1930 \mathrm{~s}$, the social conditions affecting the production of culture in particular, and the changes in the social relationships affecting artists as they responded to their social conditions. Unique to the art of the $1930 \mathrm{~s}$ is the fact that much of the known art produced was done under the auspices of the federai government, through various programs such as the Public Works of Art Project (PWAP), Treasury Section of Painting and Sculpture, Treasury Relief Art Project (TRAP), and the more far-reaching Federal Art Project (FAP) of the Works Project Administration (WPA). A study of the Federal Art Project must examine the relationship between this project and the important social conditions of the 1930s; it must also look at the relationship between the arts and the society prior to and following the FAP in order to understand the transformative character of that project, be that large or sma1l.

This approach is consistent with many of the guide- 
lines suggested by Richard Peterson (1979) who has elaborated a production of culture perspective in the sociology of the arts. According to Peterson, the production of culture approach asks not what effect a cultural code has on a society but how the code, itself, is produced and reproduced. The approach emphasizes that there are cultural specialists whose task it is to create and disseminate culture, and argues that "the organization of these specialties will critically condition the nature and development of the cultural elements involved. In this sense the production of culture perspective...focuses on how the milieu in which culture is produced influences its form and content" (Peterson, $1979: 153$ ).

Applying the production of culture perspective to a study of the FAP requires an exploration of how the project operated organizationally and how the organization fit into the milieu of the larger society. To understand this relationship it is necessary to consider government intervention during the Depression, and its patronage of unemployed artists affected by the economic crisis. The government certainly could have hired artists to work on other socially useful projects such as road and dam construction, if the problem of unemployment were its only concern. An organizational analysis is not sufficient for addressing this question; rather an understanding of the $1930 \mathrm{~s}$ points to the social movement character of that period when social change 
emanated both from the halls of Congress and from the streets and factories. Many New Deal programs can be viewed as the result of a social movement "from above," whereby progressive liberals with powerful positions attempted to improve the social conditions affecting the general populace. The same programs and much of the legislation of that period, together with the tremendous surge of unions, may be seen as a result of social movements "from below," whereby working people, whose power lay in their numbers, brought about changes through their own organized efforts. The dichotomy between social movemerts "from above" and social movements "from below" is elucidated by a class analysis perspective which looks for conflicting interests between different sectors of the upper class as well as between the general interests of the upper class and the general interests of the working class. These conflicting interests raise the issue, once again, as to why the federal government saw fit to create a special relief program for unemployed artists. Plausible answers to this question are discussed in the following section, which is followed by an elaboration of the class analysis perspective.

\section{Why Government Patronage?: Four Mode1s}

Michael Useem (1976) has proposed four models which serve as possible explanations for the government's intervention and interest in the production of culture. Each 
model has two corollaries which, Useem argues, can be empirically testable.

Resting upon the assumption that the government is a neutral instrument concerned with the maintenance of collective goals via relatively autonomcus subsystems, the first model focuses on government intervention on behaif of the arts for the sake of maintaining cultural institutions undergoing crises. Useem's corollaries to this formulation are:

1. The time of government intervention is primarily related to economic crises faced by the arts, themselves, and not to crises in the political system, economy, or elsewhere;

2. Government intervention takes the form of protecting the dominant paradigm of the arts; federal funding is allocated to the most creative artists and organizations, as defined by the "relevant artistic community."

The second mode1, predicated on the view that state expenditures are determined largely by the needs and interests of business corporations, argues that these most powerful groups in a society are able to "mobilize public funds" for their private artistic purposes. This model's corollaries are:

1. Government intervention, accompanies sharp increases in corporate consumption of art;

2. Federal funds are disproportionately allocated to 
work which has industrial application or is of utility to large corporations.

Useem's third model rests on the assumption that the government, itself, has become a major consumer of art, and it allocates funds to serve its own needs and programs. Two corollaries are:

1. The allocation of federal funds to the art: corresponds to an increasing utilization of the products by the government ;

2. Federal funds are allocated primarily to those artists whose work will be applicable to government projects and programs.

Useem's final model for explaining state expenditures for the arts is premised on the assumption that ideological control is an important state function. While structuralfunctionalists (e.g., Parsons, 1969) have assumed that this ideological control takes the form of a shared value system which helps to maintain and integrate the society on the basis of consensus, Marxists (e.g., Miliband, 1969; Lukacs, 1971) have emphasized the importance of the state in maintaining both government legitimacy and the dominant ideology of the ruling class, thus sustaining prevailing power relations through various mechanisms of ideological control. It is this latter view that is suggested by Useem's fourth model, which argues that government patronage of the arts 
serves the ideological needs of the state. ${ }^{1}$ The following corollaries stem from this model:

1. State intervention in the production of science and art accompanies a crisis or crises in government legitimacy and dominant ideology;

2. Government funding is oriented toward artists whose work will assist the restoration of the dominant belief system and confidence in the government.

An application of Useem's models to this study of the Federal Art Projects has served as a guide to research rather than as a theory to be tested. Relevant fields of inquiry and analysis were suggested by these models which have been incorporated into the main body of the thesis as categories of inquiry. Chapter Two addresses the questions

1 Based on a study of government support for the arts through the National Endowment for the Arts, Useem (1976) found evidence that its creation in the 1960 s related to the government's desire for ideological control. The midsixties witnessed a sharp increase in political dissidence and a decline in legitimacy, spawned in part by the Vietnam war; Useem observed three mechanisms used to que 11 unrest and protests: First, public relief was given to the poor; second, harassments, arrests, and violence were used against organized dissent movements; finally, the arts were supported as a means of obtaining ideological control. As evidence, Useem noted that a Rockefeller Brothers Fund report of 1965 argued that the arts could help provide a proper use of leisure time, enabling people to satisfy the "spiritual hunger" left unmet by the society; this could be done by constructively channelled activities (Useem, 1976). Useem (1976:134) concluded that "avai1able evidence at least points toward the primacy of the arts' ideological control value as an explanation for state intervention in the arts." 
of how and why the FAP was formed; the answers to these questions indirectly lend support or opposition to Useem's various mode1s. Chapter Three addresses the mode1s in terms of their application to an understanding of the social conditions affecting the production of culture on the Oregon FAP. Specifically, the discussion concerns the extent to which, and the conditions under which the needs of art as an institution, corporations and businesses, government projects and programs, and the ideological needs of the state and the orientations of its representatives affected decisions regarding what to produce and how to organize production on the Oregon FAP. While the thesis does not attempt to prove or disprove Useem's models and corollaries, generalizations from evidence concerning the relationship between the institutionalized art community, businesses, government, and ideological orientations of administrators, and the production of culture on the oregon FAP may, however, reflect upon the adequacy of these models. Chapter Three shows that each category influenced the Oregon FAP to varying degrees.

\section{Class Struggle Theory}

An understanding of government sponsorship of the arts requires consideration of the mechanisms by which governmental structures and policies are shaped, and the effect of these structures on people. Several theories of the state 
have been prominent in recent literature; four of these are introduced briefly below, before turning to the perspective which has informed the gathering and analysis of data for this thesis. The first approach is the pluralist theory which concludes that power in America is multi-based, issuespecific, and always shifting (Dah1, 196.1). The second view is the "Millsian" power elite theory which locates state power in the hands of a small group of overlapping and associated corporate, political, and military elites (Mills, 1956). A third view, somewhat related to Mills' theory, is often called the "instrumentalist" theory of the state; proponents of this view locate state power in the hands of the dominant class of society--the capitalist class. A fourth approach is the "structuralist" theory. Developed by Althusser (1971) and Poulantzas (1973), this perspective argues that state structures and policies are determined by the systematic constraints and contradictions of capitalism. According to this view, overt upper class participation in government may not be necessary at ail to insure the survival of the system and the prevailing class relations.

In contradistinction to the perspectives reviewed above, Esping-Anderson, Friedland, and Wright (1976) have advanced a "political class struggle" perspective on the state. They argue that the state, rather than being controlled by a unified ruling class or by a plurality of interests among various groups, is, itself, an object of class 
struggle. The internal structure of the state and policy choices emanating from it are "simultaneously a product, an object, and a determinant of class conf1ict" (EspingAnderson et al., 1976:191). In this context

the capitalist class attempts to create structures which channel working class political activity in ways that do not threaten capitalist political dominance and objective interests. Working class challenge makes the success of such attempts problematic. A political class strugsle perspective on the state tries to locate the state within the dialectical relationship between class dominance and systemic constraints (EspingAnderson et al., 1976:190).

Esping-Anderson et al.'s political class struggle theory of the state appears to be most viable for explaining the creation and developments of the FAP in the $1930 \mathrm{~s}$ because it combines the class analysis approach of the instrumentalists and structuralists with a social movements orientation in an attempt to understand state structures and reforms; these converge in a way that makes sense out of the volatile class relations of that time. This approach would suggest that the FAP arose as a product of class conflict, became an object of class conflict, and subsequently influenced the outcome of class conflict. Each of these aspects of class struggle is discussed in the thesis. For the sake of simplicity, the political class struggle model of the state will be referred to simply as the class struggle perspective.

Central to the class struggle perspective is the crit- 
ical point that "political challenge by the working class shapes the historical development of state structure. The actual structures of the state are thus not a simple reflection of capitalist interests, but a contradictory reflection of the class struggle between workers and capitalists" (Esping-Anders on et a1., 1976:192). This suggests that particular state structures may come about because an actively organized working class places demands upon the state directly for reforms which meet its interests; alternatively, particular structures may be developed by the state in response to the struggle between the working class and the capitalist class, although neither class need have made direct or implicit demands upon the state. In either case the theory asserts the existence of the dominance of capitalist class interests in the society and within the state; however, among the systemic constraints which limit the absolute hegemony of the upper class are both economic and political contradictions which require the state to consider the actual or potential existence of a politically organized working class. The less organized the working class, the greater the capitalist dominance of state power, and the likelier are state structures to reflect the interests of the capitalist class. The stronger the political organization of the working class, the more likely are reforms to be granted and state structures to reflect the interests of the working class. As Esping-Anderson et a1. (1976) point out, class 
struggle has often taken the form of political conflict over the structuring of state authority, and, I might add, over the character and extent of government programs and policies. Control of the state is ultimately perhaps the most volatile and ultimate arena of class struggle; the state constitutes a contested terrain where even small reforms may be reflections of class struggle within the society. In addition, the statehas become an increasingly important force in the development and regulation of the capitalist economy (cf. J. O'Connor, 1973); consequently, political neutralization of the working class has become more imperative for capitalist growth, and structural change can be a tool for this neutralization (Esping-Anderson et al., $1976: 192)$. Structural reforms thus can be both a concession to working class demands and interests and a tool for neutralizing those very organized and challenging segments of the working class that make demands in the first place. This points to the contradictory character of social reforms; one aspect of a reform may advance the interests of the working class while another aspect of the reform undermines the interests of the working class for political power and self-determination.

The cooptive nature of reforms has been discussed at length by such theorists as James Weinstein (1968) and Frances Fox Piven and Richard A. Cloward (1979). Often referred to as "corporate liberal" theorists, these writers argue 
that reforms are often granted by representatives of a liberal corporate elite which recognizes that some reforms are necessary in periods of social unrest when the failure to grant them might lead to even greater organization of the working class and a more powerful and substantive challenge to the established order. Thus, in order to save the system, the corporate liberals attempt to reform it; these reforms are carried out, however, in ways that are believed to neutralize working class political organization and subvert genuine threats to capitalist social relations. Reforms are granted which thus appease some of the demands of the working class while the basic social relations of capitalism remain intact, and, ultimately, the dominance of the capitalist class prevails.

Up to this point, the analysis of how social movements influence state structures and reforms could be paraphrased as follows: The content (cpecific demands and arenas of struggle) and character (the relative political organization and power of each class) of class struggle provide state leaders with their cues as to where changes and reforms are imperative, lest the struggle be resolved in favor of the abolition of capitalist class dominance within the state. Far-sighted members of the upper class and their representatives in the government institute changes and reforms that meet some of the implicit or explicit demands of the working class but that simultaneously can undermine the 
potential of that class to organize itself into a political1y effective and powerful group. These corporate liberal reformers do not represent a unified upper class, for inyariably there are segments within it which view the granting of reforms as dangerous. Thus, as Poulantzas (1973) pointed out, the state represents the interests of the dominant class as a whole, not of particular groups or segments within that class. The state's actions stem from the need to reproduce class relations and class domination in general --that is, to reproduce capitalist society as a whole. Thus, conflicts within the upper class have an impact on state actions and structures, but the ultimate goal of preserying the fundamental interests of the upper class, as a whole, remains the primary function of the state (Althusser, 1971 ; Poulantzas, 1973).

If the analysis were to stop at this point, an undialectical theory of social change would have been presented. Missing from the aboye analysis is the contradictory character of reforms not just for the various segments of the upper class but for the working class, as well. Reforms and new state structures may haye the effect of quelling unrest and coopting the interests of the working class, but they also haye the potential of serving both immediate and longrange needs of the working class and thus, of contributing to its political organization and power. When the working class is weak, its demands can be neutralized and channelled 
into safe outcomes; when it is well organized and strong, the state may try to alleviate the sources of discontent, but to do so it must grant major concessions to the working class. In either case, the state may try to neutralize discontent, but it cannot alter or dissolve the root sources of conflict, and unrest and insurgency are thus likely to recur in the future (Esping-Anderson et a1., 1976).2

In reality, most reforms have a contradictory character in that they are potentially cooptive and reformist as well as conciliatory and revolutionary (cf. Gorz, 1964). 3 An important theoretical question is, given a working class

${ }^{2}$ Th$_{1}$ is idea has been elaborated and explored empirical$1 y$ in a number of recent studies (cf. Ewen, 1976; Gor $\angle$, 1964; Piven and Cloward, 1979).

3 Andre Gorz (1964) has emphasized the important distinction between revolutionary reforms and reformist reforms. Reformist reforms are those which subordinate their objectives to the rationality and practicality of a given system and policy; it rejects those objectives, demands, and strategies for their attainment which are incompatible with the preservation of the system (Gorz, 1964:7). Revolutionary reforms are structural reforms which are determined not in terms of what can be, under the present system, but of what should be. Such reforms are revolutionary to the extent that they modify the relations of power and help the working class feel its power and positive strength which are capable of establishing, maintaining, and expanding autonomous working class power vis-a-vis the power of capital (Gorz, 1964:7-9). Following Gorz, then, it is possible that structural reforms can come about which are steps in the direction of changes that alter the basic social relations of capitalism in a way which could ultimately abolish the economic and political subordination of the working class to the capitalism class. Such reforms do not necessarily coopt the working class and subvert its interests; rather, they enhance its interests and expand its power, or at least make such enhancement and expansion theoretical1y more plausible. 
demand that has been granted in a reform, when does the reform constitute a reformist reform and when does it constitute a revolutionary reform? Esping-Anderson et al. (1976) look to the character of the demands, themselves, as well as to the relative strength of the working class when it makes demands, for an approach to the answer to this question. Specifically, they point out that demands for intervention which are at the level of circulation (exchange of commodities and services) and which are capable of exchange within the capitalist market structure are most likely to be "reproductive" of class relations, and thus are met as reformist reforms by the capitalist class. Demands which call for state intervention at the level of production in noncommodified ways (operating outside established market mechanisms) are most likely to be unreproductive of capitalist class relations, and thus, objectively are more capable of serving working class interests. Examples of the former include consumer-oriented demands while the latter involves point-of-production demands.

The theoretical and empirical questions regarding the reformist or revolutionary character of the state reform which was the WPA/FAP are addressed in an exploratory manner throughout the thesis, and they frame the way in which the data is analyzed. Specifically, I look at how the social movements and social relations of the 1930 s shaped the development of the WPA and the FAP and how the WPA/FAP, as a 
reform had a contradictory character. This contradictory character of reforms necessitates an examination of the positive, as well as the negative effects of the FAP for artists and for the social relations of art. This examination is conducted primarily in Chapter Three and analyzed primarily in the conclusion, Chapter Four. The models and corollaries suggested by Useem guide this examination in an attempt to yield an understanding of the extent to which working class interests were served or coopted as a result of the FAP, and how the structure of the FAP facilitated or undermined these interests.

\section{METHODOLOGICAL DISCUSSION}

Glaser and Strauss (1967) consider the discovery of theory from data, which they cali "grounded theory," to be the most important task of sociology today. They consider the methods of comparative analysis to be the most essential strategy for doing grounded research. Comparative analysis can be used for a number of purposes: To check out the accuracy of evidence; to establish the generality of evidence; to develop relevant conceptual categories and to specify the dimensions of a conceptual category appropriate to a particular unit of analysis; to help verify the emergent theory; and to help generate new theories. A11 of these uses are adyocated by Glaser and Strauss in the generation of grounded theory. The conceptual categories, their 
conceptual properties, and the hypotheses or generalized relations among the categories and properties constitute the elements of grounded theory. Thus, accurate evidence and verified hypotheses are not the central concerns in theory generation, for it is the conceptual categories and their properties upon which the theory is built, not a specific set of verified facts. It is, nevertheless, important that the facts gathered and the propositions developed be as accurate and theoretically sound as possible (Glaser and Strauss, $1967: 21-40$ ).

Glaser and Strauss (1967:33-4) argue that both substantive and formal theories must be grounded in data; while researchers may study an area with a particular sociological perspective, with a focus, and a general question or problem in mind, they should not have any "preconceived theory that dictates, prior to the research, 'relevancies' in concepts and hypotheses...A substantive theory generated from the data must first be formulated, in order to see which of diverse formal theories are, perhaps, applicable for furthering additional substantive formulations."

The strategy for data collection and analysis used in this study conforms largely with these inductive methods of research. That is, while the collection of data was approached with a general set of questions and a theoretical perspective in mind, I did not have a preconceived set of substantive or formal theories to bring to bear on the data. 
Through the simultaneous and continuous process of collection and analysis of data, conceptual categories were developed and relevant theories were then incorporated as guides to further data collection and as frameworks for the analysis of the data. Consequently, my questions and focus wero revised, expanded, and refocused as new issues emerged from the data and the theoretical frameworks brought to bear on the data. This process is elaborated below.

My study began while serving as a research assistant on a project designed to study the life satisfaction of senior Portland artists who had lived in Portland during the $1930 \mathrm{~s}$. The major focus of this research was to gather oral histories of these artists and from these, to begin to develop an understanding of the Portland art community and the relative degrees of life satisfaction and alienation among artists who were active during the depression. Before the research got under way, it became clear that a relevant question concerned a possible contradiction between the traditional isolation, estrangement, and poverty of the artist and the fact that during a time of severe economic crisis and unemployment, artists found employment and a regular income on various New Deal art projects.

I approached this initial research with the intent of studying the Oregon Federal Art Project of the WPA. The sociological perspective which guided my research could variously be called Marxist or class analysis theory or, 
more precisely, dialectical historical materialism. This perspective emphasizes the dialectical relationships between classes, between system parts and the system totality, between the present and the past, and between the economic mode of production of a society and the superstructural realm of politics, ideology, religion, etc. While positing the struggle between classes as the motive force in history, diverse theories within this perspective focus on the various permutations of this struggle. One focus of study within this perspective is the concept of alienation. This concept helped formulate many of the initial questions of my research regarding the Oregon FAP. These questions were augmented by my general understanding of the social movements of the $1930 \mathrm{~s}$, in particular the union organizing efforts in the Pacific Northwest. The concept of alienation and the category of social movements were combined in an article entitled "Alienation and Revolution" by Maurice Zeitlin, which suggested an inverse relationship between alienation and social activism among Cuban workers (Zeitlin, 1966). I developed a general set of questions with which to approach my earliest interviews with former FAP artists which focused on the artists' involvement in a social and political community, and the degree of control artists on the FAP had over the processes of conception, production, and distribution of their work. In this sense, I hoped to explore the concept of alienation in the Marxist 
sense (cf. Marx, 1976 [1844]) and develop a theoretical understanding of the political activism and consciousness of artists on the Oregon FAP.

After developing a general question and focus for my research, I approached my first few interviews only to learn that the number of artists who participated on the FAP was small, and those who were politically active was even smaller. The second interview, with Jack McLarty, on January 24, 1979 , indicated that most of the political activity among artists centered in New York City. As a result, I began to use the New York project as a source of comparison with the Oregon project. Through secondary sources I soon learned that the New York FAP was not only the largest of the FAPs, but also the most important in the shaping of national policies for the FAP (see Chapter Two).

During an interview with Charles Heaney on February 15, 1979, I became aware that he had been employed as a ditch digger just prior to getting onto the WPA. The question then occurred to me, why did the government create a project for artists rather than put them to work as ditch diggers? To Heaney, as well as to other artists interviewed, the reasons for the creation of the FAP seemed less important than the fact that it was created. Heaney seemed to have exemplified the general feeling among Oregon artists when he said that the WPA "was a manna from heaven" (Heaney, 1979a). His comment suggested to me that Oregon artists 
had little to do with the creation of the project, and $\bar{I}$ again turned to secondary sources to explore the origins of the FAP (see Chapter Two). The writings of William F. MicDonald (1969) emphasized the administrative origins of the FAP while Richard D. McKinzie (1973) elaborated on the importance of the social activism among artists who pressed the government for a permanent federal art project (see Chapter Two). Francis V. O'Connor's (1969) analysis of the FAP, with an emphasis on the New York project, filled in gaps left by my own research and the other secondary sources. Jerre Mangione's (1972) work on the Federal Writers' Project clarified the Congressional responses to the WPA cultural projects. My awareness of the general political activism among the working class in the $1930 \mathrm{~s}$, and my discovery of evidence that artists were also an active political force, led me to explore social movements literature that might help suggest ways of understanding the differences between the New York and the Oregon FAPs. The problem of the FAP's origins also led me to search for literature on government patronage of the arts--a search which culminated in the incorporation of Useem's (1976) models as guides to further data collection and analysis.

After several interviews and a search for interviews done by other researchers, I learned that an organization known as the Friends of Timberline had several files re- 
lating to the FAP which I subsequently made use of. ${ }^{4}$ These files opened up entirely new questions and ultimately proved to be among my most valuable sources of information. Two boxes of files contained letters, telegrams, memos, minutes of meetings, reports, and other records relating to the Oregon FAP. Several files were listed under the category of Timberline Lodge, while the remainder contain the relevant papers of Burt Brown Barker and Orion B. Dawson (Regional Director and iron works supervisor, respectively).

The papers of Burt Brown Barker were especially valuable in suggesting to me the relevancy and importance of the organizational structure and bureaucratic operations of the FAP. They also caused me to begin to question the class backgrounds of the project administrators of the FAP, although I was not initially certain what relevance, if any, their backgrounds had to my study. The structure and organization of the FAP was later verified through secondary sources; the class backgrounds of the administrators were checked out by examining the Portland Blue Book and Social Register of Oregon for 1936 , the Who's Who in America for the same year, and Capitol's Who's who for Oregon for 1936 and 1937. Following interviews with project administrators Gladys Everett on May 24, 1979 and Margery Hoffman Smith on

${ }^{4}$ These files are currently located at the home of Sarah Munro of Portland, but are expected to be moved to an archives at Timberline Lodge on Mount Hood. 
May 29 , 1979 , I returned to the Burt Brown Barker and T'imberline Lodge papers to $100 \mathrm{k}$ for more data that might contribute to my emerging theoretical understanding of the Oregon FAP. Simultaneously, I conducted several interviews with project participants and non-FAP artists familiar with the Portland art scene during the 1930s. Among the new issues I took to the interview were those relating to the structure of the FAP, the person's position within that structure, and the relationships between project administrators and artists. I also tried to establish the range and nature of projects carried out by the FAP and attempted to discern the person's sense of the impact the FAP had on the nature of artistic production in Oregon, in the nation, and for the individual.

Having altered the focus of my study as new data was collected, I began to explore various theories of the state and of social movements to find those that might now help focus the analysis within the general framework in which I had set out to work. Upon reading the political class struggle analysis of the state by Esping-Anderson, Friedland, and Wright (1976), I settled upon it as a useful perspective because it focused on the relationship between classes and state structures in a way that combined an understanding of social movements, organizational structures, and the nature of reforms. This perspective thus supported my inquiries into social movements, class analysis, organi- 
zational structures, and the reasons behind the establishment of the FAP; at the same time it further suggested that I examine the nature of the FAP as a reform, and look for the possible contradictory character of that reform.

As noted above, the collection and analysis of data were simultaneous processes throughout the conduct of this research. Data were collected in several ways, som a number of sources. In addition to the papers available through the Friends of Timberline in Portland, much information was collected from primary documents located in the Archives of American Art of the Smithsonian Museum and in pamphlets and records printed by the United States Government Printing Office and located in public libreries. While the primary documents available through public libraries and the Archives of American Art may have been used previously, many of those located in the files of Friends of Timberline and many of the personal interviews conducted for this research are used here for the first time. In total, nineteen separate interviews were conducted with fifteen different people who had varying degrees of familiarity with the Oregon FAP. Six of those interviewed (and nine of the interviews) were artists who worked on the FAP in Oregon and/or elsewhere; their names are Martina Gangle (now known as Martina Cur1), Louis Bunce, Mike Russo, Charles Heaney, Douglas Lynch, and Ray Neufer. Two administrators interviewed were Gladys Everett and Margery Hoffman Smith. Other 
artists, who were not on the FAP, include Jack McLarty, Louise Gilbert, Bill Givler, and Leta Kennedy. Two interviews were held with former Portland Art Museum curator Rachael Griffin; Portland architect Pietro Belluschi was also interviewed. Finally, Mrs. John A. (Barbara) Sprouse, the daughter of Regional Director Burt Brown Barker, was interviewed and made available to me a copy of her father's autobiography.

The exploratory nature of this study, designed to generate a theoretically informed understanding of the Oregon FAP, has led to what Robert Merton (1967:147-8) called post factum sociological interpretations and explanations which remain at the level of plausibility rather than leading to high degrees of confirmation. Generalizations from such interpretations may be made with care, providing it is recognized that the test of the explanations awaits further research. As pointed out above, this study was designed to generate a theoretical understanding, and to suggest general relationships between conceptual categories and properties; the generalized grounded theory developed from this study can hopefully be of use to future studies of the FAP. Hopefully, the value of this study lies not only in the fact that it is a pioneering sociological study of the Oregon FAP, but that it is a contribution to the development of theory about the linkages between social movements, social structures, and the production of culture. 


\section{CHAPTER I I}

\section{SOCIAL RELATIONS AND CONDITIONS AFFECTING}

THE NAT IONAL AND OREGON FEDERAL ART PROJECT

This chapter examines the social conditions that led to the creation of the WPA and the FAP focussing on the social relations between 1 abor, capital, and the state at both the national and Oregon levels. It also introduces the internal structure, goals, and important regulations of the national FAP, which, in turn, determined the internal structure, goals, and regulations of the Oregon FAP. Final$1 y$, the social and class backgrounds of the project administrators and the artists is discussed, focussing primarily on those affecting the Oregon FAP. As a whole, then, the chapter addresses the external and internal social conditions affecting the production of culture on the FAP at the national level, and it provides relevant background to the social conditions in Oregon which are elaborated more extensively in the following chapter. By way of introduction to the substantive issues of this chapter, a brief history of the national FAP is presented and its general structure is introduced; a short overview of the Oregon FAP is included at the end of this historical discussion. 


\section{HISTORICAL OVERVIEW}

In many ways the FAP was the successor to the Public Works of Art Project (PWAP), whose short life lasted from December 1933 to June 1934. Eleven months later, on May 6, 1935, the Works Progress Administration (WPA) became an official government relief program (U1rich, 1937) and Harry Hopkins was appointed the national administrator for WPA. Two months later, the Division of Professional and Service Projects was established under the direction of Jacob Baker. Under the auspices of this division, a program called Federal Project Number One, or Federal One for short, was established; this project contained four subdivisions: the Federal Art Project, Federal Music Project, Federal Theatre Project, and Federal Writers' Project. A two-tiered hierarchy was established which governed and administered each Federal One project. Each had its own national, regional, and state officers whose major concern was the technical and artistic direction of the project. In January 1936, however, the position of Regional Art Director was eliminated and former Regional Art Directors became either State Directors for FAP or Regional Advisors to the National Director (McDonald, 1969:162). State art project directors were thus responsible to their regional and national superiors. At the same time, each was responsible to state administrations of the WPA which had its own hierarchy of 
national, regional, and state administrators. The Division of Professional and Service Projects had similar levels of administration, to which FAP directors were responsible. Shortly after the WPA was created, the Division of Professional and Service Projects was combined with the Women's Division and became the Women's and Professional Division (McDonald, 1969:165). The WPA offices were responsible for matters concerning the employment and administration of all WPA projects, including the FAP; the Women's and Professional Division usually carried out the administrative functions for the WPA office, although in many instances was also concerned with the technical supervision of projects (Everett, 1979$)$

Holger Cahill was appointed the director of the FAP when it came into existence in August 1935; it was not until October, when Congress released funds for the project, that regional and state directors were appointed and the projects got under way. Each regional or state director was instructed to choose an advisory committee to help select artists and appropriate projects in their community.

The WPA and all of its subsidiary programs were established with two goals in mind: To create jobs for three miliion of the nation's unemployed and to do work that would be beneficial to the community. On the FAP, these goals were ordered such that the first priority was to create jobs for unemployed artists who were registered on relief rolls 
and the second priority was to create works of art of use to the larger community, using the available talents of relief artists (F. O'Connor, 1967:27). In addition to these goals, two important regulations were central to the operation of the FAP: One regulation required that no fewer than ninety percent of the personnel on the FAP come from relief rolls; the remaining ten percent was allowed for the employment of non-relief, supervisory personnel. This regulation came to be known as the "non-relief exemption clause" and the quotas for non-relief employment fluctuated between five percent and twenty-five percent throughout the course of the FAP's history (cf. McDonald, 1969; McKinzie, 1973; F. O'Connor, 1969).

The second important regulation required the FAP to attempt to find sponsors for all of its projects. The role of sponsors was outlined in a letter to Burt Brown Barker, Regional Art Director for the Pacific Northwest, from Holger Cahi11 (1935c):

... in each case every endeavor should be made to have the co-operating sponsor furnish the equipment and materials. On projects where there is no co-operating sponsor, or where the co-operating sponsor cannot do this, and the project is of outstanding artistic merit and social value, the necessary purchases may be made with WPA funds. The cost of equipment and materials, in general, should not be more than ten per cent of the total cost of the project. It is desirabie that as little as possible in the way of material and equipment costs and rental cost be charged to the Federal Government.

Thus, sponsors were to pay the material costs while the FAP 
was to pay only the labor costs involved.

The history of the FAP following its creation was, in many ways, a tumultuous one, for the project faced the continual threat of extinction as battles were waged in Congress over whether or not to continue the projects. The sources of turbulence between Congress and the FAP were twofold: One source lay in the fiscal conservatism of some members of Congress who continually tried to terminate or reduce the appropriation of funds for the WPA, and particularly for the Federal One projects, which were seen by some as "make work" projects that paid people to play (Mangione, 1972). A second source of turbulence lay in the political conservatism of some members of Congress who thought the Federal One projects were too permissive in allowing subversive ideas to be portrayed (Mangione, 1972; McKinzie, 1973; F. O'Connor, 1969). Thus, in July 1937 the Alien Rule was passed which stated that anyone not a United States citizen could not be employed on the WPA; this rule was designed to get rid of the subversive employees on the WPA, many of whom were believed to be aliens (F. O'Connor, 1969). By 1940 , Congress passed a bill specifically excluding communists from the WPA rolls (McKinzie, 1973).

The Federal Theatre Project came under the heaviest political attack of the four Federal One projects. Beginning in 1938, writers, actors, and administrators on the Federal Theatre Project and Federal Writers' Project were 
summoned before the Dies Committee of the House Unamerican Activities Committee (HUAC) to testify about alleged subversive activities and fiscal waste on Federal One projects. In July 1939 , the WPA was placed under the authority of the new Federal Works Agency and was renamed the Work Projects Administration; the new emphasis of the projects was placed on tangible results rather than on providing relief. Two months later, Congress ended Federal Project Number One. The Federal Theatre Project was ended altogether and a11 of the others were merged into the WPA Art Program and placed directly under the state administrations. The national offices of the FAP were closed, leaving no one to arrange for the allocation and distribution of art works. Two new regulations came into being which threatened the existence of the new WPA Art Program in some states: Each project was required to obtain twenty-five percent of its total cost.s from local sponsors; in addition, no one could remain on any WPA project for more than eighteen consecutive months. As a result, in those states with unsympathetic WPA State Administrators, the arts projects in all likelihood came to a near standstill (F. O'Connor, 1969; McKinzie, 1973). When the United States entered World War II, the WPA Art Program was reorganized as the Graphic Section of the War Services Program and ten months later, in January 1943, the project came to its final and official end. 


\section{The Oregon Project}

In October 1935, Burt Brown Barker, Vice President of the University of Oregon in charge of public relations, became the Regional Art Director for the states of Oregon, Idaho, Washington, and Montana. Barker doubled as de facto FAP director for the state of Oregon, until, in 1936, he became the de jure state Director for the FAP in Oregon. Barker's assistant, Margery Hoffman Smith, became the State Director of the Oregon Arts Program when it was reorganized as such in 1939. Some sources have revealed a confusion about the respective positions of Barker and Smith. Griffin and Munro (1978:33) stated that Smith was first hired as a temporary supervisor and later became a permanent supervisor of the interior decoration of the WPA-built Timberline Lodge at Mount Hood; in November 1936 she became the assistant state FAP director, and according to Griffin and Munro (1978: 33) was promoted to "state FAP director" in 1937. Gladys Everett (1979), State Director of the Women's and Professional Division for Oregon, also alluded in an interview to Smith as the state FAP director. Official letters from the Burt Brown Barker papers, however, reveal a different picture. Up until February 1936, Barker signed his official correspondence as Regional Art Director, just as Cahill (1935b) instructed him to do in a letter dated October 25, 1935. By February 4, 1936, Barker (1936a) had begun to sign 
his correspondence "State Director, Federal Art Project." As of October 8,1938 , Barker was still being addressed as the State Director for the Oregon FAP (Val Cleer, 1938). The confusion may 1 ie in the fact that Smith was primarily in charge of the technical art direction of the Oregon FAP, while Barker concerned himself with administrative matters. Griffin and Munro's (1978) chronology of events similarly appears to be erroneous, as indicated by a February 4, 1936 letter from Barker to Cahill, in which the former referred to Smith as the "Assistant State Director of Art" who was "the technical art director under me" (Barker, 1936a). Smith also had "jurisdiction of the Mt. Hood Furnishings Projects," which apparently was not considered a project of the FAP (Barker, 1936a).

When Barker and his advisory comittee met on October 25 , 1935 , several projects were proposed that would employ thirty-three artists or craft workers, at a total estimated cost of $\$ 27,666.50$, including $\$ 2,752.50$ to be contributed by various sponsors. The projects included a junior symphony stage set, etchings for the University of Oregon, murals for Portland public schools, wood carvings for the Civilian Conservation Corps, sculptures and murals for the University of Oregon, paintings for the Port of Portland, and murals for Oregon City Library and Doernbecher Memorial Hospital COregon FAP, 1935). Two or three years later, most of these works had been completed. An undated report entitled "Works 
Done on the Federal Art Project, Oregon" listed fourteen paintings and other works done for public schools in and around Portland and in Pendleton; nine carved wooden gothic screens for Portland schools; a mural series for the Oregon City Library; four works each at Doernbecher Memorial Hospital and the Port of Portland; and nine statues, carvings, sculptures, and frescos at three universities or colleges. In addition, beginning in 1936, the WPA began construction on a resort hotel at Mount Hood, which artists and crafts workers helped furnish and decorate. This mountain hotel was named Timberline Lodge and was an important project of the oregon WPA and FAP. In the same undated report mentioned above, 130 water color paintings for Timberline Lodge plus six carved newel posts and eleven paintings for the same were listed; finally, several iron gates, grills, screens, panel rails, and decorative iron objects had been completed for Timberline Lodge, Oregon State College, and the University of Oregon (Oregon FAP, undated). At present, approximately one hundred photograph negatives of murals and easel paintings completed on the Oregon FAP are located in the T:mberline Lodge files available through Friends of Timberline.

The Oregon FAP employed artists on numerous projects, including ceramics, dioramas, furniture, easel painting, murals, glass mosaics, sculpture, silkscreen, textiles, wond carving, wood marquetry, and iron works. In addition, begin- 
ning in 1938 , a Community Art Center was operated in Salem, where numerous classes, lectures, and displays were held (Salem Art Center, 1938). It can be inferred from statements by project artists that the easel projects, the mural projects, and the Salem Art Center were the most important projects of the Oregon FAP (Heaney, 1979a, 1979b; Cur1, 1980; Bunce, 1979); project administrators, on the other hand, have stressed the importance of the Timberline Lodge project and the various iron works projects (Everett, 1979; Smith 1979; Barker, 1965). An accurate 1isting of the works completed on the Oregon FAP is unavailable, in part because many of the works are currently unaccounted for. In addition to the iron works and Timberline Lodge projects listed above (which will be discussed more thoroughly in Chapter Three), it is known that at least twenty murals, paintings, wood carvings, sculptures, or silkscreens were completed for the University of Oregon; twenty-one works were completed at various public schools throughout the state; thirty-five works were done for various military installations (such as Tongue Point) after the Oregon Arts Program began to produce works in conjunction with the war preparedness effort (see Chapter Three).

Befcre concluding this overview of the Oregon FAP, two additional administrators must be introduced. Following the structure of the WPA hierarchy, a State Administrator for WPA was appointed for each state. In Oregon that person 
was Emerson J. ("E.J.") Griffith. His first assistant as Director of the Professional and Service Projects was a Mr. Ivan E. Oakes. When that division was reorganized, Portland attorney Gladys Everett became the new State Director for the Women's and Professional Projects. (Her superior on the national leve1 was E1len S. Woodward.) Everett and Smith worked closely together, particularly on the interior decoration of Timberline Lodge; Everett hired seamstresses, weavers, and rug hookers to execute the drapery, bedspread, and rug designs created by Margery Smith. Both women appreciated the cooperation of State Administrator Griffith who seemed to have been quite supportive of the art project (Everett, 1979 ; Smith, 1979).

SOCIAL CONDITIONS LEADING TO THE ESTABLISHMENT OF THE FEDERAL ART PROJECT

\section{The National Scene}

The WPA developed out of one of the worst economic crises in the history of the United States. Across the nation, nearly fifteen million people were without work when Franklin D. Roosevelt became president in 1933 (F. O'Connor, $1969: 16)$

The falling stockmarket and rising unemployment which marked the depression contributed to a social and political crisis that at least matched the economic crisis. Previous- 
ly unorganized workers joined industrial unions and went on strike by the thousands to save their jobs and maintain some semblance of a livelihood (Boyer and Morais, 1973; Lembcke, 1978). Organizations such as the Unemployed Citizens League and the Unemployment Councils were formed throughout the country (Tattam, 1970). The threat of unrest, both in industry and "on the streets" contributed in large part to the New Deal programs initiated by the Roosevelt Administration. Before his election to the Presidency, Roosevelt was aware that something had to be done about the crisis affecting the nation. In a 1932 interview he told the following story:

Our people have to be put back on their feet... It will have to be soon. They are getting restless. Coming back from the West last week, I talked to an old friend who runs a great western railroad. "Fred," I asked him, "what are the people talking about out here?" I can hear him answer even now. "Frank," he replied, "I'm sorry to say that men out here are talking revolution" (Boyer and Morais,1973).

According to a 1937 Fortune article, relief for the unemployed during the Hoover years was largely charity. During the Roosevelt Administration, however, the concept of relief was transformed from that of a handout to that of an institution designed to create work for the unemployed. The Civilian Conservation Corps was established by the President and approved by Congress on March 31, 1933; its purpose was to employ 250,000 boys and men on environmental programs. On May 12, 1933, an act of Congress created the Federal Emer- 
gency Relief Administration (FERA) designed to grant relief to the unemployed through federal grants to the various states. In November of that year, the Civil Works Administration was created to provide jobs for four million people. Although the program reached its goal within two months of its founding, it was ended in the spring of 1934 because of a lack of funds (U1rich, 1937:109-11, 174-5). The next systematic attempt to handle the problem of the unemployed was the Works Progress Aciministration (WPA), established May 6, 1935 (Ulrich, 1937:175). According to the business press of that time, "Its job was human and social and it was interested only in the kind of work which had human and social consequences" (U1rich, 1937:110). The projects undertaken by Iocal WPA administrations were to be selected in accordance with "1) the number of eligible workers in the community, 2) their skil1s, 3) the kind of project the community most needed" (U1rich, 1937:110). The primary emphasis was upon the needs and skills of the unemployed workers rather than on the needs of a community. By January 1, 1937, there were 2,188,000 workers on WPA, yet the Roosevelt administration believed there were stil1 4,500,000 "unemployed 'employables"' on relief and another 4,500,000 unemployed workers not on relief (U1rich, 1937:175). Thus, the national scene was a dismal one for some nine million or more unemployed workers. 


\section{The Oregon Scene}

In the Pacific Northwest the scene was equally dismal. One historian noted that in the Pacific Northwest "the Great Depression did not begin on October 26, 1929, but rather sometime during 1921" (Murray, 1950:226). At that time, farm income was down fifty percent; taxes on farm land went up one hundred percent between 1919 and 1929; these dual factors threw numerous agricultural workers into the labor market (Murray, 1950:226). During the period just prior to and following the stock market crash, the employment scene in the city of Portland could be viewed as a microcosm of what was happening nationally. The lumber industry and longshoring were respectively the largest and the second largest employers in the city; between 1929 and 1933, however, lumber industry employment in Oregon dropped sixty percent and sawmill employment dropped seventy percent in Portland, alone. The construction industry suffered as well; in 1929 there were over two thous and construction workers in Portland; by 1933 there were only 689 (Tattam, 1970). Unemployment was coupled with strike activity and union organizing. Industrial leaders and city officials were nervous about the reported activity of communists within trade unions and the Unemployment Councils and Citizens Leagues (Bureau of Police, 1937; Oregonian, 1934).

According to a series of accounts in The Oregonian, 
plans were made for the united action of the unemployed in al1 of Oregon as early as mid-1932 (Oregonian, 1932a:1; $1932 \mathrm{~b}: 12)$. Throughout 1933 protests and demonstrations of the unemplcyed were held in Oregon City, Douglas County, McMinnville, and Salem (Oregonian, 1933a:1; 1933b:14; 1933c: $4 ; 1933 \mathrm{~d}: 2$ ). Numerous other demonstrations and protests were held thror:ghout 1933, 1934, and early 1935. Many officials charged that these demonstrations and protests were organized by aliens and communists, and news stories proliferated throughout the early $1930 \mathrm{~s}$ telling of the struggles between the alleged "Reds" and Portland Police and city officials. In 1934 , for example, during the West Coast strike of longshore workers seeking union recognition, set hours, higher pay, and control of the hiring halls, Portland police raided houses, union halls, and the Communist Party headquarters looking for communists (Tattam, 1970). The Oregonian front page story headline on July 19, 1934 read: "Portland Police Raid Communists. 36 Arrested on Charges of Syndicalism" (1934:1).

Less than a year after the successful strike of the International Longshoremen's Association, a lumber strike was called in the Northwest, and nineteen thousand of the region's thirty thousand lumber workers went out on strike. In Pertland, alone, 3,200 of the four thousand lumber workers went on strike (Tattam, 1970). While many of those involved in the strike were Communist Party members, many who 
were not were harassed and accused of being "Reds."

Strikes such as the longshoremen's strike and the lumber worker's strike occurred all across the country in the mid-1930s. In November 1935 the Committee for Industrial Organization was formed, later changing its name to the Congress of Industrial Organizations (CIO); the CIO was the industrial union counterpart to the craft-oriented American Federation of Labor (AFL). Indicative of the concern with Communists is the following excerpt from a "Weekly Report of Communist Activities" of the Portland Bureau of Police, dated September 3, 1937 :

On May 16 th, 1937,50 of the leading Communist leaders in the Northwest received instructions at a secret meeting held in Seattle, Washington to immediately launch a campaign to make the lumber unions the spear-head of the whole C.I.O. drive in the Northwest. Within a months time, the International Woodworkers of America, under the leadership of Canadian Communist, Harold Pritchett, was formed as the result of agitation and propaganda carried on among the lumber workers by radicals, Communists, and C.I.O. organizers...

The C.I.0. is a committee cormed in November, 1935 , by the presidents of eight different International Labor Unions... The announced purpose of the C.I.O. was to encourage and promote organization of the workers in the mass production and unorganized industries of the nation.'

Experience shows that its real, its ultimate purpose is the control of labor; that it seeks, by depriving industry of the ability to employ labor, to force industry to come to the C.I.O. leadership in order to operate. This has been well demonstrated in Portland during the past two weeks.

After pointing out the links between the C.I.0. leadership 
and the Communist Party, the report concluded:

Anyone who has dealt with Communists knows that wherever you find reds you find either submission to their demands or violence and bloodshed. That there has been so little violence is doubtless due to the fact that some government officials and some of those in high places have not only countenanced but lent their support to this campaign of deception and disruption (Bureau of Police, 1937).

These comments illustrate not only the nature and intensity of class conflict that went on in Oregon, but point to the divisions within the state over how best to preserve the social system; the Portland Bureau of Police represents that segment of the state which apparently viewed the policies of the Roosevelt Administration as dangerous and too radical, for the conclusion of this report suggests that some high officials (implicitly Roosevelt) were too conciliatory to the demands of "reds."

\section{Artists Organize}

Across the country, with a focus in New York City, artists joined in the demonstrations of the unemployed and joined in the demands for the government to take responsibility for alleviating the economic crisis (Cur1, 1979a; Russo, 1979). In addition, by early 1932, artists began organizing internally to survive the depression. William F. McDonald (1969) has argued that artists began to find ways to bypass the art dealer and set up a direct and popular market for their work; implicit in their moves was "a deter- 
mination to break the claims that bound him to the art dealer" (McDonald, 1969:347). In January 1932, the front window of a New York pharmacy was converted into a gallery and artists were able to show and sell their work directly to the public. In late May of the same year, artists held an outdoor exhibit in Washington Square which proved to be a financial success (McDonald, 1969:347). The open-air exhibits and the storefront galleries gave artists their first sense that a popular market was available for their work, although this public market was too small to support artists sufficiently for them to derive their livelihood solely from the production and distribution of art. Unfortunately, the federal, state, and local governments were not prepared to step in at this time and support the artists; according to McDonald (1969:348), the initial enthusiasm experienced by the new bonds between artists and the public had waned by the time the first public relief programs were available for artists.

It was probably in December 1932, that the first two programs for unemployed artists were initiated in New York City. A public program was apparently inspired by Harry Hopkins, who was at that time the administrator of the New York Temporary Emergency Relief Administration. This program hired artists to teach adult education and high school classes in the fine and applied arts. The second program, headed by Audrey McMahon and Frances Pollak, used private 
funds to hire artists both to teach and to paint murals for non-profit institutions (McDonald, 1969:347-8). This program was also known as the Emergency Work Bureau. These two programs gave artists in New York their first taste of steady employment as artists, an experience which was to become an important factor in the eventual creation of the FAP, as is pointed out below.

On September 24, 1933, a number of artists employed by the Emergency Works Bureau--twenty-five of whom were threatened with layoffs--formed an organization called the "E.W.B. Artists Group" (Art Front, 1934). Shortly thereafter, the group renamed itself the Unemployed Artists Group and in December, 1933, petitioned Harry Hopkins, newly appointed as head of the Civil Works Administration (CWA), for a federal program of relief for artists; many of the proposals suggested by the Artists Group were eventually incorporated into the PWAP.

When the PWAP called for the employment of only a limited number of artists, a large demonstration was held at the Whitney Museum; the demonstration successfully resulted in the hiring of more artists. At that time, the Unemployed Artists Group recognized the necessity of uniting with employed artists--whose jobs were at best temporary and tenuous--and the united group changed its name to the Artists' Union. The Union's goals were for economic security and for a wider distribution and understanding of art. 
When the short-lived PWAP ended in June 1934, artists once again took to the streets with their demands. On October 27,1934 , New York artists marched to city hall with a demand "for jobs and immediate relief for all artists." A second demand was for a municipal art gallery and center to be administered by artists (Art Front, 1934:1).

In November 1934, the Artists' Union joined with another organization, the Artists' Committee of Action, and began publishing a magazine called Art Front. The magazine, which continued until December, 1937, served as a communications medium for artists' groups. Calls for participation in demonstrations were interspersed with articles analyzing and debating current issues relating to both politics and the arts. News of artists' organizations in other parts of the country were also covered. The art magazine served to unify the artists and it provided them with a sense of their own collective power. In its first issue, Art Front (1934: 2) published the demands of the Artists' Union, which included demands for a permanent federal art project, full employment, non-discrimination, representation of artists on a11 administrative bodies concerned with the arts, and the establishment of municipal art centers and galleries. The federal art project was to include the decoration of public buildings, the building of decorative sculptrre, stained glass, monuments, fine and commercial art, and the teaching of arts and crafts. Many of these ideas were incorporated 
in a Federal Art Bill which was submitted to Congress in January 1935 .

The importance of the early relief projects for artists was demonstrated in the following comments by Edward Bruce, director of the PWAP:

The files of the Public Works Project contain many letters by artists written to explain what seems to me a most interesting point in the Government's adventure into the field of art. The artists wrote that the certainty of a regular check gave them a sense of security which enabled them to work without the distraction of financial uncertainty (McDonald, 1969:363).

When the PWAP ended, artists had experienced what it was like to be a professional artist. The artists continued to put pressure on Washington for a federal art project, and, as historian McDonald said, "The growth of artists in politica1 consciousness and especially in awareness of the part that the federal government could and did play in art activities was a major cause in the initiation of the Federal Art Project" (McDonald, 1969:372). Other historians of the New Deal art projects similarly attest to the importance of the political activities of artists in causing the government to institute the FAP (cf. Mangione, 1972; McKinzie, 1973; F. 0'Connor, 1969). If it was the conditions of the depression in general that led the government to initiate the WPA, the social movements of artists had an important, and perhaps a decisive role in causing the government to create a special relief project for artists, who otherwise might have had to 
seek employment on the WPA's manual labor projects.

\section{Influences at the Administrative Leve1}

A man frequently associated with the establishment of federal relief for artists is George Biddle, an artist from an influential Philadelphia family who had attended Harvard University with Franklin D. Rooseve1t (McKinzie, 1973:5). Biddle had been influenced by the Mexican mural experience in which the Mexican government supported young artists who decorated public buildings with murals depicting the social ideals of the Mexican Revolution. Their freedom of expression, freedom from financial worry, and the social impact of their art impressed Biddle, who believed that a similar experiment could be carried out in the United States.

Biddle first wrote to the President on May 9, 1933, regarding his idea for a federal art project. Biddle felt that an American federal art project could be to this country what the Mexican mural project was to Mexico. In the letter he wrote:

The younger artists of America are conscious as they have never been of the social revolution that our country and civilization are going through; and they would be eager to express these ideals in a permanent art form if they were given the government's co-operation. They would be contributing to the expression in living monumerts the social ideals that you are struggling to achieve (McDona1d, 1969:358).

While the President was not opposed to an art projeci, he remained, until the end of his administration, more con- 
cerned with solving the larger problems of the depression and international tensions, and the art projects were relegated to a secondary concern (McDona1d, 1969; McKinzie, 1973). George Biddle was put in contact with Edward Bruce, an employee of the Treasury Department who was a lawyer by trade but a competent artist, as well. Bruce and Biddle worked together, and by influencing Mrs. Roosevelt, were eventually able to get the CWA to provide a grant to the Treasury Department to form the PWAP, which was placed under the direction of Edward Bruce and Forbes Watson. The PWAP was not primarily a relief project, however, nor did it emphasize the social ideals advocated by Biddle in his earlier letter to Roosevelt. Although it was primarily a professional art project, aimed at producing works for the government and for the public: it nevertheless was the first federally sponsored art project, and therein lay its historical importance. When the WPA was created, it changed the emphasis from a professional art project to a relief project, and rather than treating the public as mere spectators of art, it attempted to involve people in the arts through its various educational programs. The PWAP and the WPA/FAP reflected the differing philosophies of Bruce and the President--the former reflecting a primary concern with the arts and the latter more concerned with the relief aspects of the project. Harry Hopkins, as Works Progress Administrator, shared and upheld the philosophy of the President, while the 
national and regional directors of the FAP by and large shared Bruce and Biddle's concern with the professional quality of the project. The dichotomies between the relief and service nature of the FAP and the production of art nature of the project remained a source of tension between the WPA and the FAP throughout their existence (McDona1d, 1969 ; McKinzie, 1973; F. O'Connor, 1969).

A man who mediated this tension also contributed significantly to the direction and organization of the FAP. Jacob Baker, an agricultural and industrial engineer from Colorado, came to work for the Federal Emergency Relief Administration as the Director of Work Relief and Special Projects in mid-1933. Baker's main contribution to that project was his unending effort to secure a relief program for white collar and professional people. Baker was a strong believer in the idea of industrial cooperatives and he continually pushed the concept that public works projects should obtain the support and cooperation of the local community. When the PWAP was started, Baker developed a plan to make each of the entertainment and educational programs self-supporting--a plan that was never successful. Baker's position was that the art projects should have as their focus service to the community; he hoped that as the government became a patron of the arts, the community would also come to see itself as patron, thus releasing the arts from the bondage of the old patronage system (McDonald, 
$1969: 118)$.

When the WPA was created, Baker was appointed National Director of the Professional and Service Projects. Because of his position, Baker was always in the middle of the controversies between the WPA and the FAP administrators; usually the conflict involved a state representative of one and a national representative of the other. Baker's concern with local sponsorship and community support made him unpopular with the directors of the Federal One projects who felt that giving the states more control over the projects would jeopardize their existence in some states (McKinzie, 1973; Smith, 1939). Although he resigned from his position with the WPA barely a year after it was created, Barker did a great deal to promote the cause of relief work for professional workers and his ideas helped create and shape the direction of the FAP (McDonald, 1969:166).

\section{Summary of Social Conditions}

A number of social conditions and factors contributed to the establishment of the Federal Art Project. Historian McDonald (1969) gives primary emphasis in his work to the influences and negotiations that occurred at the administrative level of government. While George Biddle, Edward Bruce, Jacob Baker, and Eleanor and Franklin Roosevelt were undoubtedly central to the establishment of the FAP, an understanding of the larger social forces and social movements 
operating during the $1930 \mathrm{~s}$ is essential for a sociological understanding of the creation of the New Deal and its art projects.

Several recent works on the New Deal art projects demonstrate the importance of economic turbulence and political unrest in bringing the projects into existence; many of these same social forces led to the political reaction that led to the ultimate demise of the FAP (Mangione, 1972; McKinzie, 1973; F. O'Connor, 1969). That is to say, the economic crisis created serious problems for capital and labor, alike. The massive layoffs that took place during the early $1930 \mathrm{~s}$ created a large number of unemployed workers who became an organizing target for left-wing individuals and organizations. When Herbert Hoover could not solve the crisis for either business or the unemployed, a majority of the people turned their votes and hopes towards Rooseve1t. Thousands of marches and street demonstrations occurred throughout the country and the growth of the Communist Party and other left wing organizations gave rise to opposing organizations such as the Portland Red Squad,a semi-official organization of the Portland Bureau of Police, whose purpose it was to monitor and inhibit left-wing people and organizations (Tattam, 1970; Cur1, 1979a;1979b). The social movements of unemployed and left-wing workers, and their opposition by organizations such as the Red Squad, and 1ater the Dies Committee of the House Unamerican Activities 
Committee, reflect an aspect of class struggle which, following the class analysis theory outlined in Chapter One, had a definite effect upon the subsequent structures and programs of the New Dea1 (cf. Esping-Anderson et al., 1976). Empirical evidence has not been located which could suggest the precise effect social movements and various individuals had upon the establishment of the FAP. While I know of no previous studies of the FAP which have claimed that the President and his advisors operated in a vacuum, unaffected by the pressure exerted from the sicial movements "from below," works that have emphasized the administrative origins of the FAP, while ignoring the importance of the political unrest and social movements of that period, fail to locate history in a proper social context (cf. McDonald, 1969).

If a social context is necessary for a proper understanding of the origins of the FAP, such a context is equal1y important for an understanding of the problems the FAP confronted throughout its existence and the reasons for its eventual demise. In both the operation and the termination of the project, an analysis of class struggle illuminates the historical conditions affecting these. The director of the New York and New Jersey art projects, Audrey McMahon, was, perhaps more than any other FAP director, confronted with demonstrations, protests, and sit-ins by artists throughout her administration. These protests were not intended as personal affronts against McMahon; rather they 
were aimed at the administration of the FAP, the WPA, and the Congress, for whom McMahon was, by virtue of her position, a representative. These protests, aimed at what the artists believed to be unfair regulations, curtailment of funds to the FAP, and partial or total layoffs of FAP workers, were defensive moves aimed at preserving the life of the FAP. McMahon was usually sympathetic to the needs of the artists and firmly believed that their organized protests helped postpone the eventual termination of the project (F. O'Connor, 1969:48). These struggles of New York artists were thus beneficial to artists all across the country.

U1timately, however, neither the protests of artists nor the support they received from administrators saved the FAP and other Federal One projects from challenges that came from fiscally conservative members of Congress who saw the Federal One projects as "paying people to play" (Mangione, 1972 ) and from the right wing reaction which took the form of the Dies Committee. The militance and social consciousness of many Federal One cultural workers aroused the ire of conservatives in Congress, and the Dies Committee began extensive investigations into the alleged communism and fiscal waste on Federal One projects. While a liberal Congress had supported the creation of the WPA and the Federal One projects, the balance of power shifted to the right within a few years; when President Roosevelt asked Congress for an exten- 
sion of relief money in January 1939 , he faced strong opposition. U1timately, the only way to save the entire WPA was to agree to a Congressional move to completely cut the funds of the Federal Theatre Project, which more than the others was seen as a "hotbed of Communism" (F. O'Connor, 1969:47; Mangione, 1972). It was at this time that the other three projects were reorganized into the WPA Arts Program and placed under the direct supervision of the state administrators of WPA--then renamed the Work Projects Administration.

The formation and termination of the FAP lends support to the theory of the state advanced by Esping-Anderson, Friedland, and Wright (1976) which views the state as an arena of class struggle. It also fails to support the corollary to Useem's (1976) first model which states that the timing of government intervention is primarily related to economic crises faced by the arts themselves, not to crises in the political system, economy, or elsewhere. Clearly the 1930 s was a period of political and economic crisis, a factor that was more important to the creation of the FAP than whatever crisis "the arts" may have been facing, as we11. Whether the FAP was primarily a result of artists' social movements or the efforts of people like Biddle, Bruce, and Baker, or a combination of all of these, the desire to solve the political, economic, and social conditions of the $1930 \mathrm{~s}$ were motivating factors for all of these. 


\section{SOCIAL RELATIONS AND THE FAP}

The previous section discussed the external social conditions leading to the creation of the FAP and the important actors that brought about its creation. An understanding of the operation of the FAP necessitates an understanding of the social relations internal to the FAP. This section introduces the main actors who influenced the daily operations of the Oregon FAP, beginning with the national director, following with the key Oregon administrators, and concluding with an introduction to some of the artists on the Oregon FAP. As suggested by class struggle theory, state structures are often created in such a way that they channel working class political activity in ways that do not threaten capitalist political dominance and objective interests. This is not to say that state structures necessarily must be administered by members of the capitalist class nor that the structures necessarily work against the interests of the working class. Rather, the theory would argue, the structures may have contradictory purposes and contradictory outcomes. Indeed, it was suggested in Chapter One that the FAP became an influence on the outcome of class struggle to the extent that it altered the social relations of art. A complete examination of these issues would require one to explore the social relations between artist, patron, and public prior to the $1930 \mathrm{~s}$, look for changes that 
occurred between artist, the government patron, its administrators, and the public during the course of the FAP, and examine the changes that came about in these social relations of art production. These issues are explored in this section because of their importance to an understanding of the Oregon FAP.

\section{New Relations of Art Patronage}

Prior to the $1930 \mathrm{~s}$, art appeared to be almost exclusively the domain of the upper class. Historian Richard McKinzie (1973:4) notes that prior to the FAP, the fine arts of painting and sculpture seemed to belong to "those few thousand families who comprise the national 'aristocrary'" and who "nurtured art as part of their loudly proclaimed European origins and heritage... Thus, by definition, an upper-class American was interested in art, albeit Europeanstyle art." Domhoff (1977) also notes the importance of women who are wives of rising corporate executives seeking entrance into the upper class; charitable and artistic organizations are considered "proving grounds and socializing agents for new recruits to the inner circle" (Domhoff, 1977: 62). Around the turn of the century, a few of these upper class patrons began to support native-born artists who copied European styles and a few American artists were able to make a living as artists. By the second decade of the twentieth century, some of these artists began to develop a 
subject matter and style that was "American." During these years, liberal intellectuals began to advocate a reunification of artists with the American people, charging that the upper class had corrupted the arts by creating a situation in which quality was equated with the price of a product (McKinzie, 1973:4). Holger Cahill (1975) also felt that in the nineteenth century, art had become segregated from the people and the society and artists had become divorced from their own social background. He argued that "fully fourfifths of our art patronage has been devoted to...trailing clouds of vanished aristocratic glories" (Cahill, 1975:37). Speaking in 1938, Cahil1 (1975:38) said that "During the past seventy-five years, the arts in America have had to follow a path remote from the common experience [and] our country has suffered a cultural erosion far more serious than the erosion of the Dust Bow1." With the exception of a few metropolitan areas, the country had been left barren of art and art interest. However, Cahill noted, beginning in the late 1920s many artists and art educators began an attempt to revive the arts--particularly an American art-and movements such as the "Ash Can School" began to look to the American scene as its subject matter (Cahi11, 1975:38).

The situation in Oregon was no exception. In the $1920 \mathrm{~s}$, most artists made their living doing something other than painting, and they looked forward to weekends to go out into the country to paint and sketch (Heaney, 1979a). The 
art community appeared to have been those upper class individuals who participated on the boards of directors of the Portland Art Association and whose generous donations made it possible for the Portland Art Museum to buy European paintings or hire teachers for the Museum Art School.

In the early days of the Portland Art Museum School, the school appeared to have been a "finishing school" for sons and daughters of Portland's upper class families (Lynch, 1979; Cur1, 1979a); young working class artists either received scholarships to the school or worked during the day and attended night classes. Few artists were able to see their work, and probably fewer had any aspirations of ever making a living at painting (Bunce, 1979 ; Heaney, 1979a). As artist Charles Heaney (1979a) put it:

None of us were showing. There was no place to show... Nobody was selling anything. If they did, they sold a few but it was negligible... We were producing an almost unwanted commodity....As I say, you take your lumps. You choose this--nobody forces you into this...so you have no right to complain. But it's your life; it's your job; it's the thing that you wouldn't have anything else than.

When the FAP came to Oregon, artists, for the first time, were employed as professional artists on a project that paid them as wage-earners. Throughout the entire nation the traditional social relations between the artist and the community changed. The old relations of paternalism, which, as noted above, had done little to support Oregon artists directly, gave way to a new situation in which the 
artist was a. worker and the government was both an employer and a patron. The importance of this new economic relationship was that for the first time in United States history, large numbers of artists began to work within the dominant social relations of capitalism. Traditionally, artists had operated in a semi-autonomous fashion, either dependent for their survival as artists on the paternalism and patronage of the upper class, or required to earn their living as commercial artists, engravers, or in some field completely outside the domain of the arts (Heaney, 1979a; Cur1, 1979a; Bunce, 1979). Except for the occasional genius or lucky person, most artists were of the latter category. Whether the artist depended on the patronage of the upper class, or was forced into being an "after work" painter, an ideology developed among both artists and the community which viewed the artist as a "talented misfit" of society; artists clung to a "Bohemian legend that gave to their poverty and their isolation a kind of precious freedom and exemption from the humbling process of identifying their efforts with the efforts of others" (Wolff, 1975:239). While the FAP did not necessarily remove artists from the condition of proverty, it freed them from the perpetual worry of how to provide their next meal and thus provided a legitimacy to their work and their profession (McDonald, 1969 ; F. O'Connor, 1969). As one FAP artist wrote, the traditional isolation and resignation to poverty changed 
with the FAP, as many artists, for the first time, came to see themselves as part of a working class; the experiences that artists had with the Artists' Unions and the Artists Congress Against War and Fascism led many of them to relinquish their aloofness from everyday affairs and trends and take part in larger social movements (Heiber, 1975:243). Regardless of their subjective sense of class position, however, the fact remained that objectively, the FAP located artists within the working class, and for the first time, artists, as artists, were workers rather than Bohemian isolates, content with their poverty and isolation.

\section{Class Backgrounds of FAP Administrators}

When the FAP was established, Cahill's plan was to "appoint directors who were celebrities or who, at least, were well known in the state art circles" (McKinzie, 1973: 81). This was done in part to insure the approval of the state administrators, many of whom were not interested in the art projects at all. It also provided a way for Cahill to maintain a reasonable degree of control over the projects; by hiring administrators from a "respectable" background, Cahill could expect a certain amount of allegiance and could be fairly certain that the directors would not take the projects in unwieldy directions (McDonald, 1969). 5

${ }^{5}$ In most cases the practice of hiring celebrities worked we11, but occasionally the practice proved ineffec- 
Two characteristics thus emerged as primary ones for potential art project directors: at least a modicum of familiarity with art and eyidence that the person held the values and allegiance to the system to warrant participation in the Roosevelt Administration. In fact, Harry Hopkins, himself was primarily interested in getting administrators who were in sympathy with Roosevelt's work relief policies, although some members of Congress put pressure on him to hire their political supporters (McDonald, 1969:109-10). Whether Cahill felt as strongly as Hopkins about the need for allegiance to the New Deal is unclear, although some researchers have noted that his personal commitments to the FAP were due to its art characteristics rather than its relief qual-

tive due to the lack of administrative skills on the part of those hired. The administrators of the Illinois and Pennsylyania FAPs were two such cases. The women who headed these projects were often at odds with the workers and their inability to handle employee relations ultimately led to their release. Mrs. Increase Robinson, director of the Illirois project, was accused of running the project like an assemb.1y line. Mary Curran of Pennsylvania was accused of promoting "social disorder and flagrant fascism" and a large minority of workers on the project accused her of "fayoritism, discrimination, dictatorship, anti-unionism, inability, social waste, and official lethargy" (McKinzie, 1973:81). It shouldbe noted, however, that the protests of artists had as much to do with the removals of Robinson and Curran as did the incompetence of the latter two. By contrast, in Washington state, where artists were not organized into an active social movement, a director, who actually refused to implement the FAP, remained in office for some time until Burt Brown Barker, as Regional Director, finally put enough pressure on Cahill to get him fired (see series of letters between Barker and Cahi11, 1936 , located in Barker Papers, Friends of Timberline, Portland, Oregon). 
ity (McKinzie, 1973).

In October 1935 , Burt Brown Barker was appointed Regional Director of the FAP for Oregon, Washington, Montana, and Idaho (Cahi11, 1935a). Barker, a 1awyer by profession, had served as regional director for the PWAP and his experience on that project made him a logical choice for the new position (Cahi11, 1935a). Barker was raised on an Oregon farm and worked his way through Willamette University and Harvard University. After receiving his law degree, Barker went to work first in Chicago and then in New York as a business lawyer, where he achieved considerable financial and professional success (Sprouse, 1980). In 1928, at the age of fifty, Barker was approached by a representative of the University of Oregon and asked to become the Vice President for Public Relations (Barker, 1965). Barker had always claimed that he would retire at the age of fifty and dedicate the next twenty-five years to public service, living off his corporate stock investments. In spite of the stock market crash in 1929 , Barker was able to return to Oregon with his wife and daughter and take up a life of pubIic service--never again to work for money (Sprouse, 1980).

Upon his return to Portland, Barker soon became an active member of the local upper class; ${ }^{6}$ among other things

${ }^{6}$ According to criteria 1isted by Domhoff (1971), Barker met several of the criteria defining him as a member of the upper class. Among these were his listing in the Port1 and Blue Book and Social Register of Oregon, membership 
he served as a trustee to the Portland Art Association and on the executive committee of the Portland Civic Theatre (Marquis, 1936).

Margery Hoffman Smith was another upper class member

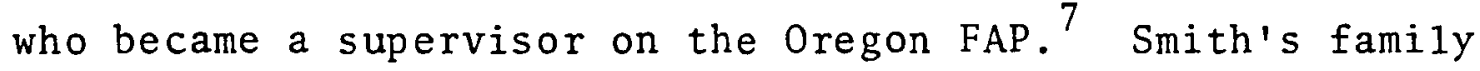
was heavily involved in the arts. Her mother, Julia Hoffman, created the Oregon Arts and Crafts Society--the first of its kind on the West Coast. Margery Hoffman attended the Art Museum School and later became established as an interior decorator.

The fact that both Margery Hoffman Smith and Burt Brown Barker were upper class and well-known within the art community may have been the most important criteria in their selection. As stated above, Cahil1's goal was to find "celebrities" or people known to the art community for the administrative positions of the FAP; that political patronage did not appear to be a criteria in their selection is indicated by the fact that both were Republicans working

in the upper class Arlington Club, and directorships of the First National Bank of Oregon and the Security Trust and Savings Company (Marquis, 1936).

${ }^{7}$ According to Domhoff's (1971) criteria, à person is a member of the upper class if a close relative is listed in the Social Register and/or belongs to one of the national upper class social clubs; Ms. Smith's brother, Lee Hawley Hoffman, met both of these criteria (Capitol, 1937). Ms. Smith, herself, attended Bryn Mawr College, one of the national elite women's colleges (Smith, 1979; cf. Domhoff, 1971). 
within a Democratic Administration (Marquis, 1936; Smith, 1979).

A third person who was at least partially responsible for the FAP was Gladys Everett, the director of the Women's and Professional Projects Division of the Oregon WPA.

Everett was located in the administrative hierarchy of the Oregon WPA below the State Administrator, E. J. Griffith, and above Margery Hoffman Smith who was Assistant State Director of FAP until 1939 when she became the State Director of the Oregon Arts Program. Gladys Everett was a respected and active Democrat and was known to be a strong woman and a capable attorney. Born in a small Oregon town, Everett became one of Oregon's first woman lawyers and was the first female municipal judge in the state. She was active in the League of Women Voters and in various aspects of state-level Democratic Party politics (Capitol, 1937). Although Everett would not have been considered a member of the upper class at the time of her employment on the WPA, she was a well known and respected civic leader of Oregon. As women in the pre-World War II era, Gladys Everett and Margery Hoffman Smith were in many ways exceptional in that they were female pioneers in the field of administration. The fact that several women were selected as supervisors for the FAP is perhaps less surprising, however, if their class positions are taken into account. Domhoff (1977) has observed that participation in the cultural sphere is 
one of the most accepted, traditional, and prestigious endeavors for upper class women or for wives of men seeking acceptance into the upper class. Charitable and artistic organizations are considered "'proving grounds' and socia1izing agents for new recruits to the inner circle" (Domhoff 1977:62). Both Domhoff (1971; 1977) and Ostrander (1980) have documented the role of upper class women in contributing to the maintenance of power and privilege in the upper class and to the maintenance of the class structure in general.

In summary, the men and women selected to direct the Oregon FAP met Cahill's criteria that they be celebrities, or at least wel1-known in the art circles of the state. In practice this meant that they were we11-known to the inner circle of elite who traditionally served on boards of directors of art museums and other art organizations; in Oregon the two people most directly responsible for the art projects were upper class individuals, whose wealth also enabled them to be generous art patrons in the community.

\section{Class Background of Artists}

A 1ist of names compiled from various documents from the Oregon FAP suggests that approximately forty different artists were hired on the project, in addition to another forty carpenters, blacksmiths, and other craftworkers involved in the wrought iron and woodcarving projects of the 
FAP. These artists were involved on the mural, sculpture, ease1, graphic arts, teaching, and miscellaneous crafts projects of the Oregon FAP (Smith, 1936; Oregon FAP, undated; Oregon FAP, 1938). As mentioned previously, in order to qualify for the FAP, artists were first required to register for relief with the state employment office. Thus, artists employed as relief workers under the FAP were, by definition, in a condition of destitution and unemployment. The WPA, however, allowed a certain percentage of project personne 1 to be non-relief employees; while these non-relief positions were intended to go to supervisory personne1, a number of artists who did not qualify for relief were hired under this "non-relief exemption quota." As a result there were both relief and non-relief artists employed on the FAP. (This issue is examined in Chapter Three.)

One example of a relief artist was Martina Gangle. Like many relief workers, she came from a poor family. She spent much of her life as a farm worker, picking nuts and berries during the summer; at age fourteen she went to work for a family in Portland so she could go to school. After high school, Gangle went to the Portland Art Museum School and did odd jobs there to support herself. In her last year at art school, she and a friend got jobs on the PWAP where she did three paintings. On the WPA/FAP she did a number of watercolor paintings of wildflowers for the hotel rooms at Timberline Lodge; she also painted two large murals at Rose 
City School, and taught adult education classes at the pub1ic schools. Getting on the WPA was "a lot of hassle" for Gangle. The relief certifiers asked many personal questions which she found degrading to both her and her mother, whom she had moved in with to save money. In order to avoid putting her mother through the embarrassment of the questioning, Gangle moved with her young son into the city (Curl, 1979 a)

Another relief artist on the FAP was Charles Heaney, who worked for many years as an engraving apprentice and later worked as a busboy in a restaurant to pay his way through art school at the Portland Art Museum School. At one time prior to working on the FAP Heaney was a ditch digger and at another time he travelled around oregon, painting signs for the highway department (Heaney, 1979a). From the time he was fifteen, Heaney worked to support his mother, who lived with him until her death. While working as a ditch digger, Heaney recalls his mother saying, "Car1! Carl! You deserve better than this." But Heaney insisted that he was happy just to have a job. It was the artist $C$. S. Price who told Heaney about the Federal Art Project and Heaney went to Burt Brown Barker, who gave him a job on the ease 1 projects. According to Heaney, the WPA was "a manna from heaven" for he could paint all day on the project without worrying about an income (Heaney, 1979a). While Heaney's memories of the FAP are all positive 
ones, one informanc remarked that he was initially embarrassed about being on relief (Griffin, 1980). There was a definite stigma attached to being on relief, even during hard times, and the ideological underpinnings of artistic independence and individualism very likely made it difficult for people like Heaney to go through what they saw as a dehumanizing process of applying for relief. As the project itself became more popular and respected in the community, particularly as later historians began to define the WPA as a magnanimous social experiment, it probably became easier to identify oneself with the WAP (Griffin, 1980).

One artist who, although destitute, remained "too proud" to go on relief was C. S. Price. Price was said to eat only two meals a day but was unwilling to accept relief status just to get onto the FAP (McLarty, 1979; Heaney, $1979 \mathrm{a})$. Because he was considered one of Oregon's better artists, Barker hired Price as a "non-relief" artist under the non-relief exemption quota. While Price characterized those artists who were unwilling to go on relief but were good enough to get hired anyway, other artists in the nonrelief category were simply ineligible for relief due to income or property restrictions. Louis Bunce was such an artist. Although Barker and his staff recognized Bunce as a promising young artist, they had to hire him as a non-relief worker because his parents owned an apartment house, although Bunce, himself, was poor (Bunce, 1979). The problem faced 
by Bunce was similar to that of artists in rural areas such as in up-state New York where many artists came from farm families that owned their own farm property (F. O'Connor, 1969).

A third type of non-relief worker was the artist who, regardless of economic status, was hired because of his or her supervisory capabilities. O. B. Dawson was a wrought iron worker who had his own business and was hired to supervise the iron work crafts projects of the FAP. Ray Neufer had his own carpentry shop when he was hired to supervise the woodworking projects of the FAP, including the building of furniture for Timberline Lodge. Finally, Margery Hoffman Smith was on the FAP payroll as a supervisory employee; initially she was hired at $\$ 150$ per month to supervise the interior decoration of the Timberline Lodge at Mount Hood (by contrast, Dawson received $\$ 150$, Neufer received $\$ 94$, and the other artists receiyed either $\$ 85$ or $\$ 94$ in the Portland area and either $\$ 69$ or $\$ 61$ outside the Portland area) (Smith, 1936).

It seems clear that with the exception of those few artists and supervisors on the FAP who came from upper class or middle class backgrounds (e.g. Margery Hoffman Smith, 0 . B. Dawson, etc.l, most of the artists who worked on the FAP in Oregon were from either working class backgrounds or lower middle class backgrounds, and the experience of the FAP placed them objectively within the working class, and thus, 
within the context of capitalist social relations. Many of the artists (e.g., Heaney) carried with them to the FAP the "Bohemian" ideology that characterized the pre-1930 position of artists. Others (e.g., Martina Gangle, Albert and Arthur Runquist, Alan Flavelle, and Louis Bunce) followed the trend of artists throughout the country and became a part of a larger social movement of artists, united in a common search for a better life through organizations such as the Artists' Unions and the Artists' Congress Against War and Fascism (Cur1, 1979a).

\section{Summary of Social Relations}

In summary, there were real class differences between those who administered the FAP and those who worked on the projects as employees. The cleavages between those who, like Ray Neufer, were low-level supervisors and the craftspeople who worked under his supervision were not nearly so great as the cleavages that divided both of these from the top administrators. It would be inaccurate, however, to suggest that the class backgrounds of the participants on the FAP determined their motives, behavior, and actual work. Such an assertion would ignore the power of ideological and structural forces that cause people to hold attitudes and interests that are often in conflict with what might appear to be the objective interests of their class. Ray Neufer, for instance, shared much of the philosophy advanced by Margery 
Hoffman Smith and, in contrast, Margery Hoffman Smith often defended the interests of the artists against elements of the community which were opposed to the FAP (Neufer, 1980; Smith, 1979). The ideological motives and class backgrounds of the actors within the FAP are only partially relevant to an understanding of the productive, structural and ideological outcomes brought about by the WPA as a whole or the FAP in particular. While I have suggested some tentative explanations for the creation of the FAP, for its particular organizational structure, and for the selection of a certain type of individual to fill the positions of that organizational structure, such inputs into the creation of the FAP only partially account for the actual production of culture throughout the life of the FAP. Once the original inputs into the project were estahlished, the actual social relations of the project interacted to affect the decisions and actions which ultimately shaped the artistic, political, and ideological orientation of the Oregon FAP.

\section{SUMMARY AND CONCLUSION}

The Federal Art Project was a product of a combination of factors which included pressure from social movements of artists, representing a subsection of a larger social movement, as well as efforts by people with entre into the decision-making realms of the Federal Government. To the extent that the WPA was a response to the social movements of 
unemployed workers responding to the economic crisis, and to the extent that the FAP was likewise a response to demands of artists, it could be argued that the WPA and the FAP were products of the class struggle. While the relief projects became structures which in some ways channelled working class activity into acceptable arenas, the FAP, itself, became an object of struggle to the extent that conflicts occurred between artists and administrators of the FAP, or between artists and the federal government, over the continuation of and direction of the projects. The FAP became an influence on the outcome of class struggle to the extent that it altered the social relations of art--transforming dedicated, after-work painters into professional workers who performed their skill for a wage.

A contradictory character of these new social relations is the fact that while the FAP freed artists from the bondage of both the patronage system and of poverty, their new employer, the government, hired as their supervisors many of the same people who either were, or could have been, their patrons under the old system. The new social relations of worker to employer gave artists a guaranteed income while they pursued their creative work; the new employer carried out its responsibility by creating a large, bureaucratic organization staffed, at least in part, by former patrons (cf. McDonald, 1969, McKinzie, 1973; F. O'Connor, 1969). Theoretically, it could be postulated that the upper class 
bureaucrats who staffed the various offices of the WPA and the FAP, brought with them a certain ideological framework that may have contributed to various conflicts between role --as bureaucrat--and position--as upper class patron. A corollary to this postulation is that if position dominated the conflict, the old social relations of art were being maintained, to a degree, albeit in a new package. Chapter Three examines these issues in the context of the Oregon FAP. Chapter Four reexamines them and suggests conclusions about the relatively reformist or revolutionary character of the FAP. 


\section{CHAPTER I I I}

\section{GOVERNMENT SUPPORT AND CONFLICTING GOALS ON THE OREGON FEDERAL ART PROJECT}

As elaborated in Chapter One, Useem's (1976) models of government support for the arts suggest that sponsorship may reflect variously the needs of (1) art as an institution, (2) corporations and industries, (3) government projects and programs, and (4) ideological needs of the state. When the FAP was established, its goals were to first put unemployed artists to work and second to use the skills of available artists to create art that met the social needs of the community. This chapter considers various factors that influenced Oregon's FAP using Useem's approach as guides for structuring the explanation, much as they served as guides for exploration and analysis of data. The chapter addresses the question: To what extent did the needs of art as an institution, corporations and industries, government projects and programs, and the ideological orientations of administrators affect the decisions about what to produce and how to organize production on the Oregon Federal Art Project? A related question is, to what extent did any of these needs and interests interfere with or enhance the stated goals of the WPA/FAP? 
NATIONAL GOALS AND THE OREGON FAP

When the FAP was created, Holger Cahill was charged with setting the goals and direction of the program. Cahill, strongly influenced by the democratic ideals of John Dewey, believed that the FAP could provide the opportunity for "democratic community participation in the creative experience" (Cahill, 1975:36). Cahill felt that art had become too separate from everyday life and that the art object had become "a minor luxury object." American Art had experienced a "cultural erosion," and as art patrons looked to European centers or to the past for aesthetic products, American artists were either forced to migrate to one or two metropolitan centers and create art that was divorced from their own experience and environment, or be virtually ignored in their local communities (Cahi11, 1975). Al1 of this began to change, Cahill noted, in the 1920 s when many artists, museum directors, critics, and educators began to create an American art with native social meaning, and thus helped bridge the gap between the American artist and the American public. It was the efforts of these people, particularly the "progressive educators" influenced by John Dewey, who paved the way for a national art program by creating a receptive environment for such a program (Cahil1, 1975: $38)$.

Cahill, himself, was part of this new national envi- 
ronment. He felt that the FAP could both help American artists develop their own creative abilities and help raise the level of artistic awareness of the American public (F. 0'Connor, 1969:27-8). At the same time, it must be emphasized that the FAP operated within a larger social context, and, indeed, came about in part because of the massive unemployment of the Depression.

According to historian Richard McKinzie (1973:80), Cahill's major concern was with the artistic quality of national life. However Harry Hopkins, Cahill's supervisor, admonished his staff, "Never forget that the objective of this whole project is...taking $3,500,000$ off relief and putting them to work, and the secondary objective is to put them to work on the best possible projects we can, but we don't want to forget that first objective, and don't let me hear any of you apologizing for it becuse it is nothing to be ashamed of" (McDonald, 1969:32).

When Cahill wrote the operating manual for FAP directors he emphasized again that "the primary objective of the project is the employment of artists who are on the relief rolls" (F. O'Connor, 1969:27). A second objective of the program was to carry out an art program which would "make contributions of permanent yalue to the community." These programs were to create contemporary American art, to create a greater national consciousness of art through teaching and recreational art activities, to aid campaigns of social 
value, and to research the native background in the arts. On the whole the project was intended to "work toward an integration of the arts with the daily life of the community, and an integration of the fine arts and practical arts" (F. O'Connor, $1969: 28)$.

Although the WPA was created in May 1935, it was October 1935 before the FAP received funds to begin allocation. In early October, Burt Brown Barker received a telegraph asking him to undertake the regional direction of the FAP for the states of Oregon, Washington, Idaho, and Montana. On October 15, 1935, Barker (1935a) telegraphed Cahi11 agreeing to undertake the projects. The following day Cahill sent Barker another telegram outlining his duties. The text of that telegraph follows:

DELIGHTED YOU WILL CONSIDER REGIONAL DIRECTORSHIP SINCE I KNOW OF YOUR EXCELLENT WORK FOR PWAP STOP DUTIES WILL BE CLASSIFYING ART PROJECT PERSONNEL REGISTERED ON RELIEF ACCORDING TO TALENT AND ABILITY AND APPROVING OR DISAPPROVING ART PROJECTS ON BASIS OF ARTISTIC INTEGRITY AND SOCIAL DESIRABILITY AND APPOINTMENT OF PROJECT SUPERVISORS TO DIRECT WORK StOP MOST OF WORK CONCENTRATED IN LARGE CENTERS OF OREGON AND WASHINGTON VERY LITTLE IN IDAHO AND MONTANA... NINETY PERCENT OF ART PROJECT PERSONNEL WOULD HAVE TO COME FROM RELIEF ROLLS TEN PERCENT NONRELIEF StOP TERMS FOR DIRECTORSHIP WOULD HAVE TO BE EITHER ON VOLUNTEER BASIS OR PER DIEM WITH ALLOWANCES FOR TRAVEL STOP WORK SHOULD NOT TAKE UP MUCH TIME ONCE IT GETS STARTED HOLGER CAHILL DIRECTOR FEDERAL ART PROJECT (Cahi11, 1935a)

In order to carry out the artistic goals of the FAP, Barker was asked to form an advisory committee which would help to find sponsors and select art projects for the oregon FAP. By late October Barker had met with his advisory com- 
mittee "consisting of prominent citizens representing the art museum, public schools, architects, and judiciary" and had begun to forumulate possible projects arising out of requests for "sixteen public school murals," wood carvings, etchings, and murals for the new buildings at the University of Oregon, murals and paintings for the children's hospital, and murals and paintings for a new high school building (Barker, 1935b). 8

With the formation of the Advisory Committee and the expression of desire on the part of educational institutions and hospitals for works of art, Barker and the FAP encountered their first problem. The Advisory Committee had begun to formulate projects without first assessing the talents and skills of the relief artists who, according to the established priority of the FAP, were to be hired. As Barker (1935b) told Cahil1, "After examining relief rolls [we] find [that] competent easel artists [are] not registered." According to Barker, the artists were incensed at the demand that they go on relief rolls and preferred to starve as they

${ }^{8}$ The advisory committee selected by Barker consisted of the following people (including Barker, himself, Vice President of the University of Oregon): Elils Lawrence, Dean of the School of Fine Arts, University of Oregon; Henrietta Failing, Assistant Curator, Portland Art Association; Morris N. Whitehouse, Architect; H. M. Tomlinson, former President of the Oregon Society of Artists; Harry F. Wentz, Instructor in Painting and Decorative Arts, Poriland Art Association (Museum Art School); H. M. Barr, Principal of Irvington School and Research Director of School District No. 1; Esther Wuest, Director of Art for Portland Public Schools (Barker 1935c). 
were currently doing. Barker claimed that he knew of many unemployed artists who were "in dire distress but too proud to ask relief...Our artist colony is small and having worked with them previous ly we know them personally and know their dire distress very intimately and therefore feel we could certify those in need" (Barker 1935b). The unavailability of artists who were both competent and on relief rolls led Barker to request that Cahill enlarge the quota of positions that could be filled with non-relief personnel from ten percent to fifty percent (Barker, 1935b).

The non-relief exemption clause, exempting ten percent of the hired personnel from the ruling that FAP employees must come from relief rolls, was designed to allow employment of supervisory personne1, and only where necessary were those quotas to be filled with artists who did not qualify for relief. The day after receiving Barker's request for a fifty percent exemption quota, Cahill sent a return telegram noting that he appreciated the difficulties in getting competent artists from relief rolls, but that, "according to Presidential order we must take ninety percent of our personal [sic] from relief and so far as I can judge no relaxation of this order [is] possible" (Cahill, 1935b). Cahill suggested Barker discuss the matter of relief for needy artists with the State Director of Certification and Intake and "in the meantime employ needy artists known to you as competent as supervisors under [the] ten percent ex- 
emption clause" (Cahill, 1935b).

The problem faced by Barker and the Advisory Committee, that the projects they envisioned were presumably beyond the capabilities of the artists on relief rolls, was solved in part by Cahill's decision to allow non-relief artists to be hired under the exemption clause. To some degree, this ruling reduced Barker's responsibility to find creative projects for the artists on relief by allowing him to hire available "competent" artists under the exemption clause for whatever projects he and the Committee deemed feasible. On the other hand, many of those who were on relief had to be employed in order to fill the ninety percent quota; the more relief workers the FAP hired, the more nonrelief workers they could hire for the more important projects. According to Barker (1935b), however, the problem was that artists themselves refused to go on the relief rolls; it thus was very difficult to operate a program designed both to employ artists on relief and to create art of use to the community, especially when the community that wanted to sponsor projects desired works of art allegedly beyond the capabilities of available relief artists.

There are three different ways to explain the problem the relief quotas caused Oregon administrators. First, it it possible that their efforts to expand the non-relief exemption quota were motivated by the desire to employ genuinely destitute, non-relief artists who did not qualify for 
relief because of stringent certification requirements. Second, it is conceivable that the problem was forced upon them by the artists, themselves, who may have been too proud to apply for relief even though they qualified. Finally, it is possible that the problem was exacerbated by elitist attitudes of some administrators whose artistic standards and "tastes" led them to downgrade the abilities or styles of relief artists.

Three incidents alluded to or discussed in various documents in the Burt Brown Barker Papers illustrate how the quota system was dealt with by project administrators, and, thus clarify the nature of the problem and its attempted resolutions.

The first incident involved a project of great interest to Barker, as Vice President of the University of Oregon. In 1936 the University was building a new library and iron worker 0. B. Daws on was hired onto the FAP to supervise the construction of large, decorative iron gates leading into the main hall of the library. Other gates were to be erected along a proposed mall at the entrance to the campus. Both followed the designs of H. Abbott Lawrence, of the University's School of Architecture and Allied Arts (Barker, 1965:137). At this time, Barker received a letter from Cahill stating that the records showed that out of sixty potential relief artists in Oregon, only twenty-nine had been employed. Cahill insisted that Barker increase the 
project's employment by February 15, and use the available allocations to hire the additional workers. Barker (1936c) refused on the grounds that he did not want to jeopardize the current projects by taking money away from them in order to hire more workers. He invoked his position at the University stating that in Oregon the FAP was working "on a big scale and...if anything should defeat what we have undertaken, it would be a very sad day for me in Oregon." Cahill (1936) responded stating that as of March 5, 1936, there was to be no new employment on the FAP and that he felt "a little bit regretful that you were not able to get your maximum employment through before the deadline." (Within months, new hirings were once again allowed.)

Concurrent with the problem of insufficient funds to hire new workers without cutting back on current projects, Barker faced the difficulty of meeting the non-relief exemption quotas. As mentioned above, soon after being appointed Regional Art Director, Barker (1935b) sent a telegram to Cahil1 requesting a fifty percent exemption on the non-relief exemption quota. His request was not the only one received in Washington, and in December 1935, the exemption was increased from ten to twenty-five percent, although it was later reduced and continued to fluctuate between five and ten percent throughout the FAP's existence (F. O'Connor, $1969: 42-6$ ).

On January 1, 1936, the WPA made a 11 Federal One state 
supervisory employees part of a "state Co-ordinating Project Unit" which received special salary funds and was not counted in the states' quotas of non-relief workers (McDona1d, 1969:160, 180). In March 1937, however, Barker (1937) received Administrative Order Number 52 (issued on February 20, 1937 [McDonald, 1969:179]) restricting the quota of non-relief workers to five percent of the total and requiring supervisory personnel to be included in this five percent. Although it was a stipulation designed partially to insure that relief funds be spent for relief workers and not for administrators and supervisors (McDonald, $1969: 181$ ), Barker objected to it strongly.

At that time, Barker had six non-relief employees:

The two Co-ordinating Project Unit employees, Margery Hoffman Smith and a Miss Taylor; iron worker O. B. Dawson; and artists Aimee Gorham, C. S. Price, and Darrel Austin. Under the new regulation, Barker would only be able to keep two of these people. In a letter to Regional Advisor Joseph A. Danysh, Barker asked for an exemption from Administrative Order Number 52. Asking whether the Co-ordinating Project employees could remain exempt from the five percent quota, Barker argued that if they had to be included ...then I can have no other non-relief workers. This would mean that Dawson would be thrown off which, as you understand, would mean that the iron project would stop; Mrs. Gorham would be thrown off which would mean that the parquetry project would stop; Price would be thrown off and also Austin. With these people out then there would be 
no one left except what you cal1 our "buck eyes" and they would be very few in number and the project would be practically dead. If, on the other hand Mrs. Smith and Miss Taylor, on the Coordinating Project, are exempted then we would be entitled to have two non-relief persons. The logical thing, of course, in that case would be to lay off Price and Austin. In so doing we would be able to carry on the iron work and the parquetry work. I think you can realize that with Price and Austin out of the picture there is technically no art work because the iron and parquetry work are really crafts. I am, therefore, greatly in hopes that you will present the matter to Mr. Cahill in such a way as to secure an exemption in our case. If we could continue with our 10 per cent exemption our project could remain and run on as at present. To make such an exemption would mean merely to carry Price and Austin (Barker, 1937).

The resolution of the problem is less important than the implications behind Parker's efforts to obtain higher non-relief exemption quotas. 9 Although the FAP was designed to find employment for unemployed artists, a combination of stringent relief certification procedures and the priorities and practices of Burt Brown Barker appear to have frustrated, to some degree, the intentions of the arts relief project. At a time when it might be necessary to lay off non-relief employees, Barker assumed that the first to go would be the two artists on the project and the last to go would be the two top supervisors.

${ }^{9}$ An exemption was granted, allowing supervisory emloyees on some projects to be paid out of a special budget. This exemption was rescinded, however, on July 15, 1937 , when Co-ordinating Project Units were abolished and all Federal One supervisors were required to be 1 isted as regular employees and included in the non-relief quota count (McDonald, 1969:180). 
A third incident suggesting the priority that was given to non-relief over relief workers concerned Margery Hoffman Smith, who felt there were not enough qualified relief artists on the Oregon FAP (Smith, 1979). In late November 1937, Smith needed to assign two non-relief persons to the Timberline Lodge project at Mt. Hood. According to the minutes of a Federal One staff meeting, Smith faced the problem of maintaining the proper quotas for relief and nonrelief workers while trying to maintain standards that available relief persons apparently could not fulfill. The minutes tell how she solved the problem: "In order that she may assign two non-relief persons to the Mt. Hood project, Mrs. Smith is going to assign ten more persons, thus raising employment on that project to twenty" and thus allowing the addition of non-relief persons while remaining within the proper quotas (Federal Project Number One, 1937). In this case, relief workers were hired for a project only because the supervisor wanted to hire additional non-relief artists. While this action seems contrary to the intentions of the FAP goals and regulations, it had a positive outcome for these additional relief workers hired.

In summary, the claim that artists were unavailable to the FAP because they were too proud appears to have been overstated. In fact, the problem of relief quotas was much more complicated. The relative lack of artists on relief rolls may have been a real problem when some were "too 
proud" (C. S. Price is the only Oregon artist I know of who fits this category) and others unqualified for relief. Nevertheless, that problem was exacerbated if the three incidents presented above can be considered typical, for in each situation the concern of the administrator was with creating or preserving jobs for non-relief employees even when relief employees were available. In the one case, those non-relief employees who were top supervisors were given priority over the more "destitute" artists hired under the non-relief exemption. According to this evidence, Barker appears to have emphasized the FAPs second priority-to carry out a viable art program--rather than the first priority--to provide employment for artists on relief. If such conclusions could be generalized, based on additional supportive evidence, it would lend support to the first of Useem's models suggesting that the needs of the established art community were served and its paradigm protected in this case of government support for the arts. In the case of the Oregon FAP, however, it was in the administration of the project rather than in the conception of its goals that the needs of the art community were served over the needs of the artists on relief.

IMPLEMENTING THE OREGON FEDERAL ART PROJECT

In this section the models suggested by Useem (1976) are used as tools to help explain the extent to which there 
were discrepancies between the stated goals of the FAP and the actual implementation of the program. Specifically, I examine the extent to which the interests of art as an elite institution, business and industry, the ideological orientations of administrators, and the policies and progress of the government either helped or hindered the implementation of the goals of the FAP. This exploration will begin to address the question: Under what conditions were the goals of the FAP carried out and under what conditions were they obstructed?

"Art for Art's Sake?"

According to Useem (1976), if government intervention in the arts is primarily on behalf of "art for art's sake" and therefore on behalf of cultural institutions in crisis, we should find the followirg corollaries holding true:

1. The timing of government intervention is primarily related to economic crises faced by the arts themselves, not to crises in the political system, economy, or elsewhere;

2. Government intervention generally takes the form of protecting the paradigm of the arts and is generally allocated to the most creative artists and organizations, as defined by the relevant artistic community.

To understand whether or not the FAP was designed to save the arts from an economic or cultural crisis, it is necessary to understand the nature of the arts prior to 1935 ; 
Chapter Two discussed the upper class nature of art patronage throughout the nation as well as in Oregon.

While the upper class in Portland sent their sons and daughters to art classes as a kind of "finishing school" and donated money for the purchase of European and Asian art objects for the Museum, the instructors at the museum school were promoting a democratic ideal of art. Many working class artists, attending the school part time or on scholarships, benefited from this instruction. Head teacher and artist Harry Wentz taught his young students to look inside themselves and to their environment and paint what was real to them; he advocated an intuitive approach to art and after providing the students with a solid foundation in the principles of color and design, set them free to paint what and how they wanted (Heaney, 1979; Curl, 1980). When the first New Deal art project came to Oregon--the Public Works of Art Project (PWAP)--Oregon artists were already painting in a regional style using regional subject matter.

When the FAP was created, it was a partial solution to the economic crisis experienced by artists in Oregon and elsewhere; to say that the FAP was a response to a cultural crisis or an economic crisis within the art world, per se, is to assume that cultural and economic well-being had previously existed. Certainly this was not the case. To the extent that there was an economic crisis within the art institutions, it was a crisis which affected that national 
elite which comprised the community of art patrons. As McKinzie (1973:4-5) pointed out, prices and sales of art works dropped considerably between 1929 and 1933 (a drop from 165 to 50 in the market price index for art); art importation went down by eighty percent; the production of artists' materials was down nearly fifty percent. The contradiction in this crisis faced by the aristocracy of art was that the depression, and the FAP in particular, changed the character and extent of American art by making more artists and their work available to a larger community. The snobbishness and artificiality of American art was undermined when, during the FAP, it was discovered that a popular art audience could be created in the United States. In Portland, Oregon, for instance, attendance at the Portland Art Museum during a two-month exhibit of FAP art was up to three times the attendance usually attained at museum shows (Works Progress Administration 1937:12). More important were the public galieries at the WPA community art centers, and the murals located in public places.

Whether the FAP was an attempt to protect the "paradigm of the arts" is a question that must be addressed in order to assess the implementation of the FAP's program. On an official level, the idea of "art for art's sake" was firmly rejected as a basis for the FAP (F. O'Connor 1975:18). This conclusion is substantiated by Cahill's own philosophies and goals for the project as outlined earlier in this chap- 
ter. Cahill felt that art "was not a matter of rare, occasional masterpieces." In criticism of the dominant paradigm of the arts, Cahill argued:

The emphasis upon masterpieces is a nineteenth century phenomenon. It is primarily a collector's idea and has little relation to an art movement. ... The organization of the Project has proceeded on the principle that it is not the solitary genius but a sound general movement which maintains art as a vital, functioning part of any cultural scheme (F. O'Connor, 1975:18).

If Cahill's comments can be taken at face value, it is clear that the FAP was not a protection of the dominant paradigm in the arts; rather it was an attempt to create a kind of cultural revolution. In the next sub-section I evaluate the scope and extent of this cultural revolution in terms of the audience reached by the FAP projects and programs .

Art for Whom?

When the FAP was started, local administrators were instructed to classify "art project personnel registered on relief according to talent and ability" and to select projects for these artists on the basis of "artistic integrity and social desirability" (Cahi11, 1935). Thus, projects were to be selected according to the talents and skills of the local artists and the needs of the local community. Often however, the term "community" was defined quite narrowly. Many of the products were designed with the specific interests of the upper middle class or the upper class in mind; 
others were geared to the needs of the business community; still others served educational ends in the public schools. The projects that had major institutional sponsors tended to be the projects that remain intact today; by contrast, many of the easel paintings and graphics have been either lost, forgotten, or destroyed.

Educational institutions were major sponsors for FAP projects in Oregon. These institutional sponsors can be divided into two types: those that reached a cross section of social classes and those that reached a fairly elite group of people. Among the former are included public schools, hospitals, and libraries; among the latter are included the University of Oregon and Oregon State Agricultural College.

One of the more productive projects within the FAP was the iron work projects done by 0 . B. Dawson and his crew. In addition to the iron gates at the University of Oregon and elsewhere, many objects were built to decorate the offices of high officials. At the Oregon State Agricultural College, for example, wrought iron coat racks, candelabra, and a fern stand were placed in administrative offices (Jensen, 1936). In a letter to 0. B. Dawson, the executive secretary of the college requested these items and asked that the fern stand be a top priority, as it would be placed in the President's office. As executive secretary W. A. Jensen noted to Dawson in regard to the fern stand: ...the effect of this would be to place the stand in a place where it would be seen by prominent 
people of the campus and of the state, as they come to that office. The stand should be of first quality and lovely, and I think it would be important for you to have the article in so prominent a place (Jensen, 1936).

Clearly the effect of the wrought iron objects created by Daws on and his crew was to enhance the pleasure and prestige of high officials. Even the iron gates in the library, entrance ma11, and museum at the University of Oregon were theoretically subject to a wider viewing public, although at that time a college education was not available to most working class people. An undated report (believed to be 1937 or 1938) noted that between the University of Oregon and Oregon State Agricultural College, one marquetry, one fresco, three wood carvings, four stone sculptures or statues, and at least thirty-two wrought iron projects such as several large gates, gril1s, screens, panel rails, candelabras, fern stands, and tables had been created by Dawson and his crew (Oregon FAP, undated).

In contrast to the art and craft work located in the universities, twenty-nine wood carvings, marquetries, ease 1 paintings, and murals had been created for several Oregon public schools, a public hospital, and a city library by the end of 1937 (Oregon FAP, undated). Because of their location, these murals reached a larger cross section of classes; unfortunately, however, many of these art works have since been destroyed or forgotten as some were painted over or torn down during remodelling efforts and others were placed 
in unfrequented rooms in the school buildings (Smith, 1979; Griffin, 1980).

The art that was produced for Oregon's universities, public schools, hospitals, and libraries was tailored for specific audiences, and in many respects, the art reflected the needs and interests of the sponsors. Many of the works had educational functions as suggested by titles such as "Culture Through the Ages," "Foreign Influence on Civilization," "Indians and Pioneers," etc. (Oregon FAP, undated).

The artists who worked on the projects for the public schools often had to do considerable research in order to meet the educational requirements of their art work. Occasionally the need to do research created problems, as reported by Martina Gangle (Cur1, 1979):

I got a mural job in the Rose City School... I worked in the basement. It seems to me I was there close to nine months...but the [second mura1] I did in my studio. I had a studio downtown. I lived in it... In a way I regretted that I had [my work] switched there, but the principal was giving me such a hard time... You know, I did a lot of research work and some days I wouldn't come [to the school] until afternoon. And he would look at me and say, "You're supposed to be here at nine o'clock, you know." And I'd say, "Well...I'm allowed to figure my own hours." I really put more hours in [than was required]. But I couldn't make him see that. He was very critical of me and it kind of bothered me, so I just switched [my work] to my studio.

The effort put into research by artists such as Martina Gangle undoubtedly added to the "social desirability" of the induvidual art products. The historical subject 
matter of many of the murals and paintings added not only to the educational value of the art work but contributed to the search for what Cahill called a "useable past" which would help American artists break from the stronghold of European artists. As such, both in terms of the audience for which this historical painting was intended and the subject matter and style of the paintings, the artists had broken with the tradition of "art for art's sake."

On the other hand, the art work and craft work that adorned the offices of college and university officials and that became a part of the structure of the campus libraries, museums, and grounds, served a different audience and different ends. It served the aesthetic needs of the same class of people who traditionally had been served by the arts--the priviledged wealthy and the aspiring upper middle class which could afford the luxuries of life. It was not until the post-World War II prosperity of the $1950 \mathrm{~s}$ and 1960 s that large numbers of middle class and working class people were able to attend the university and partake of the beauty of such projects as the iron gates at the University of Oregon library.

\section{Art for Everyone}

While the FAP art that was placed in public institutions was theoretically accessible to a larger number of people than art previously had been, it was the Community 
Art Centers that provided large numbers of people with a direct experience with art. The Community Art Centers were designed to bring art to communities without established art education institutions. It was believed that these centers would not only foster the development of art by providing training to young artists, but also would create a new audience for the arts by giving thousands of people exposure to art through art creation and art history classes, and galleries that operated in conjunction with the art centers. The Community Art Centers in Oregon were located in Salem, LaGrande, and Gold Beach. (The cities of Portland and Eugene already had art education centers through the museum and university respectively.) The Salem Art Center was the first of the three to open. The center emphasized the study of crafts, art techniques and media, and home applications for art. Its educational activities included a circulating exhibit organized by the National Office of the FAP and exhibitions of local artists' work. There were lectures arranged by the federal and state offices; 10cai lectures covered historical landmarks, local crafts, stamp collecting, art in advertising, and other topics; gallery talks aimed at explaining the gallery exhibits; finally, the center organized clubs and discussion groups such as an Index of American Design club, and a Sketch Club. Classes were held daily at the center and the gallery was open five afternoons and three evenings each week (Salem Art Center, 1938). 
The director of the Salem Art Center was a man named Charles Val Cleer. Among the artists who worked at the center were Louis Bunce, who was once made the temporary director while Val Cleer was on vacation, an artist named Lemery, Alan Flavelle, and Eric Lamade. In addition to these local artists, artists and art teachers from New York occasionally came to the center to expose the community to art from other parts of the country (Val Cleer, 1938).

In addition to the Community Art Centers, some artists taught public art classes in other settings. Charles Heaney taught drawing, composition, and art appreciation at the Irvington $\mathrm{Club}$ in Portland for two years. Burt Brown Barker had wanted Heaney to teach at the Salem Art Center but because Heaney supported his mother and did not want to move to Salem for a temporary position, he steered Barker to Louis Bunce (Hearney, 1979a). Martina Gangle taught adult education and children's classes in the Portland public schools (Cur1, 1979b).

As Francis V. O'Connor (1975) pointed out, the impact of the FAP Community Art Centers on the creation of democratic culture has yet to be investigated. It is known that on a nation-wide scale, by mid-1939 some sixty-six community art centers were operating with an average monthly attendance of 60,000 and with an aggregate attendance of six mil1ion people (Federal Works Agency, WPA, 1939:22). The importance of the Salem Community Art Center to the community is 
indicated by a petition sent to President Roosevelt signed by at least three hundred residents of communities such as Salem, Eugene, Corvallis, and Myrt1e Creek; the petition, sent in late 1938 and early 1939 protested layoffs of WPA employees and specifically protested the curtailment of funds for the Salem Art Center, asking that the center be expanded, instead (Petition, 1939). Although the activities of the Salem center may have been curtailed in 1939 , it continued to operate until the FAP ended in 1943; the centers at Gold Beach and LaGrande, begun during 1939 and 1940 (F. O'Connor, 1969), a1so continued in operation until 1943. Unfortunately, little information has been made availaille on these centers.

Summary: Art for Art's Sake?

The intentions behind the establishment of the FAP Community Art Centers and placement of much of the FAP art work in public locations attest to the democratic nature of the FAP and refute the idea that the FAP was an attempt to promote art for art's sake, as suggested by Useem's first mode1. As William F. McDonald (1969) has stated, government sponsorship for the arts broke down the "star system" of art and allowed hundreds of artists to compete anonymous 1y (in the Treasury Relief Art Project) and succeed in their own community; the Federal Art Project, McDonald claims, threatened private art institutions by creating a new public 
patron for the arts--both in the form of the government, which sponsored the artists directly, and in the new audience that was created by the FAP. In this sense, the FAP succeeded in creating a cultural revolution. This revolution was recognized at the time by a writer for Fortune who noted that the FAP had filled a vacuum for artists who previously thought their only audience was the small group of millionaires who bought art (at a necessarily high price) as a sign of culture; the FAP showed artists the existence of "the true American audience," and in so doing, created "a sort of cultural revolution in America" (Fortune, 1937: $108)$.

While the dispersion of art among the masses of American people indicates something of a cultural revolution, the Oregon data suggest that much of the art produced was aimed at the elite institutions of the community: Universities and businesses. The iron works projects by 0. B. Dawson, located on university campuses and in president's offices, and the entire Timberline Lodge project all suggest an art project geared to the same elite audience which traditionally had consumed art. On the other hand, much of the art suggested issues and events of the Pacific Northwest and reflected pioneer or industrial subjects (Federal Writers' Project, 1940:133); 1ike much of the art of the thirties, it was an attempt to capture "the American scene" in its historical and contemporary contexts. This subject matter, and 
the public mural form, in many ways reflected the resurgence of popular, democratic social consciousness among the American working class, as a whole, and indicated another aspect of the cultural revolution which attempted to make art more accessible to the American people.

To the extent that there was a cultural "revolution" in the 1930s, it was a revolution limited by the social constraints of that period. I have argued that those who were responsible for implementing the Oregon FAP were upper class individuals and members of an elite community that held the economic and political power in Oregon. Reform-minded, these people, as a group, facilitated the dispersion of democratic art and democratic art institutions while containing that dispersion within boundaries which they control1ed. Thus, many projects were selected primarily on the basis of the availability and interests of sponsors and only secondarily on the basis of the needs and talents of artists on relief. With respect to Useem's model regarding "art for art's sake," it could be concluded that while the FAP did not perpetuate and protect the traditional paradigm of the arts, the most important work was "allocated to the most creative artists... as defined by the relevant artistic community" (Useem, 1976); the most creative artists were, in many cases, the non-relief artists for whom administrators attempted to expand the quota of the non-relief "exemption clause"; the relevant artistic community remained the tra- 
ditional elite group of art patrons who formed the art advisory committee for the Oregon FAP. Even the artists hired by the FAP were aware of this artistic elite and their participation in the project. Charles Heaney reported that he heard through "the grape vine" that when Barker wanted to know who to hire on the FAP he "took expert advice from the so-called 'informed' people--the elite... He had advisors-the elite around town; people who would buy things" (Heaney, 1979a).

\section{Art and the Business Community}

Useem's second model suggests that government intervention in the arts may have overt business and commercial purposes and as such serve the interests and needs of business corporations. The corollaries to this model are:

1. Government intervention accompanies sharp increases in corporate consumption of science and art;

2. Government intervention is oriented toward fostering art of utility to large corporations; federal funds are disproportionately allocated to work which has industrial application.

There is no evidence, to my knowledge, that there existed an increase in business consumption of art prior to the establishment of the Federal Art Project. Nor is there evidence that the art of the FAP had direct industrial applications (prior to World War II) in the sense that it 
aided in the accumulation of capital. There is evidence, however, that many resources of the Oregon FAP went into artistic production that served the needs of Oregon's business community and upper class. Whether the motive behind the production of certain art objects was primarily to serve business needs or whether the needs of the business community merely provided convenient outlets for the production of art on the FAP is unclear. Worth considering is the extent of business community involvement in the development of the FAP projects, the extent to which art thus produced served the needs of the business community, and the extent to which other needs--in particular the goals of the FAP--suffered or benefited from this involvement by business.

One project initially conceived because of its potential interest and value to Oregon's business community was the Timberline Lodge project--a "ski hotel" on Mount Hood. The history of Timberline Lodge suggests that it was conceived as part of a long-term commercial venture designed to promote Oregon's tourist and winter sports industries. While the lodge, itself, was not expected to operate at a profit, it was designed to be a drawing card for Oregon, and was believed to be an addition to Oregon's tourist industry.

The conception of the lodge began long before the WPA was ever created. In October 1931, the Portland Winter 
Sports Association was incorporated for the purpose of promoting winter sports activities in Oregon (Portland Winter Sports Association, 1931). Early in 1935 the statewide Oregon Winter Sports Association appointed a committee "whose purpose it became to investigate, and if possible, secure for the Mount Hood area proper Hotel facilities" (Meier, 1939). The group became known as the Mount Hood Recreational Association. When the WPA was founded, the Association became interested in the possibility of having the WPA provide the funds to build a lodge for them. In January 1936, the Mount Hood Recreational Association incorporated under the name of the Mount Hood Development Association whose primary objective was to be the official sponsor for the building of the lodge. The WPA promised the association it would donate $\$ 250,000$ for construction and labor costs if the Association could raise and additional $\$ 20,000$. The Forest Service agreed to provide the equivalent of about $\$ 10,000$ in building materials and the Association was left with only $\$ 10,000$ to raise. On Janaury 7, 1936, Jack Meier, President of the Association and a prominent businessman, approached the Portland Chamber of Commerce requesting a guarantee of $\$ 10,000$ which could immediately be available to the WPA. In the meantime, the Association planned to incorporate so as to have the authority to sel1 $\$ 20,000$ worth of non-interest bearing twenty-year debenture bonds" (State of Oregon, 1936), in order to reim- 
burse the Chamber of Commerce. In the discussion on the motion to provide the money, the manager of the Chamber of Commerce noted that this was a unique opportunity to "get a $\$ 250,000$ hotel on Mt. Hood at so small a local outlay..." E. J. Griffith noted that "travellers will be attracted from all over the world because of the unusual and beautiful location in which this hotel will be built." He pointed out that funds would be made available for several art projects in the building, thus making it a "year round resort and without question... a project which will interest the entire city." Mr. Horton from the Forest Service argued that "the hote1, when built, will bring great advertising to Portland and Oregon." The motion to provide the $\$ 10,000$ guarantee was approved unanimously (Portland Chamber of Commerce, $1936)$.

State Administrator E. J. Griffith supported the construction of Timberline Lodge and in September 1936, over 460 men were employed on the construction of the hotel, the road leading to the hotel, and in the camp set up to house the workers. However, Timberline Lodge was not necessarily intended to be a place for those people who built the lodge. In a report on the lodge Griffith said:

There was never any intent of making Timberline Lodge a charitable institution or a recreational housing for people of near relief status. On the contrary, it was built to give work to the unemployed for the subsequent use of the taxpayers who foot the bills for relief. But while the Lodge does meet the most exacting demands of those who 
are willing to pay for same, it was designed to cater to all pocketbooks. This conception has worked out in a sirprisingly successful way. The relief worker got a job that not only revived his self-confidence but restored him to public esteem, while the taxpayer applauded the expenditure [emphasis added] [Griffith, 1938 : 6).

While the lodge was not intended as a place for the poor (who in the mid-1930s constituted a large proportion of the population), its aesthetic beauty and ideal location for both summer and winter recreational activities were intended to attract the middle and upper class populations whom Griffith referred to as "the taxpayers." In the desire to make the lodge a year-round resort, it was decided to make use of the FAP to turn the lodge into an aesthetic monument. 10 According to Margery Hoffman Smith (1979) the architects who were designing the lodge approached the prominent Portland architect John Yeon, saying that they "really need a woman's advice in the construction of Timberline's interior. Have you any idea of a good, smart woman who could do it?" Because Margery Smith had been

10 While the success of Timberline Lodge as a business venture is not particularly relevant to the discussion at hand, it is interesting to note that in 1947 the President of the Oregon Winter Sports Association claimed that Mount Hood was "unquestionably the most heavily used winter sports area in America" and "Mt. Hood was visited by more than twice as many sports lovers as any of the National Forests or National Parks in the country last season" (Erwin, 1947). Regardless of whether or not this claim was true, it is an indication that Timberline Lodge was believed to have enhanced Oregon's tourist and winter sports industries, possibly having positive side effects for Portland retailers. 
decorating the interior of Yeon's own house, he was able to recommend her for the job. With the encouragement of Gladys Everett and the assistance of the WPA sewing project, Smith supervised numerous artists, craftspeople, and unskilled workers on the sewing, weaving, painting, carving, wrought iron, and furniture projects. Smith, herself, was a skilled artist and craftsperson who approached the job not as a commercial venture but as an aesthetic challenge; as a result of her ingenuity, and the skill and talent of the artists and craftspeople under her supervision, Timberline Lodge is, indeed, an aesthetic sight to behold.

Establishing the business motives behind the construction of Timberline Lodge is less difficult than establishing the meaning this business support had for the Oregon FAP. Did the government support for the arts, which in this case was encouraged by, and intended to support, the interests of the business community of Oregon, help or hinder the goals of the FAP to provide employment to artists on relief? A major difficulty in answering this question lies in the fact that all local projects were expected to have local sponsors; the distribution of projects of the Oregon FAP between those with business ties and those without business ties may have been a direct result of the availability of sponsors in the business and non-business communities. Sufficient data is presently unavailable to this author to determine the ratio of potential available sponsors to the actual num- 
ber of sponsors to whom FAP artists were provided. At the peak of employment on the Timberline Lodge project, however, two other types of sponsors were making use of FAP artists. The first type includes both the University of Oregon and Oregon State College. These have been typed together under the category of "Elite Institutions" because of the relative1y exclusive audience available for the works of art 10cated in these institutions (and their officials' offices) where, during the $1930 \mathrm{~s}$, few working class or even middle class people were likely to venture. The second type is the "Public Institution," including public schools, libraries, and hospitals around Oregon. Table I gives the breakdown of number of people employed and total salary costs in October 1936 under the three types of sponsorship: Timberling Lodge, Elite Institutions, and Public Institutions.

\section{TABLE I}

NUMBER OF WORKERS AND SALARY EXPENDITURES ${ }^{a}$ FOR THREE TYPES OF SPONSORS

Workers Total Salary

Timberline

Elite Institutions

Public Institutions

Tota1
29

9

18

56
$\$ 2695$

746

1505

$\$ 5046$

SOURCE: Smith, 1936

${ }^{a}$ Figures refer to the month of October 1936. Salary expenditures refer to total expenditures on salary for the month of October 1936. 
While these data represent only one month, they nevertheless suggest a relationship that is conclusive enough to support the relevance of these three categories and their relationships to the FAP in the generation of grounded theory. The data suggest a proposition that business-sponsored projects absorbed proportionally more human resources than did projects sponsored by other institutions. A simple calculation on the data in Table I shows that, while the average monthly wage-per-employee for the FAP (based on the October 1936 figures) was $\$ 90.10$, the average month1y wage for the other projects were $\$ 92.90$ on the Timberline project, $\$ 83.60$ on Pub1ic Institution-sponsored projects, and $\$ 81.70$ on Elite Institution-sponsored projects. Thus, in terms of total employees, total salaries, and monthly wage-per-employee, the Timberline Lodge project was the highest recipient.

It is obvious from the data, however, that the Elite Institution-sponsored projects received the fewest workers, the lowest salary expenditures, and the lowest monthly wageper-employee of the three categories. This would seem to contradict the logic of the earlier proposition if elite institutions are considered closer kin to business institutions that would be consistent with general class analysis theory [cf. Domhoff, 1971]). This apparent discrepancy suggests that perhaps the origins of sponsorship do not sufficiently account for differences in human resource and monetary a110- 
cations on the Oregon FAP. More likely, however, the discrepancy can be accounted for by the limited generalizeability of one month's data. If equally detailed figures were available for later months, a more precise analysis could be constructed about the relationships between and the relative importance of these categories. The fact still remains that Timberline Lodge was given priority during October 1936; this fact poses the question as to the extent to which that project affected the goals and outcome of the Oregon FAP.

Table II gives an indication of the allocation of human and monetary resources within the Timberline Lodge project, itself. The table shows that of the eight artists employed on the Timberline project, six of them were nonrelief artists; among the crafts workers, sixteen were relief

\section{TABLE II}

NUMBER OF WORKERS AND SALARY EXPENDITURES ${ }^{a}$ AT TIMBERLINE LODGE

Workers

Workers

Relief Non-Relief Total

Artists

Craftworkers 16

Total

2

6

8

5

21

11

29

18 5
Salary

Relief Non-Relief Total

$\$ 169 \$ 649 \quad \$ 818$

1369

508

1877

$\$ 1538$

$\$ 1157 \$ 2659$

SOURCE: Compiled from Smith, 1936.

${ }^{a}$ Figures listed for month of October 1936. 
workers and five were non-relief.

In Table III the figures 1 isted in Table II are broken down by percentages. Only thirty percent of the salary expenditures by the FAP for Timberline Lodge work went to the employment of artists, and only six percent of the total employed were relief artists. By comparison, Table I showed that more than half of the total FAP expenditures on salaries was devoted to the Timberline Lodge project. Table III gives the percentage breakdown of the proportion of expenditures and human resources devoted respectively to relief and non-relief workers and to artists and crafts workers. Craft workers on relief make up the largest proportion of the Timberline FAP work force; these people were primarily blacksmiths and cabinet makers by

TABLE III

$$
\begin{aligned}
& \text { PERCENT OF WORKERS AND SALARY EXPENDITURES }{ }^{a} \\
& \text { FOR RELIEF AND NON-RELIEF } \\
& \text { ART ISTS AND CRAFT WORKERS } \\
& \text { AT TIMBERLINE LODGE }
\end{aligned}
$$

Workers

$\frac{\text { Relief }}{7}$

Artists

Craftworkers

Total

$$
55
$$

62

Non-Re 1

SOURCE: Compiled from Smith, 1936.

a Data for month of October 1936. 
trade. Those artists who were hired to do work for Timberline Lodge were, for the most part, from non-relief sources. The disproportional underrepresentation of relief artists on the Timberline Lodge project is even clearer when the data for Timberline Lodge are compared with the data for the Oregon FAP as a whole. Artists, both relief and nonrelief, made up only forty-three percent of the total employment on the Oregon FAP, compared to twenty-eight percent at Timberline Lodge; relief artists at Timberline Lodge accounted for seven percent of the total employment compared to twenty-three percent on the total project. Relief craft workers constituted forty-eight percent of the total oregon FAP employment, compared to seventy-two percent at Timberline Lodge. Clearly, the majority of relief personnel at Timberline Lodge was craft workers rather than artists. For whatever reasons these distributions occurred, the fact remains that Timberline Lodge did not provide substantial employment for Oregon's relief artists (two relief artists employed in October 1936 were officially listed as employees on the "U. S. Forest Service Project" [Smith, 1936]). The generalizeability of this statement can only be established through the collection of data for other months. 11 The data

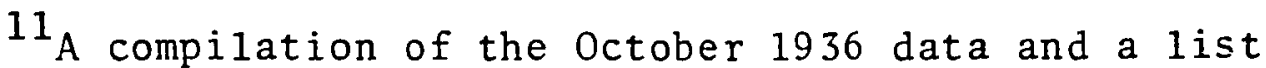
of artists who worked on Timberline Lodge art work reveals that throughout the entire project there were probably six relief artists (painters) and ten non-relief artists (painters, sculptors, and wood carvers). The six relief artists were Virginia Darce, Karl Feurer, Martina Gangle, Charles 
are compelling enough, however, to warrant further investigation.

In order to make a connection between the relative absence of relief artists on the Timberline Lodge project and the fact that the project began as a business venture it is necessary to compare the distributions of artists and craft workers, and relief and non-relief workers, for the different types of sponsoring agencies mentioned above. Table IV shows the distribution of total monthly salary expenditures for each category of sponsorship, according to percentage and actual dollar figure of expenditures.

As Table IV indicates, Timberline Lodge provided proportionately more employment for non-relief artists and craftspeople than did any of the other projects. While only fifty-seven percent of money for salaries went to relief workers on the Timberline Lodge project, eighty-seven percent and seventy-six percent went to the University-sponsored and public institutional-sponsored projects respective1y. In fact, only six percent of the salary funds went to pay relief artists at Timberline Lodge compared with forty-

Heaney, Douglas lynch, and Howard Sewall. The non-relief artists were Darrel Austin, 0. B. Dawson (officially a craft worker), Dora Erickson, Aimee Gorham, a Mr. Jeffrey, Ray Neufer, C. S. Price, Florence Thomas, a Mr. Schubert, and Margery Hoffman Smith. Six other artists, whose relief status is not known to me, include Melvin Keegan, Erich Lamade, Thomas Laman (believed to be non-relief), John Blew, Pete Ferrarin, and Jerome Seliger. The latter three were assistants to Lynch, Darce, and Gorham, respectively. 
TABLE IV

DISTRIBUTION OF MONTHLY SALARY EXPENDITURES ${ }^{\mathrm{a}}$ FOR TIMBERLINE LODGE, ELITE INSTITUTIONS, AND PUBLIC INSTITUTIONS, BY PERCENTAGES AND ACTUAL DOLLAR FIGURES

Timberline Lodge Elite Institutions Public Institutions Relief Non-Relief Relief Non-Relief Relief Non-Relief

Artists

Dollar

$169 \quad 649$

370

94

$549 \quad 376$

Percent

$6 \quad 24=30$

$49 \quad 13=62$

$34 \quad 23=57$

Craft-

workers

Dollars

$1369 \quad 508$

282

0

680

0

Percent

$51 \quad 19=70$

38

$0=38$

42

$0=42$

Total

Dollars

$1538 \quad 1157$

652

94

1229

376

Percent

of total

$57 \quad 43=100$

$87 \quad 13=100$

$76^{c}$

$23=99^{\mathrm{C}}$

SOURCE: Compiled from data in Smith, 1936.

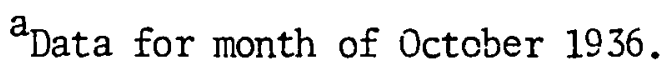

${ }^{b}$ Percent of total expenditures for each category of sponsor: Timberline, Elite Institutions, and Public Institutions.

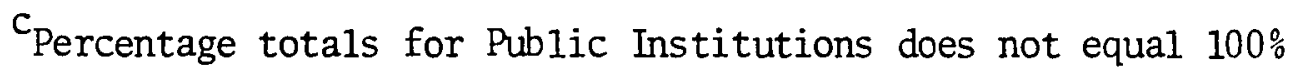
due to rounding errors.

nine percent and thirty-four percent for the other two types of sponsors. While these figures do not present a clearcut case that the business-supported Timberline Lodge project obstructed the project goals to hire relief artists, the facts that over half of the Oregon FAP's personnel and 
monetary resources went into the decoration of the lodge, while only two of the total fifty-six employees on the FAP were relief artists employed to decorate Timberline Lodge, are strong indications that the priorities of the Mount Hood hotel project took precedence over the goals set by the national FAP.

In terms of the relative merits or demerits of the Timberline Lodge project for Oregon's relief artists, two conclusions are possible. One conclusion would suggest that the importance of Timberline Lodge for the WPA, and the Portland business community and Forest Service which sponsored the project, far outweighed the artistic skills and talents of Oregon's artists on relief, leading administrators to hire non-relief artists to execute the important art work for this structure. In order to maintain the proper quotas of relief and non-relief workers, a large number of relief workers had to be employed on the FAP. A second conclusion would suggest that a craft project was a viable and necessary outcome of the interior decoration needs of Timberline Lodge. If the lodge was to be an attractive year-round resort, it had to have aesthetic and comfortable furnishings and decorations. Whether or not competent artists were unavailable for this important project the fact remains that the relief quota for the FAP was filled largely by craft workers. The motive for their hiring may have been primarily to decorate Timberline's interior 
or primarily to fill quotas so that non-relief artists could be hired for the more important art work. The fact that Margery Hoffman Smith was, herself, a craft worker and interior decorator lends credence to the conclusion that the craft project was a bona fide project irrespective of the desires to hire non-relief artists. The facts that Smith (1943) considered Oregon artists "mediocre" and that Barker (1935b) felt that competent artists could not be found on the relief rolls support both the contention that a crafts project was needed in Oregon and the suggestion that relief quotas had to be filled and relief slots expanded so that more non-relief (and presumably more competent) artists could be employed.

Returning to the question suggested by Useem's mode1 regarding business interests in the FAP, the case of Timberline Lodge substantiates to some degree that business interests shaped the production of culture on the Oregon FAP. While the business community felt that an aesthetic mountain hotel would serve its business and recreational interests, the project provided minimal employment to Oregon artists. Its major contribution to the FAP was that it provided employment for so many craft workers who learned to use their skills as blacksmiths and cabinet makers in the production of artistic objects and furnishings. The sixteen relief craft workers made it possible to employ another four or five non-relief artists or craft workers. In fact, 
it was primarily the non-relief artists, rather than the relief artists who, in October 1936, benefited most direct$1 y$ from the Timberline Lodge project. ${ }^{12}$

\section{Art and Government Programs}

Two projects of the Oregon FAP had direct application for government projects and programs, suggesting the utility of Useem's third model which states that:

1. The allocation of federal funds to the arts corresponds to an increasing utilization of the products by the government; and

2. Federal funding is allocated primarily to those artists whose work will be applicable to government projects and programs.

For the most part, the art produced on the Oregon FAP was not of direct use to the government. The FAP itself was a government program and its yery existence indirectly served the oyerall objectives of the WPA. On a national scale, the poster project of the FAP served the larger pro-

12 It should be pointed out that two of the non-relief, supervisory craft workers considered themselves artists. 0 . B. Daws on considered himself an iron sculptor and Ray Neufer was a talented draftsman, sculptor, and photographer. Their work produced for Timberline Lodge nevertheless was classified as craft work, although there is a fine line of distinction between their craft work and what might be classified as artistic, functional sculpture. The relief workers these men supervised, however, by-andlarge had little training or self-perception of themselves as artists. They learned to apply their trade skills to the art of craft work while on the project (Neufer, 1980). 
gram of the WPA and other government programs by creating posters designed to generate public support for these programs. Before the FAP, posters had been used primarily as an advertising medium and the design qualities of the puster took second place to the commercial potential; similarly, poster designers were often considered inferior artists (Floethe, 1975:177). The FAP helped develop the poster as an art form, and the talents of poster artists were put to use advocating better nutrition and safety practices, and promoting zoos, libraries, Community Art Centers, and the WPA itself. When first employed on the FAP, Charles Heaney went to work in the poster and graphic arts division of the project making maps, charts, and publicity posters that were used in a public lecture series sponsored by the WPA (Heaney, 1979b).

The second major project that directly benefited the government and its programs came after the WPA and the FAP were reorganized in 1939 into the Work Projects Administration of the Federal Works Agency under the Oregon Arts Program. At that time, while the cultural projects of Federal One came under attack from a conservative Congress, the country was embarking on a massive war preparedness effort. In an effort to save the Federal Art Project, Cahill and others began to explore how the art project could be used to aid the war preparedness effort. In fact, in 1942, the WPA Art Program of the Federal Works Agency became 
the Graphic Section of the War Services Division.

In Oregon, most of the work that was done for the war effort involved the decoration of servicemen's clubs and quarters. Ray Neufer and Margery Hoffman Smith designed and built furniture for the naval base at Astoria and a variety of art work was allocated for the decoration of clubs and living quarters (Everett, 1979). 0. B. Dawson (1940) had a proposal as to how his iron workers could serve the war preparedness effort more directly; he felt that these skilled workers could help "in the construction of tanks, gun carriages, truck bodys [sic] and even in making aeroplane parts." Believing he was capable of "engineering the construction of any thing to be made of iron" Dawson proposed to E. J. Griffith that the WF'A set up a program to make the iron workers part of the armament program (Dawson, 1940). Although Dawson's proposal apparently did not come about, it suggested his desire to be a part of the war effort.

The war-related projects of the Oregon Art Program were not sufficient to warrant a conclusion suggesting that government programs were a major recipient of the art work of the FAP. Because of Portland's centrality to the shipbuilding industry, many of Oregon's artists found jobs in the ship yards when the FAP began to cut back on employment. While some artists were involved in direct production as welders (e.g., Martina Gangle), others like Louis Bunce, 
got jobs in the ship yards, drawing pictures of parts to show how they should be assembled for the benefit of those construction workers whose reading skills were minimal (Cur1, 1979b; Bunce, 1979).

\section{Art and Ideology}

To the extent that Useem's fourth model of government support for art is valid we should find the following corollaries to be true:

1. State intervention in the production of art accompanies a crisis in government legitimacy and dominant i deology;

2. Government funding is oriented towards artists whose work will assist the restoration of the dominant belief system and confidence in the government.

These corollaries stem from Useem's overall contention that government intervention in the arts is designed to serve the ideological needs of the state. The difficulty in discussing these corollaries stem from the fact that a precise definition of and indicators for the "dominant ideology" of the system are difficult to discern. Max Weber (1958) perhaps provides the place to begin the search for the characteristics of the ideology of a capitalist system. For Weber, the ideology of capitalism was the ideology of rational accumulation; at first aeveloping out of the Protestant ethic, the spirit of capitalism was able to discard 
its religious trappings once modern capitalism developed a momentum of its own, bound to "the technical and economic conditions of machine production..." (Weber, 1958:181). The spirit of capitalism was exemplified by the values of honesty, punctuality, industry, and frugality; it involved a drive toward acquisition combined with a sense of duty and obligation towards one's work (Weber, 1958).

Antonio Gramsci argued that the beliefs, attitudes, and myths of a people are material forces in a society in that they motivate people to act or not to act in shaping the direction of society (Boggs, 1972). Gramsci's concept of ideological hegemony has been explained by Guiseppe Fiore $(1973: 238)$ as

...the acceptance by the ruled of a "conception of the world" which belongs to the rulers. The philosophy of the ruling class passes through a whole tissue of complex vulgarizations to emerge as "common sense": that is, the philosophy of the masses, who accept the morality, the customs, the institutionalized rules of behavior of the society they live in.

As Glen Hirsch (1975:79) argued, "In order to preserve ideological hegemony, it is only necessary for the ruling group to reinforce dominant values and at the same time prevent the dissemination of opinion that effectively challenges the basic assumptions of the society." To the values of honesty, punctuality, industry, and frugality discussed by Weber (1958), contemporary studies of ideology have added the related values of self-reliance, individualism, and 
utilitarianism (see Kellner, 1970; Gitlin, 1979).

In this section I will accept the validity of these values as indicators of the "dominant ideology." If the dominant ideology of any system is that of its ruling class as Marx and Engels have argued, it follows that the dominant ideology will be one that perpetuates the system; contrary ideologies that threaten the basic assumptions of the system will either be repressed, discouraged, or, at best, tolerated.

If the FAP was part of an effort to preserve the dominant belief system and if, in fact, it accompanied a crisis in government legitimacy and in the dominant ideology, then we should, indeed, find those artists and projects being encouraged which could help restore confidence in the system and promote the values of self-reliance, individualism, frugality, and industry.

It has already been established that the WPA and the FAP came out of a severe crisis in the society which, indeed, threatened both the legitimacy of the government and the dominant ideology. Artists joined the larger working class in organizations and activities that sought an end to the individualist, rational acquisitive value system of capita1ism. While not all of these working class activists sought an end to capitalism, there appeared to be a virtually unanimous demand for more democracy in political, economic, and cultural affairs of the country. Unions demanded recogni- 
tion, threatening the sanctity and autonomy of the free enterprise system as it had been constituted; the very existence of the depression challenged the sacred myth that everyone should be able to "pull themselves up by their bootstraps"; because of this contradiction between the myth and the reality, militant protests of unemployed workers demanded that the government intervene on their behalf, thus challenging and attempting to replace the values of individuality and self-reliance with collectivism and government accountability. While utilitarianism and frugality had developed among the working class out of necessity, the values of individualism and self-reliance channelled the former in such a way that they undermined the oppositional, socialist tendencies developing within the working class, which should they reach fruition, could ultimately undermine the very core of the capitalist system.

Studies of the FAP which focus on New York or on the national scene provide contradictory evidence as to the extent to which the FAP encouraged those artists whose work benefited the ideological needs of the state and repressed or discouraged those whose work promoted ideas that threatened the dominant ideology and legitimacy of the state (0'Connor, 1969; McKinzie, 1973; Mangione, 1972). Numerous artists recall experiencing a great deal of freedom in terms of both the form and content of their work (O'Connor, 1969), but others, whose work was more explicitly political, ex- 
perienced yarying degrees of censorship and repression (cf. McKinzie, 1973). A major reas on for the termination of the WPA/FAP in 1939 was the belief of many national leaders that the FAP and the other cultural projects were harboring communists and producing dangerous work (cf. McKinzie, 1973; Mangione, 1972).

In order to assess the relative freedom or censorship on the Oregon FAP a great deal of data would be needed which is currently either unavailable or unknown. ${ }^{13}$ The only case of an overt attempt at censorship of an art work in Oregon was reported by Margery Hoffman Smith (1979). Smith reported that some members of the community "got very agitated about one of the murals. It might have had a hammer and sickle in it; they got pretty radical, you know... We didn't have anything too radical [but] there was a feeling against communists--a strong feeling against them." When members of the community wanted to have the mural painted over, Smith's husband went on the radio to protest the censorship (Smith, 1979).14

${ }^{13}$ A national study of this nature would be more feasible, as a larger sample of artists and their work is available. A study of the TRAP murals in public buildings could suggest the degree of censorship or political control on that project, for records are available which show the various mural sketches submitted for jury which could be analyzed for political content and compared with those that were selected.

${ }^{14}$ McKinzie (1973) discussed several incidents in which 
While censorship of Oregon artists apparently did not occur, some artists experienced what they believed was a form of political harassment. Several Oregon artists were members of the Communist Party at various times during the 1930s. The most active of these was Martina Gangle, who was frequently harassed by the FBI and Portland's Red Squad --a semi-official branch of the police department that specialized in following and impeding the activities of actual and suspected communists. One time Gangle was summoned to the FBI office where an FBI agent told her they would see to it that she never became successful as an artist (Cur1, 1979a). A number of events succeeded this occasion that Gangle believed were attempts to discredit her in the art community and cause other Party members to question her commitment.

I think that there was a fear of artists--progressive artists and actors and writers. I think there was a real fear because, you know how they treated them nationally; I think they were more afraid of them than they were some of the workers... They didn't beat me up but they did some awful things to me... Did I tell you about how they picked up my friend and told him I was a "chippy?" Now that kind of thing is really hitting you below the belt... He was working in the peace movement; he wasn't in the (Communist)

\footnotetext{
artists' work was changed, or came under attack, due to alleged communist content. August Henkel of New York painted an airport mural that was removed because a portrait of an early parachutist looked like Lenin. Arshile Gorky's mural "Aviation" came under attack because it displayed a "suspicious red star, which, upon investigation, turned out to be the trademark of the Texaco Oil Company (McKinzie, $1973: 165-6)$.
} 
Party but he was in the peace movement. My house was kind of open to progressives who came in; I had a big place... Men and women that came in from out of town... would come in and stay there and I just let them because I had a place for them to stay... That might have been the basis of what [the FBI] based [the "chippy" accusation ] on.

[My friend] came to visit me one night and when he went to go home, his car was gone. They took it to the police station. Then when he went to get it, that's when they kind of "third-degreed" him... It was kind of threatening; they told him a11 these things about me... They threatened to punch him and they'd knock his teeth out... I suppose it was to discourage him. (Curl, 1979b).

In another incident Gangle was sitting on a park bench near Burnside and a man came up and asked her to go to lunch with him. She told him that if he was hungry he could come to her house and she'd fix him a meal. When he insisted that she go out with him she looked around and noticed a police car nearby. She felt like this man was trying to set her up to look like a prostitute.

During the time that another progressive artist, Arthur Runquist, was painting a mural for the Pendleton school, he was picked up in a car one night, taken out into the country, beaten, and dumped from the car. His hand got so infected that he was in the hospital almost a year. Many people suspected that the Red Squad or their "goons" were responsible for this beating although they never found out for sure (Curl, 1979a; 1979b; McLarty, 1979).

Politically active artists believed such incidents were political harassment designed to "keep them in line" 
and prevent them from creating overtly subversive works. Another subtle form of censorship came about in 1939 when the FAP was placed under the direct supervision of the states and each project was directly controlled by the individual sponsor which provided twenty-five percent of the funds. As McKinzie (1973:165) has noted, this reorganization of the project served as an effective deterrent to free political and artistic expression, for artists quickly learned that it was in their self-interest to produce what local sponsors wanted. Nevertheless, even known communists were allowed to be on the FAP until, in 1940, Congress passed a bill specifically excluding communists from employment on the WPA, requiring that they sign loyalty oaths in order to get hired.

Ideological Orientations of Oregon Supervisors

This section considers specific ideological orientations of two Oregon FAP supervisors in an attempt to discern to what extent and in what manner the project may have contributed to the restoration of confidence in the system and to the promotion of values characteristic of the dominant belief system. Two concrete indications of their ideological orientations are discussed below. One deals with an emphasis on improvisation and the other with utilitarianism. Both emphasize individual self-reliance, which, while objectively practical, was ideologically supportive 
of dominant belief systems that were being militantly challenged in the streets and in working class organizations. Improvisation as an Ideology of Self-Reliance In early 1936 , shortly after Gladys Everett gained supervisory control over Oregon's art project, Margery Hoffman Smith was hired to supervise the interior decoration of Timberline Lodge. The project was unique in that it coordinated the efforts of many WPA projects such as the road project, the construction project, and the arts projects. Gladys Everett, because of her position as head of the Women's and Professional Projects Division, coordinated the efforts of all of the projects under her supervision. The sewing project was coordinated with the art project to make curtains, bedspreads, and throw rugs for the lodge. She worked closely with the director of the construction projects and, unlike the case in many states, was fortunate to have a state administrator who supported artistic and creative endeavors. (According to Ms. Everett, E. J. Griffith was a very progressive administrator in that he allowed the people under him to use their own creativity and judgement when they were put in charge of a project.) Everett took women from the sewing project, who had been hemming bed sheets by hand, and first taught them to make stylish clothes for relief workers and then taught them to follow the designs made by Margery Hoffman Smith in making the cur- 
tains and bedspreads for Timberline Lodge (Everett, 1979). Margery Hoffman Smith was responsible for designing and supervising all of the craft work at Timberline Lodge, which included furniture, light fixtures, wood carvings, rugs, and the room furnishings. She also supervised the paintings, murals, mosaics, and parquetry work that was used to decorate the Lodge.

Both Margery Hoffman Smith and Gladys Everett believed that people should learn to improvise, use whatever materials and talents they had, and still be able to turn out a good product. Many of the rugs at Timberline Lodge were made out of discarded army uniforms; decorations on the draperies were cut from scraps of material from the sewing project. Both women believed that they were teaching workers important values as well as skills through the way they organized the projects (Everett, 1979).

Gladys Everett came to be known, among workers under her supervision, for her constant insistence that they learn to "improvise." She recalls that the workers would complain occasionally because they did not have certain items they needed, and she would insist that they improvise. One of the programs Everett organized was a housekeeping project in which she trained WPA women workers to go into homes of the poor and sick, fix up the house, clean it, and improvise to make it more comfortable and pleasant. One woman wanted to make one such house warmer and more pleasant, 
so she improvised by wallpapering the house with newspaper. The value of the project, according to Everett, was that the WPA women came to see that there were people worse off than they were. Because they learned housekeeping skills, they learned to improve their own homes as well. One anecdote Everett related involved a joke the women she supervised played on her. She went to the housekeeping training house to see how things were going and when she went to use the bathroom, she found strips of newspaper where toilet paper was supposed to be. Above the newspaper strips was a sign that said, "Improvise" (Everett, 1979).

The emphasis on improvisation and self-reliance, while serving genuine utilitarian needs in a time of scarcity, also reflects an ideology which encourages "bullet biting" instead of collective organizing at a time of crisis. Theorists have argued that this kind of ideology obscures class relations and is an obfuscation, in many ways, consciously promoted by the upper class, the government, and corporations (see Kellner, 1979; Gitlin, 1979). The nature of this philosophy thus promoted individualism and selfreliance at a time when the poor were demanding governmental and corporate responsibility for human welfare: It supported "adaptation" rather than change.

The Ideology of Utilitarianism: From Art Project to Craft Project

In 1939 the Federal Art Projects were put under the 
direction of the State administrations of WPA because Congress refused to continue appropriations for a nationallydirected project. at that time, the Oregon Federal Art Project became the Oregon Arts Program and the WPA took on a new name with the same initials--the Works Projects Administration. As its new name suggests, this transition reflected a shifting concern from one of providing employment to workers on relief to one of producing socially useful products, using workers who were on relief. This new utilitarian shift reflected the increasing conservative nature of Congress, a growing majority of which began to resist government welfare and social service programs, in part in the belief that they were merely subsidizing Communists (see McKinzie, 1973).

When the Federal Art Projects were placed under the supervision of the states, Margery Hoffman Smith became the director of the new Oregon Arts Program. Believing that Oregon artists were mediocre, at best (Smith, 1979), Smith attempted to turn the art projects into a craft project. In a final project report she wrote, "Based on the conviction that a good craftsman is better than a mediocre artist and the talent of the Oregon artists assigned to the projects was mediocre on the whole, the Oregon Art Project was transformed as rapidly as possible and for the greater part to a craft project" (Smith, 1943). What was begun at Timberline Lodge with the creation of many fine crafts projects 
was completed when Smith became the state director of the arts projects. As a consequence, skilled and unskilled craftspeople were put to work. At the same time, a national regulation required all people who had been on WPA for more than eighteen months to be released from WPA employment, a regulation that threw hundreds of artists out of work on a national scale. This national regulation, combined with Smith's decision to turn the project largely into a craft project, potentially meant that a number of Oregon artists would no longer find work on the WPA.

At least three explanations could account for Ms. Smith's decision to convert the art project to a craft project. One interpretation suggests an attempt to promote the crafts because of the popular and democratic nature of the crafts. Margery Smith believed that crafts provide a creative use of leisure time; they also allowed people to "make things for themselves they couldn't possibly afford--you know, silver of all kinds--and it made them happy to own lovely things [which] they knew they couldn't afford...to buy..." (Smith, 1079). In this statement, however, Smith was referring to the kinds of crafts that were done at the Arts and Crafts Society school founded by her mother, Julie Hoffman, not to the woodworks and iron works that made up a large part of the craft work done on the FAP. Unfortunately a complete listing of craft and art projects on the FAP has not been located or compiled, making an overall evaluation 
of the actual craft nature of the projects impossible. Nevertheless, the implication behind Smith's own testimony is that people could find greater happiness by learning how to make those things they cannot afford to buy--an implication that has both practical and ideological character.

A second interpretation of Smith's emphasis on the craft nature of the FAP is one that reflects her upper class values and artistic standards as much as it reflects on the overall quality of Oregon artists. Margery Hoffman Smith came from a fairly wealthy family and throughout her life she collected fine furniture and art objects from around the world. It is possible that she held somewhat elitist attitudes toward Oregon artists and the "uncluttered" public made up primarily of working people. The art produced on the Oregon art project was largely the art of poor working people, some of whom had had little professional training, and most of whom were trying to honestly paint the scenes and experiences of the Northwest. While most of these works would never become collectors' items, they reflected the sincere efforts of Oregon artists. Most of the works I have seen (approximately 30 originals and 100 photographs of work) suggest that the artistic quality was sufficient to warrant a continuation of the project as an art project, if for no other reason than as a testimony to the Oregon artists who, like many artists of the day, had their first opportunity to create works of visual art as paid professionals. 
A third explanation for Smith's craft emphasis is that there were not enough artists--even mediocre ones--to fill the available slots on the FAP. The figures currently available are simply not conclusive on this matter. According to a 1935 unemployment census (Works Progress Administration 1938:730) there were" thirty-six people listed on the Oregon relief rolls as artists, five months before the Federal Art Project was even approved by Congress. By February of 1936 the Oregon project had funds to hire sixty persons, yet only twenty-nine were employed (Cahill, 1936). By October of 1936, Margery Hoffman Smith reported that fifty-six people were employed on the projects. According to her list of people and projects, twenty-five of these people classified as artists and thirty-one of them were craftspeople. Included in the category of artists were etchers, sculptors, and wood carvers. At Timberline Lodge, out of the twenty-seven people working for the FAP in October 1936 , twenty were craftsworkers (primarily cabinet makers and iron workers). In the state as a whole, thirty out of the fifty-six employees were craftsworkers, and only fifteen of the twenty-six artists were actually from relief rolls, indicating that ten of the previously registered artists were either no longer on the relief rolls or were possibly being overlooked by the FAP (Smith, 1936).

The tentative conclusion suggested by the available evidence is that two factors combined to cause Margery Smith 
to convert the Oregon art project into a craft project: one factor was her own interest in crafts as a skilled designer and craftsperson; the other was her belief that Oregon artists could not produce good art. The nature of the crafts done on the FAP was not that which primarily taught people the creative use of their leisure time, thus there is no indication that the philosophy which inspired the creation of the Arts and Crafts Society school carried over into the FAP. Available figures on unemployed artists and artists on the FAP suggest that in all likelihood more artists were available for the art project than were actually hired by it. Finally, the strongest evidence that suggests an elitist attitude towards art is that as of October 1936 only non-relief artists had been hired to do non-craft art work at Timberline Lodge, which, as pointed out above, was one of the most important projects in the eyes of the business community. By contrast, all of the relief workers on the Timberline Lodge art project were cabinet makers, iron workers, or blacksmiths. The women who did the weaving and sewing for the draperies, rugs, and bedspreads were hired from the sewing projects under Gladys Everett's supervision. All of these craftspeople were hired to carry out the designs created primarily by Margery Hoffman Smith, and, as she tells it, "I'd stand over the rug hookers and tell them how far to go with a certain color and how far to go with another color." She also worked directly with Ray 
Neufer, the chief furniture builder: "I would stand over a piece of furniture and he'd built it as we stood there and planned it. Then after it was all planned and built, we'd make a blueprint of it" (Smith, 1979). As indicated by these comments, the nature of these craft projects was such that people were not necessarily encouraged to develop their individual creative talents.

Ideological Struggles and the End of the FAP

The ideological orientation of Gladys Everett and Margery Hoffman Smith, as demonstrated in their emphasis on crafts and their emphasis on improvisation, was expressed out of a sincere belief that these values would be of benefit to the relief workers they supervised. The fact that the values these women stressed may have objectively contributed to the maintenance of the basic assumptions of the system does not negate their sincerity. Indeed, the sincerity of the administrators of the WPA and the FAP suggests a fourth way in which the system deals with ideological challenges. Rather than tolerate, discourage, or repress oppositions to the system, an astute ruling class should be able to use the demands of its opposition as clues to the solution to its social problenis. Thus, when artists began joining communist and socialist movements to demand the fair treatment of working people, the government responded favorably to their demands and stemmed the tide of more serious unrest. The demands of the activists in the thirties were 
demands for jobs and for expanded and artist-controlled gallery space; for the most part, however, demands were not made for working class control of the system; artists did not demand that they, as workers, run the FAP (although one artist expressed her disapproval over the hiring of upper class people to run the Oregon FAP when competent people were available who needed the work). As a result, it was possible for FAP administrators to push for reforms within the system without undermining the assumptions of the system, itself. As some theorists have argued, a reformminded ruling class is believed to be essential to the longterm maintenance needs of a system that must continually confront social challenges (cf. Hirsh, 1975; Domhoff, 1971 ; Ostrander, 1980; Weinstein, 1968).

On a national level, the liberal and humanitarian sincerity of many of the local and regional administrators of the FAP was matched by an equally conservative and utilitarian reaction by some members of Congress and the conservative community they represented. This conflict reflected a split over the correct strategies and tactics for dealing with the political and economic crisis at home and abroad. The conservative wing of Congress charged that the Federal One projects were "more dangerous than the Communist Party, itself" (Mangione, 1972). In 1939, when the Federal One projects were placed under the direct supervision and sponsorship of the states, new priorities were established for 
the art projects. The original priorities of the WPA were thus reversed, requiring that the first priority in the selection of projects be utilitarian considerations. This requirement reflected a utilitarianism designed to remove from the government relief rolls those who were alleged to have used the project to "spread class hatred" (Mangione, 1972 ); it also reflected a shift in fiscal priorities away from social welfare considerations in favor of military expenditures.

Although Margery Hoffman Smith protested the decision to place the FAP under state contro1, her protest was based on a belief that the projects were better off with the technical supervision and support of the highly specialized national personnel in the field of art. This was a concern consistent with the need to protect the "paradigm" of the arts, reminiscent of Useem's (1976) first model. In a letter to Florence Kerr, the national advisor for the Women's and Professional Projects, Smith argued that while Oregon was fortunate to have sympathetic directors like E. J. Griffith and Gladys Everett, other states were not so fortunate (Smith, 1939). Kerr, however, believed that it was necessary to transfer the FAP to the state administrations in order to insure that they remain "safe." She believed that there "must have been something wrong with the theatre project or what happened to it would not have happened" (McKinzie, $1973: 164)$. 
Ultimately, however, neither the protests of artists nor the defense and support of administrators could save the FAP and other cultural projects from the challenge of right wing reaction, which took the form of the Dies Committee of the House Unamerican Activities Committee. The militance and social consciousness of many of the WPA artists, which contributed to the formation of the FAP, aroused the ire of conservative members of Congress, who, through legislative reform, terminated the Theatre Project and limited the others by utilitarian considerations. When, in an effort to save the projects, Cahill, in June 1940, proposed that the art projects become part of the national defense effort, creative production became subordinate to the utilitarian and ideological needs of the state. Ultimately, the combination of the entrance of the United States into World War II and the right wing reaction within Congress brought an end of the eight year history of the Federal Art Projects, which was terminated in January 1943.

Ideology and Support for the Arts: Conclusions

As this section has demonstrated, there were certain ideological underpinnings to the FAP that contributed to the promotion of values characteristic of the dominant belief system. The Oregon administrators of the FAP operated within the context of the New Deal spirit which ultimately saved the system by reforming it. Consistent with New Deal 
ideology, these people were neither radicals nor working class reformers; they were part of a progressive wing of the upper class which believed that people had both the responsibility and the right to work on socially useful projects which, in turn, were of benefit to the larger community of taxpayers and to the self-esteem and psyches of the individuals employed on relief projects. The ideological needs of the state were thus served by the WPA as a whole, which showed the unemployed that the system could work on their behalf. The democratic ideals of artistic freedom allowed FAP artists to express socially conscious and critical themes in their art; the circumstances surrounding the final years of the FAP and its termination, however, attest to the limits of such reforms within capitalism.

The extent to which the ideological needs of the state affected the goals of the FAP can be summarized as follows: The tendency of the state to preserve the system by reforming it provided the structural conditions that made the FAP possible in the first place. The fact that upper class and otherwise elite people were selected to run the projects appears to have been an important factor in insuring that the FAP, as a New Deal reform, remained within acceptable boundaries. While there was a general level of artistic freedom in terms of form and content, a small amount of evidence exists in Oregon (and considerably more national1y) to indicate that when artists stepped beyond the acceptable 
ideological boundaries it was the duty of the administrators to bring them back into line. Finally, while the local administrators were advocates for the unemployed, they were not advocates of welfare. They promoted the values of work and self-reliance, yet no attempt was made to encourage collective work or self-management. The women on the sewing project who made clothing for other workers and who sewed the curtains and bedspreads for Timberline Lodge worked in a manner that was designed to prepare them for the assemblyline work of modern industry ${ }^{15}$ (Everett, 1979).

The conditions described above had little to do with affecting the FAP priority that relief artists be hired, except to the extent that utilitarian considerations led to the hiring of relief craft workers rather than to the creation of projects for artists on relief. The need to promote a positive attitude towards the nation in a time of crisis possibly contributed to meeting the FAP goals, to the extent that artists were hired to paint the "American scene." Within the constraints of the FAP, some artists were able to exploit their freedom and create art that was intended as a challenge to the ideological hegemony of the system. When conservatives perceived this challenge as serious, the FAP was ended, in a second attempt to restore the legitimacy and

15 The clothing manufacture $r$ Jantzen donated equipment to the WPA and helped set up the same work process for WPA workers which they used in their factory, thus helping to prepare the women for private employment after the depression (Everett, 1979). 
ideology of the system.

\section{SUMMARY AND CONCLUSIONS}

In this chapter I have explored the goals of the FAP and the extent to which the interests of art as an institution, corporations and business, government projects and programs, and ideological orientations of administrators and needs of the state, interfere with the carrying out of these goals.

The suggestion that government support for the arts is conditioned by the needs of government programs and projects is the least valid for the FAP in Oregon. Indeed, the actual programs of the government appear to have had little effect on the FAP until it appeared that the FAP would be discontinued because of the war and the reaction from Congress. It is possible that the subjugation of the FAP to the war-preparedness effort enhanced the Oregon FAP in that it allowed the projects to continue. The momentum behind the effort to convert the projects into the service of the government's defense program appears to have come from Cahill, himself, in an effort to save the program in some form (McKinzie, 1973).

I have argued that certain aspects of the dominant ideology were promoted on the FAP and that the FAP, itself, was part of an attempt to salvage the system from a political and economic crisis. The use of public relief to quell 
the violence and protests of dissident movements has been documented (cf. Piven and Cloward, 1971). While not always or necessarily cooptive, these reform measures often have the effect of securing ideological control in the hands of authorities; as Useem $(1976: 134)$ has argued, the arts have been seen by national leaders as a vehicle for satisfying "the 'spiritual hunger' left unmet by the society's political and economic institutions." The available evidence on the national scene, and to a lesser extent the data available on Oregon, support the contention that the FAP served the ideological hegemony. These ideological needs initially helped to create the FAP; then, in 1939 , when strong forces in the government perceived that the country's values and goals were being threatened from the inside as well as from abroad, ideological interests in part led to the destruction of the FAP. These ideological battles which occurred primarily in Washington, D. C. and in New York City had a direct effect on the FAP in Oregon; in many ways the conflict was carried out through fiscal measures and legislative rules and procedures. Every victorious demonstration or sit down strike by New York artists was felt in Oregon as funds reappeared and regulations were altered; every victory by conservatives in the House Appropriations Committee was also felt in Oregon as programs were cut and artists were either laid off or not hired to begin with. Finally, Oregon was not untouched by the political struggle of the 1930s; 
in many ways Oregon was a center for the battle between communists and anti-communists within the trade unions (cf. Lembcke, 1978) and the general political climate was central in the consciousness of at least ten or twelve of Oregon's artists (Cur1, 1979a; Cur1, 1980; Bunce, 1979; Griffin, 1979). While this political climate encouraged a social consciousness in the art of many artists, it also became a mechanism of control that was largely self-regulating.

When Burt Brown Barker was told to employ more artists on the Oregon FAP, even at the risk of abandoning the iron gates project at the University of Oregon, he responded by saying that the Oregon FAP had made commitments to its sponsors and its artists for certain large projects; if he were to abandon these projects, he would be faced with a catas trophe which he "could not live down in a life time... If anything should defeat what we have undertaken, it would be a very sad day for me in Oregon" (Barker, 1936c). This problem is indicative of the tension that existed between the two goals of the FAP--to hire artists on relief and to create projects for the community. The attempt to serve the community's needs could undercut the goal of hiring artists on relief--particularly when the term "community" was narrowly defined to refer to the elite and the business community of Oregon. While the interests of the elite and the business sector enhanced the FAP by providing it with sponsors for art projects, it has been suggested that the 
elite-sponsored and business-sponsored art projects consumed a disproportionate share of the FAP's resources and in some cases provided employment primarily for non-relief rather than for relief artists. While it could not be concluded that the interests of the business community and the elite hindered the goals of the FAP, the data suggest that neither did they enhance the implementation of those goals. Whether the responsibility for the discrepancies lay with the business and elite communities, themselves, or with the directors and supervisors of the FAP is in many ways irrelevant, for in large part they were one and the same. To the extent that the FAP administrators felt primary commitment to, and identification with sponsors, they seem to have overlooked their mandated responsibility to relief artists, and the goals of the FAP were relegated to second place behind the needs or desires of various sponsors.

At times the attempt to create socially useful projects of artistic integrity prevented or obstructed the good faith hiring of relief workers. In and of themselves, however, the dual goals of providing socially useful projects and of hiring relief artists were not contradictory; the conflict came when the means to implement the goals were unavailable because of lack of funds or because they conflicted with the desires of sponsors and/or the administrators. The problem lay not in the goals, themselves, but in the regulations governing their implementation. The one regu- 
lation that seems most to have impeded the implementation of goals on the Oregon FAP was the rule that expected a project to have a sponsor and that the sponsor provide the costs of materials. This expectation was of obvious financial benefit to the FAP, and it also was seen as a way of confirming the social utility of a product to the community, as well (McDonald, 1969). While local sponsorship was not an absolute requirement for projects, it was strong$1 y$ encouraged and was expected to be the rule rather than the exception. This system, however, limited the pool of available sponsors due to the financial obligations expected; the determination of what would be produced and what was socially useful was usually made by a powerful group of community leaders--the upper class, businessmen, government officials, and educational leaders such as school boards, principals, and university heads. By necessity, the sponsors were those organizations with money to spare; the leaders and clients of those organizations may have been defined as the community to be served by the FAP. Left out were those organizations without sponsoring money and those individuals and groups that were not represented by a sponsoring agency. Alternative models to the sponsoring agency model could have been developed to allow more grass-roots participation in determining what kinds of art products the "unaffiliated" community desired; for example, an elected board of representatives from important sectors of the com- 
munity could have been a part of the decision-making process. Other models could have been developed to encourage a more democratic distribution of the products of the Oregon FAP. When sponsors participated financially with the FAP, they naturally were concerned that they get the best art product for their money, and consequently, priority was given to the creation of works of art rather than to the employment of relief artists. The elite members of the community who represented the organizations requesting the FAP's art work were thus objectively, although not necessarily actively, in a conflictual position to the unemployed artists needing relief work.

While the sponsorship system cannot be blamed for the FAP's failures, any more than it can be credited with its successes, it appears to have been a major variable in affecting the production of culture on the Oregon FAP. In addition, the quota system divided unemployed artists along an arbitrary line known as "relief eligibility" and allowed project administrators to gear projects to the abilities of the presumably more qualified non-relief artists. These two internal conditions within the FAP served to impede or control the growth and development of the cultural revolution in Oregon in two important ways: The sponsorship system was premised on the social relations of private property, and while there were many democratic and posjtive outcomes of the Oregon FAP, this system was a "check" on the cultural 
revolution in that so many resources were directed towards the elite and upper middle class which presumably could have been directed toward a more representative audience. Secondly, because of the way the quota system was handled, the traditional ideology encouraging competition among individual artists was perpetuated where a more collectively-oriented project could have been created. 


\section{CHAPTER IV}

\section{CONCLUSION: A MODEL OF THE OREGON FEDERAL ART PROJECT}

This thesis has addressed the broader question of the relationship between art and society by examining the production of culture on the Oregon Federal Art Project. It has been argued that the social conditions of the $1930 \mathrm{~s}$ shaped the art that was produced during that period. The Oregon FAP has been examined not for the content of the works of art created, but for the social conditions and decision-making processes that determined the production of culture; that is, how was art produced, who produced the art, who consumed the art, and how were decisions made regarding each of these? I examined some of the internal social conditions of the FAP--the official structure and goals--and some of the external conditions favorable and adverse to the internal conditions. I argued that the structure and goals of the FAP--indeed, its very existence--were themselves created in response to the external conditions of the larger society: The economic crisis, the growing class struggle, and the election of a liberal democratic President.

Based on the analysis presented in the thesis, the political class struggle perspective of the state remains 
the most viable for guiding an analysis of state structures and reforms, as presented in this case study of the Oregon FAP. Weinstein (1968), Milband (1969), and Domhoff (1971) emphasized in their research views of the state which share in common an emphasis on the power and hegemony of the upper class, without taking into consideration the power of the working class in influencing state structure; thus, they have a tendency to overlook the contradictory character of state reforms and structures made possible through class struggle. Structuralists (e.g., Poulantzas, 1973) fall short in their analysis by underemphasizing the importance of human action in shaping the structures of the state and its reforms. P1uralists (e.g., Dah1, 1961) point to the various segments and groups in society that exert influence and power on the government; however, by failing to recognize that different strata and groups in society are linked by the concept of class, and that class interests have a general cohesiveness that reflects their varying relationships to the mode of production, they fail to acknowledge the different sources of power belonging to each class, and the importance of relations of power and struggle between classes. The political class struggle perspective avoids many of the pitfalls of the above theorists by emphasizing the dialectical relations between classes in struggle and the contradictory character of the outcome of struggle. A model is presented below which attempts to summarize 
the dynamics which affected the production of culture on the Oregon FAP by looking at the national and local social conditions that affected the projects. For the sake of analytical clarity, I have divided the concept of social conditions into the sub-categories of external conditions, referring to political-economic factors outside the WPA/ FAP, itself, and internal conditions, referring to the structure, goals, and regulations internal to the FAP as an institution. I have also separated the national from the local social conditions for both external and internal conditions. 16

Because the model refers to the production of culture on the Oregon FAP, the domain and the generality of the model are limited. It is possible, however, that the model could be applied to the study of other state FAP programs, and from this specific mode1, more general models san be developed with applicability for the entire FAP and other government programs.

A MODEL OF SOCIAL CONDITIONS AFFECT ING THE OREGON FEDERAL ART PROJECT

A number of laws of interaction, with varying levels

${ }^{16}$ The model presented is intended as a heuristic device and boundaries are suggested for the sake of clarifying relationships between categories which, while not static, are also not random. A dialectical view of social structure is assumed, with dynamic interrelationships existing between categories. 


\section{FIGURE I}

A MDDEL OF THE SOCIAL CONDITIONS AFFECTING THE PRODUCTION OF CULTURE ON THE OREGON FEDERAL ART PROJECT

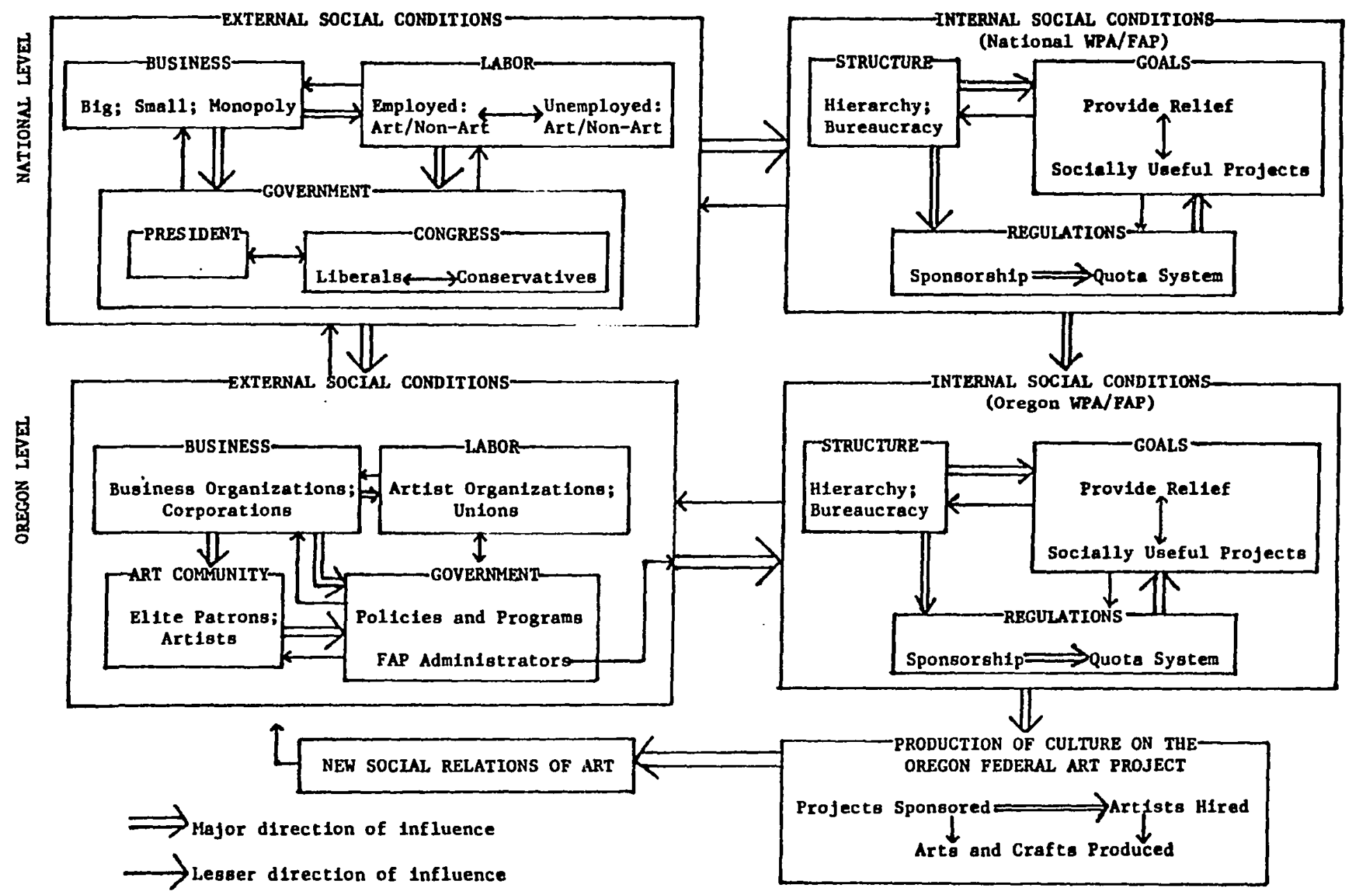


of efficiency could be suggested for the model. These are stated below not as formal propositions, but as propositional statements about the conditions affecting the production of culture on the Oregon FAP.

The model has been divided into four sections relating to the external and internal social conditions on the national and state or local level.

Beginning with the external social conditions, it should be noted that the Presidency was in the hands of a liberal Democrat. This factor is assumed to remain constant throughout the model. It is assumed that the entire outcome of the model would be different if this factor had changed, although the amount of change is unpredictable. The external social conditions on the national level include the relations between business, labor, and government. The same relations exist on the Oregon level, and, although I have not adequately dealt with the larger labor scene in Oregon, it is assumed that the responses of the Oregon business community and government to the FAP were influenced and affected by the local labor scene. The national external social conditions and the local external social conditions of the FAP are presented in the model as primarily affecting the creation of the FAP in the former case and the implementation of the FAP on the local level in the latter case. I have explored the state-level external social conditions affecting the Oregon FAP using four categories sug- 
gested by Michael Useem (1976); Business interests, art community interests, interests of government programs, and ideological needs of the state and orientations of the project administrators. While the last category could be considered part of the internal conditions of the local FAP, I have included it under the external conditions for the sake of explanatory clarity.

The internal social conditions of the FAP refer to the structure (heirarchy; division of labor), goals (relief goals; social utility goals), and regulations (sponsorship requirement; quota system) which existed on both the national and the state level. The national internal conditions directly affected the state-level internal conditions, for the structure, goals, and regulations were created at the national level. The external social conditions on the state level, however, appear to be the key variables that must be examined for an understanding of the implementation of the state-level Federal Art Projects. A comparative study could be done by applying the state-level external and internal social conditions to a study of various state FAPs.

While the model shows the general determining directions of relationships between the different units and categories of the model, the precise impact of each unit on the others cannot be determined. In the statements which follow, however, I attempt to suggest which units and which 
relationships were most determinant for the Oregon FAP. The design of the model follows the guidelines suggested by Robert Dubin (1978) who points out that groups of variables can exist together in a "system-state," and systemstates can interact and carry variable measures just as individual units do.

\section{External Social Conditions}

The workings of the capitalist system, involving social relations between capital (business) and labor and the state (federal government), contained contradictions that ultimately led to the economic crisis of the $1930 \mathrm{~s}$, whose beginning is marked by the stock market crash in 1929 . While the economic crisis was not an external factor affecting the social relations of capitalism, it was a catalyst (albeit an internal catalyst) to the conditions which led to the creation of the FAP. This economic crisis had a negative effect on business by impeding the accumulation of capital. Business responded to the crisis by laying off workers. Labor, thus, was hard hit by the response of businesses to the economic crisis.

With the layoff of workers, the ratio of unemployed to employed workers increased. Left-wing organizations began to organize unemployed workers, including artists. Organizations of the employed and the unemployed began to put pressure on the federal government to provide relief 
and create jobs in order to deal with the problem of unemployment. Among artists, the Artists' Union was the most outspoken organization; among its demands was one asking for a federal art project.

Within the system-state I have called the Government in the model, I have included the President and the Congress (although other elements are important to the federal government). The Congress, itself, is a system-state, which I have subdivided into the units of liberals and conservatives; the battles in Congress at that time (particularly those which related to the WPA) were drawn along liberal and conservative lines rather than House and Senate or Republican and Democrat lines. In general, however, the Republicans tended to be conservatives and the Democrats tended to be liberals. When the ratio of liberal to conservative was high within the Congress, policies favorable to the working class tended to receive approval as well as funding. Thus, in 1935 the WPA was created along with its sub-program of the FAP. The FAP, approved by Congress in 1935 was inspired by the demands of the Artists' Union and the ideas of artist George Biddle who was able to convince his friend, the President, to go along with the establishment of a federal art project. When, in 1938, the high liberal-conservative ratio was supplanted by a high conservative-liberal ratio, President Roosevelt's New Deal programs came under attack by the then conservative Con- 
gress.

The liberal-conseryatiye ratio in Congress appears to have been one of the key variables affecting the FAP during its eight year history; however, this ratio itself is a reflection of the larger class struggle throughout the country and, thus, relates to the other units within the larger system-state I haye called the external social conditions at the national level. Within this larger system-state, some general propositions could be stated, such as:

When labor is strong, relative to business, the liberal-conservative ratio in Congress will be high; (2) when labor is weak, relative to business, the liberal-conservative ratio in Congress will be low; (3) progressive programs, favorable to the working class, will most likely be implemented when the liberal-conseryative ratio in Congress is high; (4) progressive programs, fayorable to the working class, will most likely be curtailed when the liberal-conservative ratio in Congress is 1ow. Propositions (1) and (3) relate to the creation of the WPA/FAP; propositions (2) and (4) refer to the curtailment and termination of the WPA/FAP in 1939 and 1943, respectively.

\section{Internal Social Conditions}

on the National Level

The heirarchy of the WPA and the FAP were created in such a way that control could be maintained at the national 
leve1; both Harry Hopkins and Holger Cahill feared that, if left solely to the administration of the states, both the relief project and the art project might suffer (McDonald, 1969). Both programs were decentralized in regards to their operations, although a heierarchy was maintained which made the regional and state offices accountable to the national. Within the WPA, the various programs were also decentralized according to specialty, thus providing each WPA program with a two-tiered system of heierarchy. The FAP then, operated within the heirarchical structure of the WPA as a program of Federal Project Number One, which was first under the jurisdiction of the Professional and Service Projects Division and later the Women's and Professional Projects Division. At the same time, it had its own heierarchical structure with a chain of command from the national office, to the regional office, to the state office, and in larger states, to a division office. Within the state and regional offices, then, a division of functions existed, with the WPA State Administrator responsible for matters relating to the certification of relief workers and the FAP directors responsible for approval of projects, matching of artists with projects, and budgetary matters regarding the projects. This division of responsibilities apparently caused considerable difficulties in some states (cf. McDonald, 1969).

Because it was a program of the WPA, the FAP was 
charged with the same goals as all WPA programs: The foremost goal of the WPA was to provide jobs for people certified for relief; the second goal was that socially useful projects be created according to the talents of relief workers and the needs of the community. Within the FAP, these goals often conflicted with a third, unofficial goal of FAP directors, which was to see that high quality art works were created. This conflict could be summarized as a conflict between the relief aspect of the project and the art aspect; the conflict also took the form of various emphases on the community service character and the professional emphasis of the projects.

In order to insure that the WFA remain primarily a relief program, Roosevelt directed that at least ninety percent of all persons working on a work project come from the public relief rolls (McDonald, 1969:173). FAP directors on all levels felt that either the relief rolls did not provide them with sufficient numbers of artists to make a program possible, or that the artists who were available were unqualified. Thus, as soon as appropriations for the project were granted, project directors began to seek exemption from the ninety percerit relief requirement (McDonald, 1969; McKinzie, 1973). While this exemption was granted, it was later rescinded by the Congress, which apparently was not interested in funding an art project unless it was also and primarily a relief project. A generalization could be made 
that liberals in Congress feared that relief funds were being used on non-relief people while conservatives feared what they saw as uselessness and waste inherent in such projects.

Prior to 1939 , it was not a requirement that local art projects receive local sponsorship, yet it was a very strong suggestion. This suggestion was emphasized and pushed by Joseph Baker, who believed that if a community really supported a project in spirit it should be willing to do so financially, as well. If a sponsor could not be found for a project, the state project director could appeal to the national office for funds.

The struggles that took place on the national level within the WPA and the FAP reflected, in many instances, the social conditions external to the organizations. The attempts to increase the non-relief quotas reflected, on the one hand, the desires of administrators to emphasize the professional as opposed to the relief aspects of the projects; on the other hand, they at least partial:y reflected the desires of both artists and administrators to find employment for destitute, but qualified, artists, who for one reason or another did not qualify for relief. Both of these desires conflicted with the intent of the WPA to be a work relief program, although in some cases the requirements for getting on relief rolls may have been too stringent. While in the initial stages of the FAP, the non-relief quotas were 
increased and sponsorship requirements were lenient, an increasingly conservative Congress gradually cut away at the non-relief quotas, and in 1939 , required that all work projects receive at least twenty-five percent of their funds from local sponsors. These moves reflected the conservatism of Congress but also may have reflected the declining influence of artists as a politically organized force. Artists in New York are reported to have had a strong impact on postponing attempts to curtail the FAP, but their influence was not all-powerful. The fact that their magazine, Art Front, ceased pulication in late 1937 is perhaps an indicator that some of the earlier urgency of their movement had either dissipated or had been repressed, or perhaps had just moved into other directions.

\section{Social Conditions in Oregon}

Many of the same social conditions that operated on the national level operated in Oregon, as well. The business community faced the economic crisis in a way that increased the unemployment level for the state. Oregon workers, like their counterparts elsewhere, created militant organizations of unemployed workers and started a union organizing movement that became the major focus of the CIO's organizing drive on the West Coast (Bureau of Police, 1937; Lembcke, 1978; Tattam, 1970). The population of artists in Oregon was relatively small however. Although some Oregon 
artists were politically active in the social movements of the $1930 \mathrm{~s}$, their only political involvement as a social movement of artists came in 1936 when the Artists Congress Against War and Fascism was formed (Cur1, 1979; Bunce, 1979). Otherwise politically active Oregon artists were rank-and-file members of the various Workers' Alliance 10cals and of the Communist Party (Bunce, 1979; Curl, 1979a, b; Salem Local Workers' Alliance, 1938). As a political force that affected the operation of the Oregon FAP, they were negligible, although many of them participated in a nation-wide WPA strike and later circulated petitions protesting the curtailment of the Salem Art Center (Cur1, 1979; Salem Local Workers' Alliance, 1938).

The upper class and other influential members of the Portland art community participated in the direction of the Oregon FAP as administrators and as official and informal advisors to the program. Chapter Three examined in detail the various relations between the Oregon business community, various levels of government, and the FAP administrators and the effect of these on the implementation and internal social conditions of the Oregon project. Suffice it to say that many of the external social conditions conflicted with the implementation of the goals of the FAP. Most notable was the sponsorship of the business community and the elite institutions (such as the University of Oregon) which created an emphasis on the professional rather than the relief 
aspect of the project, thus causing the non-relief exemption clause to be exploited to its fullest, at the expense, perhaps, of Oregon's relief artists. Such a conclusion must be moderated, however, by the fact that no evidence has been located suggesting that the project failed to hire any available relief artist. While it is possible that the nonrelief exemption clause was used to expand the total employment of artists on the FAP, the fact remains that it was the non-relief, rather than the relief artists who primarily seem to have benefited from the sponsorship of business and elite institutions.

Several possible, although tentative, conclusions could be derived from this analys is of the Oregon FAP. The cooperation among the business community, the artistic patrons, public administrators, and the FAP administrators made possible such grandiose projects as the building of iron gates for the University of Oregon and the building of Timberline Lodge. Those projects sponsored by the business community and the University and colleges were neither relief oriented nor community service oriented; thus, more than any other projects, these went against the larger goals of the WPA to create socially useful projects for the available relief artists. Those projects sponsored by the public schools and local communities resulted in the murals and the Community Art Centers that reached a greater cross section of people, provided more work for relief artists, and 
were probably more in line with the concept of community service projects than were the former projects. Finally, the easel projects employed both relief and non-relief artists, though the placement of most of those works is unknown.

Some general propositions that could be generated from these conclusions include: (1) The social milieu of the sponsors of a project and the social milieu of the community served by a project tend to be positively correlated; (2) the more upper class the social milieu of the sponsors of a project, the more likely is the project to emphasize the professional character of the project over the social service or relief aspects of the project; (3) the more oriented a project is to the social service of a working class community the more likely it is to emphasize the employment of relief over non-relief artists; (4) the more upper class the administrators of a state project, the more likely they are to be concerned with the professional artistic over the relief character of the project; (5) the less organized and active the artists are in the community, the more likely will there be projects sponsored by and for the business community and the professional elite. Each of these propositions have emerged from the data on the Oregon FAP following a class struggle perspective, although none of them have been tested, as such. The propositions are suggested as guidelines for further comparative research on 
the Federal Art Projects of different states. They suggest a theoretical framework for applying the class struggle perspective suggested by Esping-Anderson, Friedland, and Wright (1976) which argues that class struggles shape state structures and that the level of working class organization inversely affects the existence of capitalist class dominance of state power and the likelihood that state structures will reflect the interests of the capitalist class. Thus, in New York City, a politically organized group of working class artists won concessions through their political activity that served the interests of working class artists everywhere; the state structures that were created, however --the WPA and the FAP--were created in such a way that the upper class maintained control over the structures, particularly in places like Oregon where working class artists focused their political activity outside the artistic arena.

\section{THE CULTURAL REVOLUTION}

Two key aspects of the FAP seem to have encouraged a democratization of art in Oregon, thus changing if only partially, the social relatic:? of art--in particular the social relations between the artist and the audience. First, the art form of the public murals was potentially more accessible to a larger number of people due to their location and their size. This effect was limited, however, by the relatively small number of murals produced and by the fact 
that most, if not all, were located inside buildings, rather than on outside walls that could be seen by all. The second aspect of the FAP which had a strong democratizing effect and, again, altered the social relationship between artist and audience, was the partial emphasis on making art accessible and known to the public through the programs of the Community Art Centers. These centers altered the distributive nature of the artist-audience relationship by making the audience a participant in art; the audience thus became the artist and the artist, as teacher, became the audience. The importance of exposing, challenging, and changing the social relations of art was emphasized by playwright Bertolt Brecht and reiterated by literary critic Terry Eagleton (1976).

The question still remains whether the reforms created via the WPA and the FAP were ultimately revolutionary reforms or reformist reforms. It could be argued that the FAP was a reformist reform to the extent that it coopted the demands of artists for a permanent Federal art project and for control over gallery space and it quieted them with a temporary work relief program. On the other hand it cannot be denied that the FAP provided employment to a large number of artists and gave them the economic security to grow and develop as artists. The demands made by the New York Artists' Union were of a productive nature following EspingAnderson et al.'s (1976) terminology, although they had 
aspects of both commodified and non-commodified demands (see Chapter One). These demands had the potential of yielding nonreproductive reforms (cf. Esping-Anderson et a1., 1976). Their demands focused on the production of culture rather than the circulation of culture (although the demand for an artist-controlled gallery can also be seen as a circulatory demand; the difference is that their demands included the control over the circulation of their product through their own galleries; thus, they attempted to circumvent the traditional market structure of the gallery system); their concerns were also with the production of socially progressive works of art, rather than commodities to be exchanged for the benefit of someone else's profit accumulation. Theoretically, such demands have a greater potential of leading to structural reforms that have a revolutionary character. It appears as if the FAP in New York, the art center of the country, was of much greater political significance than were the projects in the hinterlands, where the FAP was not seen as a result of conscious, organized activism, but was probably seen primarily as a gift from Washington. Without the self-conscious political force of an organization of artists, the FAP in Oregon was objectively able to operate somewhat oblivious to the interests and demands of the working class artists; by contrast, the New York City FAP and the national offices of the FAP were constrained by the organized force of an active artists' move- 
ment in New York City and in other parts of the country. It was these larger class struggles which shaped the structure and character of the FAP on a national level. Following the Esping-Anderson et al. theory, the social conditions in Oregon, including the absence of a politically organized, strong artists' social movement, made it objectively possible for the local government officials within the Oregon FAP to neutralize whatever political class struggle may have been present, to insulate the FAP from working class artists' influence, and possibly to insure that the FAP did not encourage nonreproductive demands and non-reformist reforms within Oregon.

The reforms of the FAP had a contradictory character in that the projects were ruled by a bureaucracy rather than a collective, and many actors within the bureaucracy were upper class individuals or members of a social elite that was not trying to transform the system, but alter its facade in order to salvage it. Nevertheless, those representatives of the state who supported and worked within the WPA and the FAP represented a liberal wing of the upper class and the government and they genuinely hoped that the FAP would continue the earlier attempts at a cultural revolution aimed at uniting the artist more closely with the American people.

The cultural revolution of the FAP brought with it profound changes for the arts in Oregon, and the art scene in Oregon today can only be understood by looking to the 
roots from whence it developed. The roots begin with the democratic ideals taught by instructors such as Harry Wentz at the Portland Art Museum School who influenced a large number of FAP artists, many of whom have achieved local, regional, or national prominence. The FAP watered the roots of Oregon art by developing both artists and an art audience. The development of both artist and audience combined with the post-war prosperity, made possible by the rise of United States hegemony in the world, to create the social conditions that made possible the proliferation of art galleries, amateur artists, and open-air exhibits-all indicators of a new interest in art among middle class and possibly working class people.

The failure of mural painting, socially conscious art, and "American scene" art to continue to develop following World War II has been partially explained by Cahill as a failure of American artists to take seriously the search for their own "useable past" in the cultural heritage provided by the original Native American tribes of this continent. A further explanation must lie somewhere in the events and meaning of the McCarthy Period--a period in which it would have been dangerous to create some of the art that was created during the depression.

For whatever reasons, the cultural revolution of the FAP did not turn out to be the subversive, working class revolution some feared and others hoped. It did, however, 
result in a sort of petit bourgeois revolution that challenged some of the Feudal remnants of the patronage system by making way for artists as entrepreneurs, operating through a market system controlled by a proliferation of galleries which serve as the "middleman" between the artist and the new mass of middle class consumers. While artists in Oregon still seek government patronage, it is sought through the established foundations that fund individuals and projects on a case-by-case basis. Artists who choose to act collectively often have ventured into the entrepreneurial form of the cooperative, hoping to survive through self-managed, artist-owned cooperative galleries. Other artists have individually sought protection and renown through the currently dominant private gallery tradition. This small business tradition is a far cry from the permanent federal art project demanded by the Artists' Union in 1934 and 1935. However, as the end of post-war prosperity becomes evident, and as we look to an indefinite future of economic crisis and instability, some contemporary artists have begun to revive the traditions of socially conscious art. New attempts have been made by young Oregon artists to create art that is informative, politically progressive, yet artistically fresh and creative. ${ }^{17}$ Hopefully, the les-

${ }^{17}$ Examples of this kind of art in Oregon can be found in the murals in the Albina district in Portland, painted by young Black artists; five Black women poets recently published An Anthology of Black Women Poets of Oregon; a group 
sons to be learned from the 1930 s New Deal art projects can help guide the current practice of these artists.

of Chilean refugees recently painted a mural at the International Longshore Workers Union hall in Coos Bay; a theatre group calling itself the Portland Labor Players II has recently produced an original play based on the 1934 Longshoremen's Strike in Portland. 


\section{REFERENCES}

Althusser, Louis

1971 Lenin and Philosophy. New York: Monthly Review.

Art Front

1934 "National Correspondence." Art Front (November).

1935 "National Correspondence." Art Front (January).

Barker, Burt Brown

1935a Postal Telegraph to Holger Cahi11, October 15, 1935. Burt Brown Barker Papers. Friends of Timberline, Portland, Oregon. (Hereafter referred to as Barker Papers).

1935b Western Union Telegram to Holger Cahill, October 28, 1935. Barker Papers.

1935c Letter to Holger Cahill, December 19, 1935. Barker Papers.

1936 a Letter to Holger Cahi11, January 20, 1936. Barker Papers.

1936b Letter to Holger Cahi11, February 4, 1936. Barker Papers.

1936 c Letter to Holger Cahi11, February 26, 1936. Barker Papers.

1937 Letter to Joseph A. Danysh, Regional Advisor, FAP, WPA, San Francisco, March 6, 1937. Barker Papers.

1965 Autobiography of Burt Brown Barker. Unpublished Manuscript. (Copy in possession of Mrs. Barbara (John A.) Sprouse, Portland, Oregon.)

Berger, Peter L. and Thomas Luckmann

1967 The Social Construction of Reality: A Treatise in the Sociology of Knowledge. Garden City: Anchor.

B1ue Book Association

1936 The Portland Blue Book and Social Register of nregon, 1936. Portland: The Blue Book Associa- 
tion, Publishers.

Boggs, Carl Jr.

1972 "Gramsci's 'Prison Notebooks'." Socialist Revolution 11:79-118.

Boyer, Richard 0 . and Herbert M. Morais

1973 Labor's Untold Story. New York: United Electrica1, Radio and Machine Workers of America.

Bureau of Police

1937 "Weekly Report of Communist Activities." Portland, Oregon, September 3. (Copy in possession of author.)

Bunce, Louis

1979 Personal Interview. Portland, Oregon, August 16,1979 .

Cahil1, Holger

1935 a Postal Telegraph to Burt Brown Barker, October 16, 1935. Barker Papers.

1935b Letter to Burt Brown Barker, October 25, 1935. Barker Papers.

1935 c Western Union Telegram to Burt Brown Barker, October 29, 1935. Barker Papers.

1935 d Letter to Burt Brown Barker, October 31, 1935. Barker Papers.

1936 Letter to Burt Brown Barker, March 6, 1936. Barker Papers.

1975 "American Resources in the Arts." Pp. 33-44 in Francis V. $0^{\prime}$ Connor (ed.) Art for the Millions. Boston: New York Graphic Society.

Capitol Publishing Company

1937 Capitol's Who's Who for Oregon, 1936-7. Port1and: Capitol.

CETA (Roger Coleman, ed.)

1978 An Artist's Source Book. Portland: CETA.

Curl, Martina Gangle

1979a Personal Interview. January 17, 1979. Portland, Oregon.

1979b Personal Interview. March 22, 1979. Portland, Oregon. 
1980 Personal Interview. June 4, 1980. Portland, Oregon.

Dah1, Robert A.

1961 Who Governs: Democracy and Power in an American City. New Haven: Yale University Press.

Daws on, Orion B.

1940 Letter to E. J. Griffith, May 19, 1940. 0. B. Dawson Papers. Friends of Timberline. Portland, Oregon.

Domhoff, G. William

1971 Higher Circles: The Governing Class in America. 2nd Edition. New York: Vintage.

1977 "The Ruling Class and the Women's Page." Insurgent Sociologist VII-1:59-64.

Dubin, Robert

1978 Theory Building. Revised Edition. New York: Free Press.

Eagleton, Terry

1978 Marxism and Literary Criticism. Berkeley: University of California Press.

Erwin, Jack

1947 Telegram to Mr. Fred Vanderschmidt, Managing Editor, Newsweek. February 18, 1947. Timberline Lodge Files. Friends of Timberline, Portland, Oregon. (Hereafter referred to as Timberline Files.)

Esping-Anderson, Gosta, Roger Friedland, and Erik Olin Wright

1976 "Modes of Class Struggle and the Capitalist State." Kapitalistate IV-5:186-98.

Everett, Gladys

1979 Personal Interview. May 24, 1979. Portland, Oregon.

Federal Project Number One

1973 Staff Conference Minutes. November 30, 1937. Barker Papers.

Federal Works Agency

1939 "Questions and Answers on the WPA." Pamphlet located in U. S. WPA General Publications: Volume 2 . 
Federal Writer's Project

1940 Oregon: The American Guide Series. Portland: Binfords \& Mort.

Finkelstein, Sidney

1976 How Music Expresses Ideas. New York: International.

Fiori, Guiseppe

1973 Antonio Gramsci: Life of a Revolutionary. New York: Schocken.

Flothe, Richard

1975 "Posters." Pp. 177-8 in Francis V. O'Connor (ed.) Art for the Millions. Boston: New York Graphic Society.

Fortune

1937 "Unemployed Arts: WPA's Four Art Projects: Their Origins, Their Operations." Fortune (May): $108-17 \mathrm{ff}$.

Gilbert, Louise

1979 Personal Interview. July 5, 1979. San Francisco.

Gitlin, Todd

1979 "Prime Time Ideology." Social Problems 26-3: 251-66.

Givler, William

1979 Personal Interview. March 3, 1979. Portland, Oregon.

G1aser, Barney and Anse1m L. Strauss

1967 The Discovery of Grounded Theory: Strategies for Qualitative Research. Chicago: Aldine.

Gorz, Andre

1964 Strategy for Labor: A Radical Proposa1. Boston: Beacon.

Griffin, Rachael

1979 Personal Interview. April 24, 1979. Portland, Oregon.

1980 Personal Interview. May 1, 1980. Port1and, Oregon.

Griffin, Rachael and Sarah Munro (eds.)

1978 Timberline Lodge. Portland: Friends of Timberline. 
Griffith, Emerson J.

1938 Mimeograph Report on Timberline Lodge. Timberline Files.

Hadjinicolaou, Nicos

1978 Art History and Class Struggle. Louise Asmal, translator. London: Pluto.

Heaney, Charles

1979a Personal Interview. February 15, 1979. Portland, Oregon.

1979b Personal Interview. May 17, 1979. Portland, Oregon.

Hirsch, Glen K.

1975 "Only You Can Prevent Idological Hegemony: The Advertising Council and Its Place in the American Power Structure." In G. William Domhoff (ed.) New Directions in Power Structure Research. Eugene: Insurgent Sociologist.

Jensen, W. A.

1936 Letter to O. B. Dawson. July 7, 1936. Daws on Papers. Friends of Timberline, Portland, Oregon.

Kellner, Douglas

1979 "T. V., Ideology, and Emancipatory Popular Culture." Socialist Review 45.

Kerr, Florence

1939 Letters to Clarence Bates, February 21, 1939, and H. Nelson, March 8, 1939. RG 69/WPA, Ro11 DC 100.

Lembcke, Jerry L.

1978 The International Woodworkers of America: An Internal Comparative Study of Two Regions. $\mathrm{Ph}$.D. Dissertation. University of Oregon.

Lukacs, Georg

1971 History and Class Consciousness: Studies in Marxist Dialectics. Rodney Livingstone, trans1ator. Cambridge: MIT Press.

Lynch, Douglas

1979 Personal Interview. May 3, 1979. Portland, Oregon. 
Mangione, Jerre

1972 The Dream and the Deal: The Federal Writer's Project, 1935-1943. New York: Avon.

Marquis, A. N., Company

1936 Who's who in America. Chicago: The A. N. Marquis Company.

Marx, Kar1

1976 The Economic \& Philosophic Manuscripts of 1844. Dirk J. Struik, ed. (1844) Martin Milligan, translator. New York: International.

McDonald, William F.

1969 Federal Relief Administration and the Arts: The Origins and Administrative History of the Arts Projects of the Works Progress Administration. Columbus: Ohio State University Press.

McKinzie, Richard D.

1973 The New Deal for Artists. Princeton: Princeton University Press.

Meier, Jack

1939 Mount Hood Development Association, President's Report. Timberline Files.

Merton, Robert K.

1967 On Theoretical Sociology: Five Essays, 01d and New. New York: Free Press.

Miliband, Ralph

1969 The State in Capitalist Society. New York: Basic Books.

Murray, Keith A.

1950 "Issues and Personalities of Facific Northwest Politics, 1889-1950." Pacific Northwest Quarterly XLI:216ff.

Neufer, Ray

1980 Personal Interview. March 1, 1980. Clackamas, Oregon.

0 'Connor, Francis V.

1969 Federal Support for the Visual Arts: The New Deal and Now. Greenwich, Connecticut: New York Graphic Society. 
O'Connor, James

1973 The Fiscal Crisis of the State. New York:

St. Martin's.

Olsen, Tillie

1978 Silences. New York: De1ta.

Oregon FAP

1935 "Allocation by Regional Director and Advisory Committee at Meeting He1d 3:30 P.M., October 25, 1935." Barker Papers.

Undated "Works Done on Federal Art Project." (Believed to be late 1937) Barker Papers.

1938 "Report of Art Project--0. P. 565-3-1, March $1938 . "$ Barker Papers.

Oregonian

1932 a "Jobless Lay Plans for United Action." Oregonian (July 7):1.

1932 b "Unemployed to Unite." Oregonian (September 28): 12 .

1933a "New Deal Sought in Relief System: Marchers Voice Demands at Oregon City." Oregonian (March 7):1.

$1933 b$ "Protest Colony Urged." (May 3):14.

1933c "Jobless Break Camp. Compromise Ends 3 Day Demo." (June 6): 4 .

1933d "Curb on Jobless Urged. Governor to be Asked to Halt Demonstrations." (June 26):2.

1934 "Portland Police Raid Communists. 36 Arrested on Charges of Syndicalism." (July 19):1.

Ostrander, Susan

1980 "Class Consciousness as Conduct and Meaning: The Case of Upper C1ass Women." Pp. 38-50 in G. William Domhoff, ed., Power Structure Research II. The Insurgent Sociologist IX-2,3.

Parsons, Talcott

1968 The Social System. Fourth Printing of Paperback Edition. New York: Free Press. 
Peterson, Richard

1979 "Current Trends in the Concept of Culture." Annual Review of Sociology.

Petition to Franklin D. Roosevelt

1939 National Archives. Records of the WPA. Central Correspondence Files. Regional Group 69. Archives of American Art. Microfilm Rol1 DC 100 (Hereafter referred to as RG 69/WPA, Roll

Piven, Frances Fox and Richard A. Cloward

1979 Poor People's Movements: Why They Succeed, How They Fail. New York: Vintage.

Portland Chamber of Commerce

1936 "Minutes: Meeting of the Board of Directors, Portland Chamber of Commerce." January 7, 1936. Timberline Files.

Portland Winter Sports Association

1931 "By-Laws of Portland Winter Sports Association." Timberline Files.

Poulantzas, Nikos

1973 Political Power and Social Class. London: New Left Books.

Russo, Mike

1979 Personal Interview. July 20, 1979. Portland, Oregon.

Salem Art Center

1938 Bulletin. Robert Bruce Inverarity Papers, 193641. RG 69/WPA. Rol1 D/NDA/I.

Salem Local Worker's Alliance

1938 Resolution. RG 69/WPA. Ro11 DC 100.

Sanchez Vazquez, Adolfo

1973 Art and Society: Essays in Marxist Aesthetics. New York: Monthly Review.

Smith, Margery Hoffman

1936 "Report of Art Project Number 265-6900 for October 1936." Barker Papers.

1939 Letter to Florence Kerr. June 15, 1939. RG 69/WPA. Ro11 DC 100. 
1943 "Report of Oregon Art Project." Margery Hoffman Smith Papers, 1936-39. RG 69/WPA. Ro 11 NDA 1.

1979 Personal Interview. May 29, 1979. Portland, Oregon.

Sprouse, Barbara

1980 Personai interview. June 23, 1980. Portland, Oregon.

State of Oregon

1936 "Articles of Incorporation. Mount Hood Development Association." February 17, 1936. State of Oregon Corporation Department.

Szymanski, Albert

1978 The Capitalist State and the Politics of Class. Cambridge: Winthrop.

Tattam, William M.

1970 Sawmill Workers and Radicalism. M.A. Thesis. University of Oregon.

Ulrich, Mabe 1

1937 "Unemployed Arts." Fortune 15 (May):108-17.

Us eem, Michael

1976 "Government Patronage of Science and Art in America." In Richard A. Peterson, ed., The Production of Culture. Beverly Hills: Sage Publications.

Val Cleer, Charles

1938 Letter to Burt Brown Barker. October 8, 1938. Barker Papers.

Weber, Max

1958 The Protestant Ethic and the Spirit of Capita1ism. New York: Charles Scribner's Sons.

Williams, Raymond

1975 The Country and the City. New York: Oxford University Press.

Weinstein, James

1968 The Corporate Ideal in the Liberal State: 19001918. Boston: Beacon.

Wolff, Robert Jay

1975 "Chicago and the Artists' Union." Pp. 239-42

in Francis V. O'Connor, ed., Art for the 
Millions. Boston: New York Graphic Society.

Works Progress Administration

$193 \varepsilon$. Workers on Relief in the United States in March 1935. Volume I, A Census of Usual Occupations. Washington: United States Government Printing office.

Zeitlin, Maurice

1966 "Alienation and Revolution." Social Forces (December) :224-37. 
APPENDIX A

ADMINISTRATIVE HEIRARCHY OF THE FEDERAL ART PROJECT

Program Division:

Works Progress

Administration

(May 1935-Sept. 1939)

Work Projects

Administration

(Sept. 1939-Apri1 1943)

Division of Professional and Service Projects

(1935-1936)

Division of Women's and Professional

Projects

(1936-1943?)

Federal Art Project

(Aug. 1935-Sept.

1939)

WPA Arts Program

(Sept. 1939-March 1942)
Nationa1 Director

Harry Hopkins

Jacob Baker

E11en S. Woodward

(1936-1939)

Florence Kerr

(1939-1943?)

Holger Cahi11

Holger Cahil1
Regiona1 Di rector/Advisor

State Director

Emerson J. Griffith

Emerson J. Griffith

Ivan Oakes

Florence Kerr

(1936-1939)

Burt Brown Barker

(1935-1936;1939?-1943?)

Joseph A. Danysh

(1936-?)
Gladys Everett

Burt Brown Barker

Margery Hoffman Smith 
Program Division:

Graphic Section

of the War

Services Division

(1942: March-October)

Graphic Section of

the Division of

Program Operations

(October 1942-

Apri1 1943)
Holger Cahi 11

Holger Cahil1
State Director

Margery Hoffman Smith

Margery Hoffman Smith 


\title{
APPENDIX B
}

\author{
RELIEF AND NON-RELIEF ARTISTS AND CRAFT WORKERS \\ ON THE OREGON FEDERAL ART PROJECT \\ NON-RELIEF ARTISTS AND CRAFT WORKERS
}

Darrel Austin: Painter; worked on easel projects and Timberline Lodge

Louis Bunce: Painter; worked on easel projects and taught at Salem Art Center; member American Artists' Congress

Orion Benjamin Dawson: Blacksmith and metal artists; supervisor of iron works projects at Timberline Lodge, University of Oregon, and Oregon State College

Dora Erickson: Painter and sculptor; painted watercolors for Timberline Lodge

Alan Flavelle: Painter; worked on ease1 projects; member American Artists' Congress

Eduard Friske: Blacksmith; worked on Timberline Lodge iron project

Aimee Gorham: Marquetry craftswoman; did marquetries at Timberline Lodge, Irvington School, Jefferson High, Alameda High, all in Portland

Mr. Jeffrey: Artist; worked on Timberline Lodge art project

Phillip H. Johnson: Painter; did fresco mural at University of Oregon School of Architecture

Gabriel Lavarre: Sculptor, draftsman; was senior draftsman for Timberline Lodge iron project; did work for Dallas Memorial; taught at Salem Art Center

Mr. Lemery: Painter; did "scene paintings" for Portland schools; designed stage sets for Federal Theatre Project "Vaudeville Screens" 
Mr. Lewin: Cabinet maker; worked on Timberline Lodge interior decoration

Ray Neufer: Cabinet maker, artist in charge of woodcarving; did work for Portland Public Schools and Timberline Lodge, including furniture and carved Gothic screens (for the schools)

Clayton S. Price: Painter; worked on easel and mural project; murals at Beach School in Portland and Pendleton Jr. High School; two paintings at Timberline Lodge

Mr. Schubert: Sculptor; did work for Timberline Lodge

Margery Hoffman Smith: Interior decorator; designed furnishings and interior of Timberline Lodge plus furniture for other places; supervised Timberline Lodge art work

Florence Thomas: Sculptor and craftsperson; supervised sculpture at Timberline Lodge

\section{RELIEF ARTISTS IN OREGON}

Mr. Anderson: Painter, foreman of scene painting in Portland schools

Mr. Bashav: Painter; worked on Timberline Lodge art work

Mr. Bates: Woodcarver; carved wood panels at University of Oregon as assistant to Clough

Mr. Bendixon: Painter; worked on mural and easel projects

E. Belle Clayston: Painter; worked on easel projects

Art Clough: Woodcarver; carved wood panels at University of Oregon (1ibrary)

Fred Collins: Plasterer, Sculptor; did six sculptures for the University of Oregon

Virginia Darce: Painter, stained glass artist; did stained glass mural at Timberline Lodge; mural at Oregon City Library (painted out during remodelling); worked on easel projects; work located at Doernbecher Memorial Hospital 
Ms. Dupee: Artist; collected art works for Corvallis Public High School

Karl Feurer: Painter; painted watercolors of wildflowers for Timberline Lodge

Martina Gangle (Cur1): Painter, woodcarver; painted murals for Rose City School; worked on easel projects, did woodblock prints, and other miscellaneous work; taught adult education classes in Portland; painted wildflowers for Timberline Lodge; member, American Artists' Congress

Mr. Gilkey: Etcher; did works for the University of Oregon

Charles Heaney: Painter, engraver; worked on easel and printmaking projects

Douglas Lynch: Painter, commercial artist; did linoleum carved painted mural for Timberline Lodge coffee shop

Mr. McIntosh: Photographer; photographed WPA projects

Mr. Philpott: Painter; worked on "scene painting" projects for Portland schools

Arthur Runquist: Painter; painted murals at University of Oregon (assisted by brother Albert) and in Pendleton; worked on easel project; member, American Artists' Congress

Howard Sewall: Painter; murals at Timberline Lodge and Oregon City Junior High

Louise Utter: Sculptor: did one stone relief and one cast stone piece for Oregon State College (journalism building and Library).

Valentine Weise: Woodcarver; did woodcarvings for library at Oregon State College and for Principal's Office at Iryington School in Portland

Mr. Wells: Painter; worked on scene painting at Portland schools 
RELIEF CRAFTSWORKERS

Iron Workers

For Timberline Lodge Project

Mr. Allison: Foreman

Mr. Blioch: Blacksmith

Mr. Eckles: Foreman

Mr. Fredolph: Blacksmith

Mr. Ritthaler: Blacksmith

Mr. Siegmund: Foreman

Mr. Sumpter: Assistant iron worker

Mr. Walton: Assistant iron worker

Woodworkers and other Craft Workers

Mr. Behnke: Cabinet maker; worked on Timberline Lodge project

Mr. Benders: Carpenter; worked on Portland school projects

Mr. Benedict: Lithographer, slide colorist; did works for University of cregon

Mr. Bitters: Cabinet maker; worked for Timberline Lodge

Mr. Boivin: Carpenter; Portland school projects

Mr. Carlson: Cabinet maker; Timberline Lodge projects

Mr. Curry: Cabinet maker; Timberline Lodge projects

Mr. Downs: Cabinet maker; Portland schools projects

Charles Haller: Craftsman; helped Virginia Darce on stained glass project at Timberline Lodge; built frames for FAP easel projects

Mr. Hedgepeth: Cabinet maker; Portland schools projects; assisted on marquetry panels at Oregon State College 
Mr. Keinath: Cabinet maker; assisted Gorhain with marquetry work at Timberline Lodge and Portland schools

Mr. Loggan: Carpenter; Portland schools projects

Mr. Miller: Carpenter; Portland schools projects

Mr. Neese: Cabinet maker; Timberline Lodge projects

Mr. Thomas: Cabinet maker; Timberline Lodge projects

Mr. Wageman: Cabinet maker; Timberline Lodge projects

Mr. Wagner: Cabinet maker; Portland schools projects

\section{ARTISTS AND CRAFTSWORKERS WITH \\ UNKNOWN KELIEF STATUS}

George Berry: Sculptor; worked with Laman on sculpture at Franklin High School, Portland

John Blew: Commercial artist; assisted Lynch at Timberline Lodge

Littleton Dryden: Painter; worked on easel projects for Soil Conservation

Pete Ferrarin: Craftsman; assisted Darce with stained glass murals at Timberline Lodge; worked on furniture for Timberline Lodge

John Fiske: Painter; made mural map for Portland Chamber of Commerce

Margaret Gallagher: Ceramicist

Howard Gibbs: Painter; did paintings and furniture for Tongue Point (19.42)

Orie Graves: Painter; did paintings for Tongue Point (1941)

Melvin Hardy: Ceramicist

Henry Harth: Iron worker; worked on iron projects at Timberline Lodge (made fire screen, cigarette canister, andirons, and brass bow 1 )

Margot Helser: Painter; painted watercolors and oil easels for Doernbecher Memorial Hospital 
Melvin Keegan: Painter and Sculptor; carved three wooden panels and designed a floor tile mosaic at Timberline Lodge

Bue Kee: Ceramicist

Erich Lamade: Painter, sculptor; carved wooden panels at Timberline Lodge dining room; taught at Salem Art Center

Thomas Laman: Sculptor, painter; designed wall mosaic at Timberline Lodge; assistant supervisor to Smith at Timberline Lodge; did the Benjamin Franklin sculpture at Franklin High School in Portland

Charlotte Mish: Painter, lithographer; worked on easel projects; did several works for the Port of Portland

John W. Peterson: Wood craftsman; made fireplace fender for Silver Creek State Park

Jack Price: Silkscreener; silkscreened draperies for Tongue Point

Ms. or Mr. Pritchard: Sculptor; made a stone statue at the University of Oregon and a stone drinking fountain at Linfield College in McMinnville

Ms. or Mr. Purcell: Painter; worked on ease1 projects for Irvington School in Portland

Franya Prudhomme: Textile worker; did hooked wall tapestries

Ms. or Mr. Quigley: Painter; did mural for Irvington School, Portland

Jerome Seliger: Marquetry craftsman; worked under Gorham at Timberline Lodge

David Shook: Craftsman; made dioramas for University of Oregon Museum of Natural Science and the United States Forest Service

Elsa Snodgrass: Painter

William Witt: Sculptor; did sculpture for Gold Beach School

SOURCES: CETA, 1978; Oregon FAP, undated; Oregon FAP, 1938; Smith, 1936 


\author{
APPENDIX C \\ PERSONS INTERVI LWED NOT ON THE \\ OREGON FEDERAL ART PROJECT
}

Pietro Belluschi: Portland Architect

Louise Gilbert: Painter, printmaker, commercial artist; lived in Portland during the 1930s; now lives in San Francisco; member of American Artists' Congress

Rachael Griffin: Painter; former curator of the Portland Art Museum; art historian

William Givler: Painter, lithographer, teacher; former dean and instructor at the Portland Art Museum Schoo1; member of American Artists' Congress

Leta Kennedy: Painter, teacher; former teacher at the Port1and Art Museum School

Mike Russo: Painter; was on the Federal Art Project in Connecticut and was active in political issues; moved to Portland to teach at the Portland Art Museum School in the $1940 \mathrm{~s}$

Barbara Sprouse: Daughter of Dr. Burt Brown Barker; lives in Portland and is active in historic preservation activities 